\title{
Characterization of the Air Quality Index in Southwestern Taiwan
}

\author{
Yen-Yi Lee ${ }^{1}$, Yen-Kung Hsieh ${ }^{2 *}$, Guo-Ping Chang-Chien ${ }^{3,4 *}$, Weiwei Wang ${ }^{5^{*}}$ \\ ${ }^{1}$ Center for General Education, Cheng Shiu University, Kaohsiung 83347, Taiwan \\ ${ }^{2}$ Ocean Affairs Council, Kaohsiung 80661, Taiwan \\ ${ }^{3}$ Super Micro Mass Research and Technology Center, Cheng Shiu University, Kaohsiung 83347, Taiwan \\ ${ }^{4}$ Department of Cosmetics and Fashion Styling, Cheng Shiu University, Kaohsiung 83347, Taiwan \\ ${ }^{5}$ School of Resources and Environmental Engineering, Hefei University of Technology, Hefei 246011, China
}

\begin{abstract}
This study provides an investigation of atmospheric $\mathrm{PM}_{2.5}, \mathrm{PM}_{10}, \mathrm{SO}_{2}, \mathrm{NO}_{2}, \mathrm{CO}$, and $\mathrm{O}_{3}$ in the period from $2015-2017$ in the southwestern and central part of Taiwan. In addition, the seasonal distribution of six AQI classes and corresponding primary pollutants were further analyzed. The daily AQIs were 15-194 in 2015, 17-213 in 2016, and 16-184 in 2017, respectively. During the three year period, in the studied area, the mean proportions of levels with Grade I, II, III, IV, V, and VI were $3 \%-31 \%, 30 \%-57 \%, 17 \%-46 \%, 0 \%-12 \%, 0 \%-1 \%$ and $0 \%$ in spring; were $38 \%-76 \%, 21 \%-57 \%, 0 \%-10 \%$, $0 \%-2 \%, 0 \%$ and $0 \%$ in summer; were $2 \%-45 \%, 34 \%-77 \%, 13 \%-36 \%, 0 \%-18 \%, 0 \%$ and $0 \%$ in fall, and were $0 \%-12 \%$, $38 \%-67 \%, 24 \%-41 \%, 1 \%-22 \%, 0 \%$ and $0 \%$ in winter. Generally, it was found that summer has the best air quality and that winter has the worst, where spring and fall are similar in terms of air quality. $\mathrm{PM}_{2.5}$ was the typical primary air pollutant when the AQI classes were 51-200, followed by $\mathrm{O}_{3}$ in summer, spring and fall, and $\mathrm{PM}_{10}$ in winter. As for class 201-300, the primary air pollutant was $\mathrm{O}_{3}$ and the 300-500 class did not occur.
\end{abstract}

Keywords: AQI; $\mathrm{PM}_{2.5} ; \mathrm{PM}_{10} ; \mathrm{SO}_{2} ; \mathrm{NO}_{2} ; \mathrm{CO} ; \mathrm{O}_{3}$.

\section{INTRODUCTION}

In recent years, air pollution has become a particularly serious issue in many cities in the world (Ran et al., 2011; Li et al., 2012; Tang et al., 2012; Li et al., 2014). Previous investigation demonstrated the close relationship between air pollutants and human health (Pope and Dochery, 2006; Cao et al., 2012; Heal et al., 2012; Pope and Dochery, 2013; Jin et al., 2017). Air pollutants in the atmospheric environment, including ozone $\left(\mathrm{O}_{3}\right)$ and particle matter (PM), have had serious impacts on human health (Liu et al., 2002), such as premature death (Schwartz et al., 1996), respiratory-related hospital admissions and emergency room visits (Thurston et al., 1992), acute respiratory symptoms with aggravated coughing and difficult or painful breathing, chronic bronchitis, aggravated asthma (Anderson et al., 1992), lung function experienced as shortness of breath, and so on. It is important to inform the public about the current air quality and to take corresponding health protection measures.

\footnotetext{
* Corresponding authors.

E-mail address: yk886963@gmail.com (Y.K. Hsieh); guoping@csu.edu.tw (G.P. Chang-Chien); 1326642149@qq.com (W. Wang)
}

Initially, a local Environment Pollution Administration (EPA) established the Pollutant Standards Index (PSI) system to estimate air quality in Taiwan. Base on the US EPA, this PSI system contains sub-indices for ozone $\left(\mathrm{O}_{3}\right)$, coarse particulate matter $\left(\mathrm{PM}_{10}\right)$, carbon monoxide $(\mathrm{CO})$, sulfur dioxide $\left(\mathrm{SO}_{2}\right)$, and nitrogen dioxide $\left(\mathrm{NO}_{2}\right)$. These sub-PSI indices were associated with ambient pollutant concentrations scaled from 0 to 500 , where an index value of 100 can be defined as normal, and an index value of 500 is associated with significant harm to human health (Liu et al., 2002). A daily major pollutant is defining as a pollutant with the largest daily sub-index value. The PSI system was based on general increases in $\mathrm{O}_{3}$ concentrations and decreases in $\mathrm{PM}_{10}$ levels in a steadily increasing PSI system. It was replaced with the Air Quality Index (AQI), which can lead to a better understanding of the effects of $\mathrm{O}_{3}$ and fine particulate matter $\left(\mathrm{PM}_{2.5}\right)$ on the general air quality.

In Taiwan, the air quality in several areas has worsened along with growth in population density and the rapid increases in the use of coal-fired power plants and motor vehicles. Since 1955, the control of air pollution began to gain attention, and Taipei began to implement controls on the burning of coal (Lee et al. 2018). Previous studies have demonstrated that the pollutant standards index (PSI) in Taiwan is often between 50 and 100, and some places even reach more than 100 (unhealthy air quality) (Bureau of Air 
Quality Protection and Noise Control, 1991; Fang and Chen, 1996). These factors, including geographic conditions, emission sources, and meteorological factors are all important contributors to the air quality problem in Taiwan (Zhang et al., 2009; Liu et al., 2012; Liu and Wang, 2014; Zhang and Cao, 2015; Li et al., 2017a; Shen et al., 2017).

The object of this study was to examine air quality in the southwestern and central part of Taiwan through a discussion of the characteristics of atmospheric $\mathrm{PM}_{2.5}, \mathrm{PM}_{10}, \mathrm{SO}_{2}$, $\mathrm{NO}_{2}, \mathrm{CO}$, and $\mathrm{O}_{3}$, after which the calculated Air Quality Index (AQI) was used as an important basis for judging the air quality. In addition, the seasonal variations in AQI are further discussed, as well as the corresponding primary pollutants. This research is intended to provide valuable information and better understanding of the air pollution characteristics in seven specific areas of Taiwan.

\section{METHODS}

The air quality of seven cities or townships in Taiwan, Puzih, Singang, and Chiayi in Chiayi City, and Douliou, Taisi, Lunbei, and Mailiao in Yunlin County, were analyzed in this study. From January 2015 to December 2017 in these districts, meteorological data, including $\mathrm{PM}_{2.5}, \mathrm{PM}_{10}$, $\mathrm{SO}_{2}, \mathrm{NO}_{\mathrm{x}}, \mathrm{CO}$, and $\mathrm{O}_{3}$ levels, were collected from local air quality stations.

Chiayi City is located in the southwestern part of Taiwan, which is crossed by the Tropic of Cancer and has a subtropical humid climate, with an annual average temperature of $22.0^{\circ} \mathrm{C}$ and an annual rainfall capacity of $1,500 \mathrm{~mm}$. Yunlin County is a central area, located in the center of Taiwan. It has a south subtropical humid climate, where the annual average temperature is about $22.6^{\circ} \mathrm{C}$, and the precipitation is approximately $1,697 \mathrm{~mm}$.

\section{Air Quality Index (AQI)}

The sub-AQI of the six criteria pollutants was first calculated with the observation concentrations, as shown in Eq. (1) (She et al., 2017; Shen et al., 2017). The overall AQI represents the maximum of the sub-AQI of all pollutants, where when the AQI is higher than 50, the highest sub-AQI contributor is defined as the primary pollutant on that day, as shown in Eq. (2) (She et al., 2017; Shen et al., 2017):

$$
I A Q I_{P}=\frac{I_{\text {high }}-I_{\text {low }}}{C_{\text {high }}-C_{\text {low }}}\left(C_{P}-C_{\text {low }}\right)+I_{\text {low }}
$$

$A Q I=\max \left(I_{1}, I_{2}, \ldots, I_{n}\right)$

$I A Q I_{P}$ : the air quality sub index for air pollutant $P$.

$C_{P}$ : the concentration of pollutant $P$.

$C_{\text {low }}$ : the concentration breakpoint that is $\leq C_{P}$.

$C_{\text {high }}$ : the concentration breakpoint that is $\geq C_{P}$.

$I_{\text {low }}$ : the index breakpoint corresponding to $C_{\text {low }}$.

$I_{\text {high }}$ : the index breakpoint corresponding to $C_{\text {high }}$.

The six criteria air pollutants have acute effects on human health. The daily AQIs were calculated using the 24-hour average concentrations of $\mathrm{SO}_{2}, \mathrm{NO}_{2}, \mathrm{PM}_{2.5}, \mathrm{PM}_{10}$, $\mathrm{CO}$, and the daily average 8-hour maximum concentration of $\mathrm{O}_{3}$. Based on the United States Environmental Protection Agency (U.S. EPA) AQI, the ranges of the AQI values related to air quality can be classified into six classes: Grade I: 050 (Good, Green); Grade II: 51-100 (Moderate, Yellow); Grade III: 101-150 (Unhealthy for Sensitive Groups; Orange); Grade IV: 151-200 (Unhealthy; Red); Grade V: 201-300 (Very unhealthy; Purple), and Grade VI: 300-500 (Hazardous; Maroon) (Hu et al., 2015; Lanzafame et al., 2015; She et al., 2017; Zhao et al., 2018).

\section{RESULTS AND DISCUSSION}

\section{$\mathrm{PM}_{2.5}$ Concentration}

$\mathrm{PM}_{2.5}$ is suspended in the atmosphere for long periods and transports over long distances, which has a detrimental effect on both human health and air quality. During the period from 2015-2017, the atmospheric monthly $\mathrm{PM}_{2.5}$ concentrations in Puzih City, Singang Township, and Chiayi County are presented in Figs. 1(a)-1, 1(b)-1, 1(c)-1, and those in Douliou City, Taisi Township, Lunbei Township, and Mailiao Township are presented in Figs. 1(a)-2, 1(b)-2, 1(c)-2, respectively.

Among the seven cities and townships under consideration, the highest annual mean $\mathrm{PM}_{2.5}$ concentration occurred in Lunbei Township $\left(31.1 \mu \mathrm{g} \mathrm{m}^{-3}\right)$, which was in the range of $15.8-47.1 \mathrm{\mu g} \mathrm{m}^{-3}$, and the lowest level was found in Puzih City $\left(24.0 \mu \mathrm{g} \mathrm{m}^{-3}\right)$, with a range of $10.0-39.1 \mu \mathrm{g} \mathrm{m}^{-3}$ in 2015. In 2016, the highest annual concentration of $\mathrm{PM}_{2.5}$ occurred in Lunbei Township $\left(29.3 \mu \mathrm{g} \mathrm{m}^{-3}\right)$, with a range of $15.5-41.8 \mathrm{\mu g} \mathrm{m}^{-3}$, and the lowest level was found in Taisi Township $\left(24.7 \mu \mathrm{g} \mathrm{m}^{-3}\right)$ and was $11.1-35.9 \mu \mathrm{g} \mathrm{m}^{-3}$. In 2017, the highest annual average $\mathrm{PM}_{2.5}$ concentration was found in Mailiao Township $\left(27.9 \mu \mathrm{g} \mathrm{m}^{-3}\right)$, which ranged from $14.8-39.9 \mu \mathrm{g} \mathrm{m}^{-3}$, and the lowest values occurred in Puzih City $\left(21.9 \mu \mathrm{g} \mathrm{m}^{-3}\right)$, with a range of $10.0-32.0 \mu \mathrm{g} \mathrm{m}^{-3}$. Overall, the three-year mean $\mathrm{PM}_{2.5}$ concentrations in Puzih City, Singang Township, Chiayi County, Douliou City, Taisi Township, Lunbei Township, and Mailiao Township were 24.1, 24.9, 27.2, 27.5, 25.0, 29.2 and $25.7 \mu \mathrm{g} \mathrm{m}^{-3}$, respectively. It was found that the highest levels occurred in Lunbei Township and the lowest in Puzih City. These investigated districts were all above the WHO air quality regulated standard $\left(10 \mu \mathrm{g} \mathrm{m}^{-3}\right)$. Furthermore, with the exception of Douliou City, they exhibited annual declines in $\mathrm{PM}_{2.5}$ concentration $\left(29.1,26.7\right.$ and $26.6 \mu \mathrm{g} \mathrm{m}^{-3}$ in 2015, 2016, and 2017, respectively). The fluctuations did not have obvious downward trends in the other six cities and townships. $\mathrm{PM}_{2.5}$ is the primary air pollutant in these districts; thus more efforts to reduce the $\mathrm{PM}_{2.5}$ concentration would be meaningful.

As for seasonal variations, during 2015, the mean concentrations of $\mathrm{PM}_{2.5}$ ranged between 23.0 (Puzih City) and $29.4 \mu \mathrm{g} \mathrm{m}^{-3}$ (Lunbei Township) in spring, were between 8.8 (Mailiao Township) and $17.5 \mu \mathrm{g} \mathrm{m}^{-3}$ (Lunbei Township) in summer, ranged from 25.2 (Mailiao Township) to $35.9 \mu \mathrm{g} \mathrm{m}^{-3}$ (Lunbei Township) in fall, and were between 33.7 (Taisi Township) and $42.0 \mu \mathrm{g} \mathrm{m}^{-3}$ (Douliou City) in 


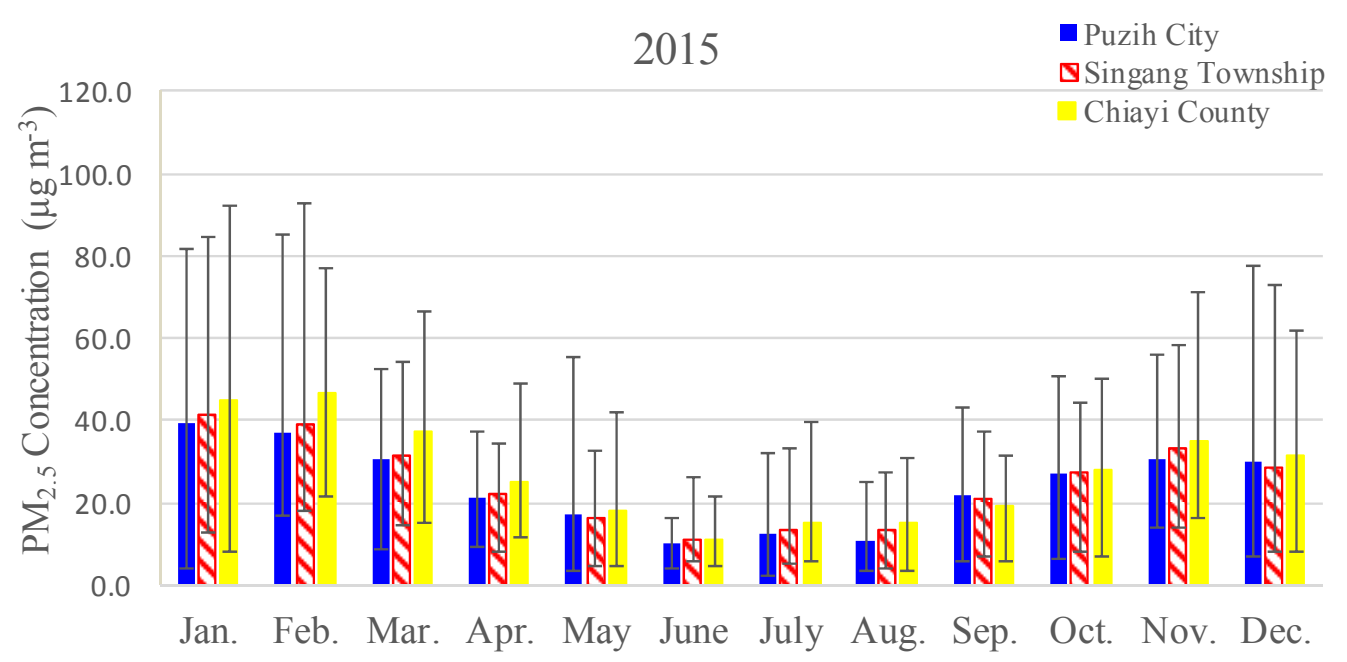

Month

Fig. 1(a)-1. Monthly average atmospheric $\mathrm{PM}_{2.5}$ concentrations in Puzih City, Singang Township, and Chiayi County in 2015.

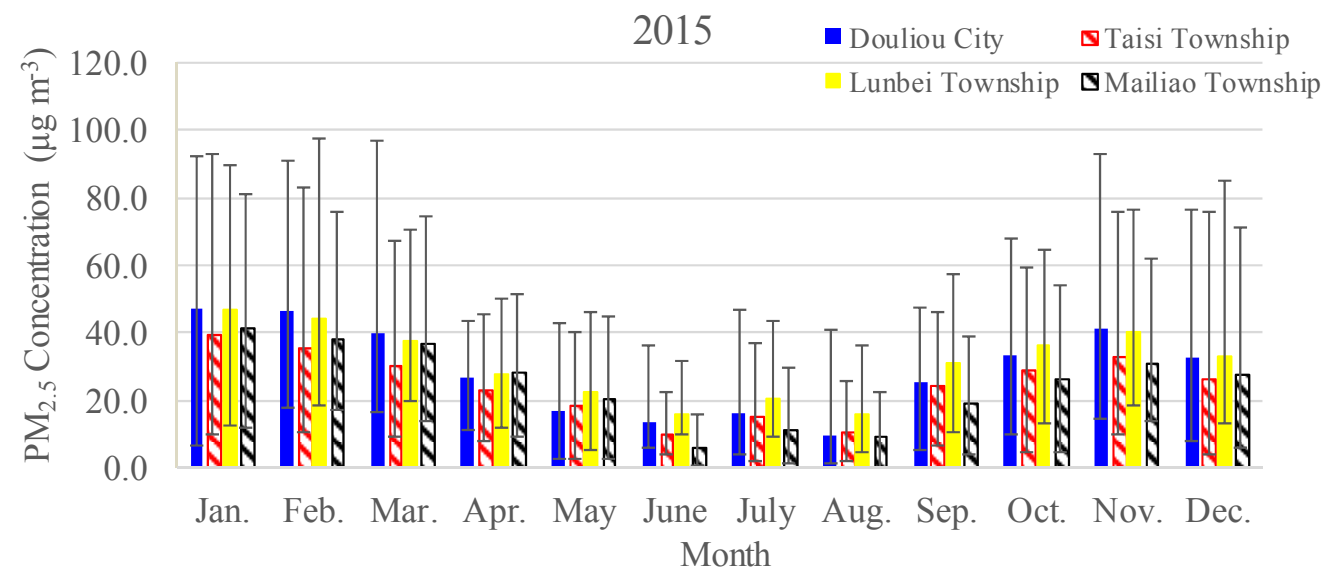

Fig. 1(a)-2. Monthly average atmospheric $\mathrm{PM}_{2.5}$ concentrations in Douliou City, Taisi Township, Lunbei Township, and Mailiao Township in 2015.

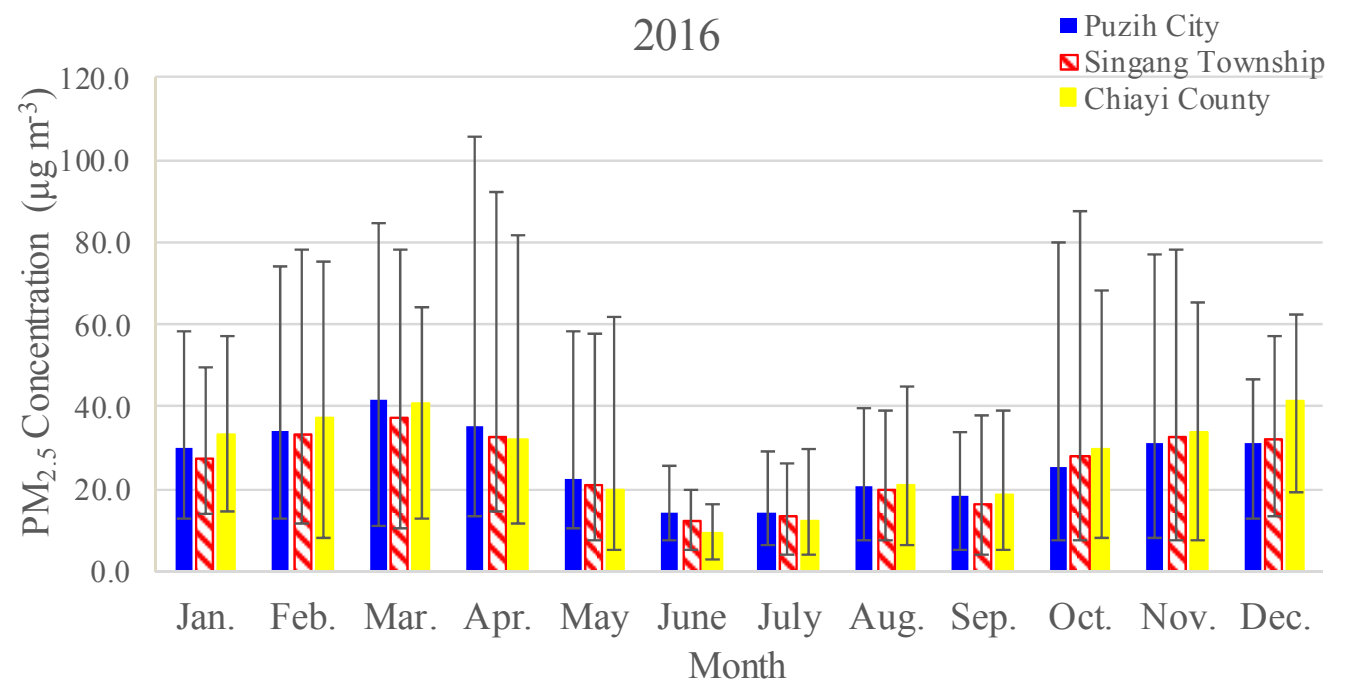

Fig. 1(b)-1. Monthly average atmospheric $\mathrm{PM}_{2.5}$ concentrations in Puzih City, Singang Township, and Chiayi County in 2016. 


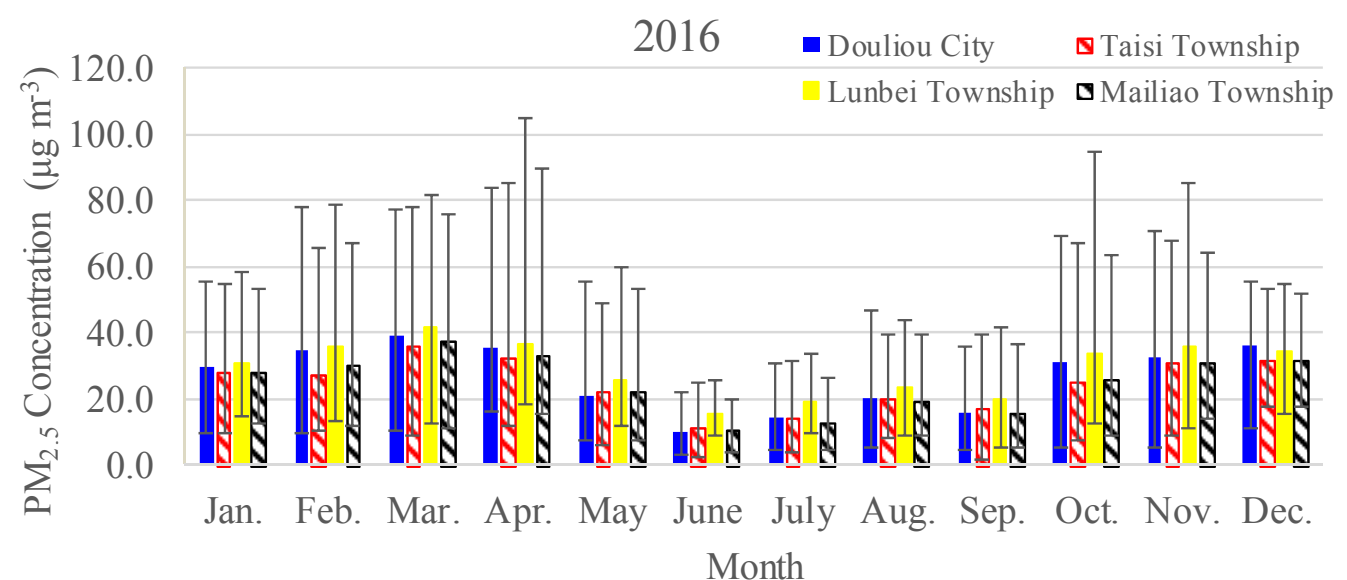

Fig. 1(b)-2. Monthly average atmospheric $\mathrm{PM}_{2.5}$ concentrations in Douliou City, Taisi Township, Lunbei Township and Mailiao Township in 2016.

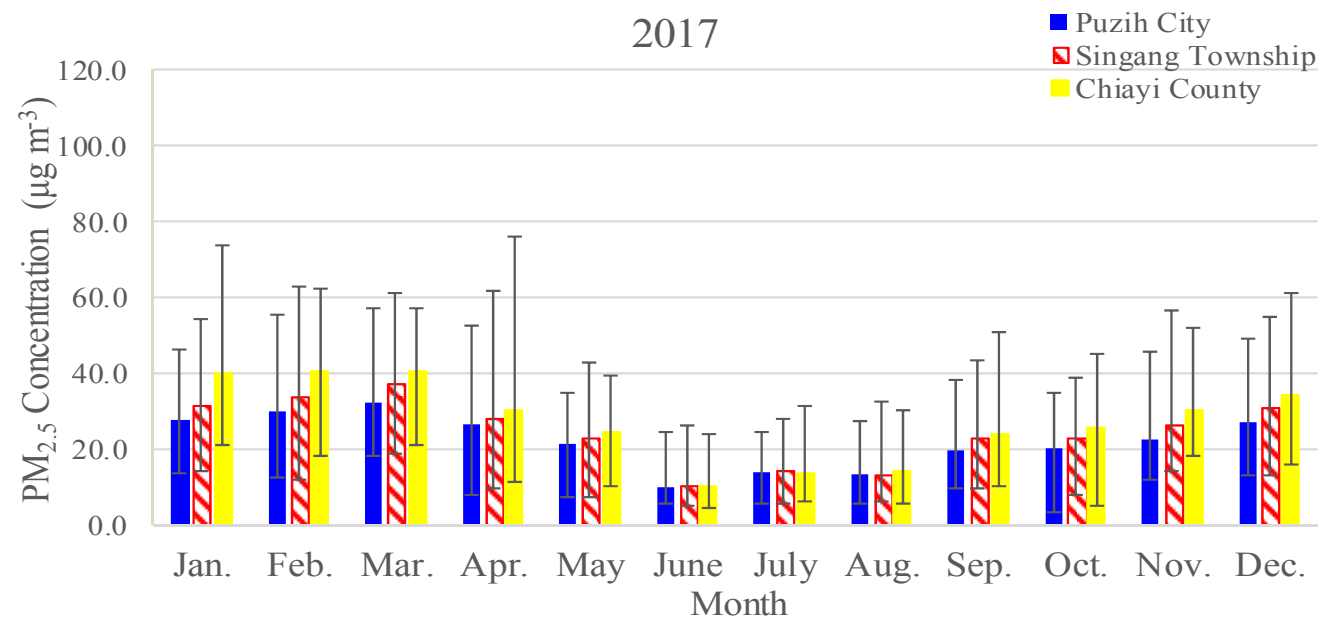

Fig. 1(c)-1. Monthly average atmospheric $\mathrm{PM}_{2.5}$ concentrations in Puzih City, Singang Township, and Chiayi County in 2017.

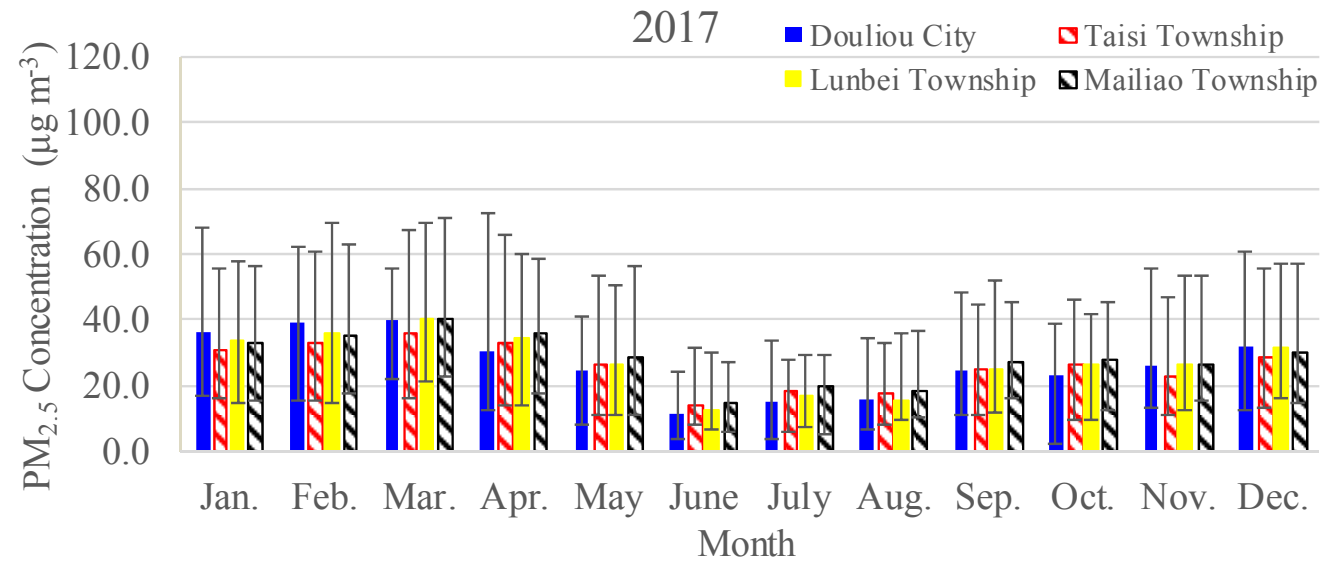

Fig. 1(c)-2. Monthly average atmospheric $\mathrm{PM}_{2.5}$ concentrations in Douliou City, Taisi Township, Lunbei Township, and Mailiao Township in 2017.

winter. In 2016, the mean concentrations of $\mathrm{PM}_{2.5}$ ranged between 30.1 (Taisi Township) and $34.6 \mu \mathrm{g} \mathrm{m}^{-3}$ (Lunbei Township) in spring, were between 14.1 (Chiayi County) and $19.3 \mu \mathrm{g} \mathrm{m}^{-3}$ (Lunbei Township) in summer, ranged from 24.3 (Mailiao Township) to $29.7 \mu \mathrm{g} \mathrm{m}^{-3}$ (Lunbei Township) in fall, and were between 29.0 (Taisi Township) 
and $37.3 \mu \mathrm{g} \mathrm{m}^{-3}$ (Chiayi County) in winter. In 2017, the mean concentrations of $\mathrm{PM}_{2.5}$ ranged between 26.5 (Puzih City) and $34.5 \mu \mathrm{g} \mathrm{m}^{-3}$ (Mailiao Township) in spring, were between 12.4 (Puzih City) and $17.4 \mu \mathrm{g} \mathrm{m}^{-3}$ (Mailiao Township) in summer, ranged from 20.6 (Puzih City) to $26.8 \mu \mathrm{g} \mathrm{m}^{-3}$ (Mailiao Township) in fall, and were between 28.1 (Puzih City) and $38.1 \mu \mathrm{g} \mathrm{m}^{-3}$ (Chiayi County) in winter. The above study indicated that the $\mathrm{PM}_{2.5}$ concentrations in the seven counties and townships generally occurred in the following order: winter $>$ spring $>$ fall $>$ summer. This result is similar to that obtained locally by Lee (2018), who studied atmospheric $\mathrm{PM}_{2.5}$ concentrations in 22 cities and counties in Taiwan and pointed out that the mean $\mathrm{PM}_{2.5}$ concentrations were $23.2,12.1,19.1$, and $25.0 \mu \mathrm{g} \mathrm{m}^{-3}$ in spring, summer, fall and winter, respectively. This may have been caused by the various air temperatures in different seasons, where temperature inversions easily occur under low ground temperature conditions, which will impede the dispersion of air pollutants and lead to elevations in atmospheric $\mathrm{PM}_{2.5}$ in cold seasons (Tang et al., 2017; Xing et al., 2017; Lee et al., 2018; Wang et al., 2018a).

The primary sources of fuel combustion, including industrial facilities, vehicle emissions, and power plants can release fine particles, and secondary atmospheric gaseous emissions, such as VOCs, $\mathrm{NO}_{\mathrm{x}}$, and $\mathrm{SO}_{2}$, also transform $\mathrm{PM}_{2.5}$ (Mao et al., 1997; Yang et al., 1997; Liu et al., 2002). This universal source of $\mathrm{PM}_{2.5}$ determines its crucial effect on regional air quality. Therefore, it is of great significance to reduce the level of $\mathrm{PM}_{2.5}$ by reducing the number of automobiles and promoting clean energy in order to improve overall air quality.

\section{$\mathrm{PM}_{10}$ Concentration}

$\mathrm{PM}_{10}$ comprises inhalable particles. These coarse particles are usually derived from motor vehicles running on unpaved asphalt and cement roads, the crushing and grinding of materials, as well as dust from the wind. $\mathrm{PM}_{10}$ can be inhaled by humans and is deposited in the upper respiratory tract and pulmonary alveoli and causes related diseases (Song et al., 2008; Tao et al., 2009; Matus et al., 2012; Sun et al., 2014; Liang et al., 2016). $\mathrm{PM}_{10}$ can affect residents' health and the air quality of a region (Liu et al., 2002). For the period from 2015-2017, the monthly average $\mathrm{PM}_{10}$ concentrations in the ambient air in Puzih City, Singang Township, and Chiayi County are presented in Tables 1(a)-1, 1(b)-1, and 1(c)-1, and those in Douliou City, Taisi Township, Lunbei Township, and Mailiao Township are presented in Tables 1(a)-2, 1(b)-2, 1(c)-2, respectively.

It can be seen in Tables 1(a)-1 and 1(a)-2 that Mailiao Township $\left(72 \mu \mathrm{g} \mathrm{m}^{-3}\right)$ has the maximum levels of $\mathrm{PM}_{10}$, ranging from $36-149 \mu \mathrm{g} \mathrm{m}^{-3}$, while Taisi Township $\left(47 \mu \mathrm{g} \mathrm{m}^{-3}\right)$ has the minimum values, ranging from 20 $94 \mu \mathrm{g} \mathrm{m}^{-3}$ in 2015. Table $1(\mathrm{~b})-1$ and $1(\mathrm{~b})-2$ shows that the highest $\mathrm{PM}_{10}$ concentration occurred in Mailiao Township $\left(66 \mu \mathrm{g} \mathrm{m}^{-3}\right)$ and ranged from $31-125 \mu \mathrm{g} \mathrm{m}^{-3}$, while the lowest $\mathrm{PM}_{10}$ concentration occurred in Taisi Township $\left(45 \mu \mathrm{g} \mathrm{m}^{-3}\right)$ and ranged from $19-85 \mu \mathrm{g} \mathrm{m}^{-3}$ in 2016. For 2017, Tables 1(b)-1 and 1(b)-2 demonstrate that the highest annual average $\mathrm{PM}_{10}$ concentration was found in Mailiao
Township (71 $\mu \mathrm{g} \mathrm{m}^{-3}$ ), which ranged from 36-144 $\mu \mathrm{g} \mathrm{m}^{-3}$, and that the lowest values occurred in Taisi Township (49 $\mu \mathrm{g} \mathrm{m}^{-3}$ ), with a range of 24-104 $\mu \mathrm{g} \mathrm{m}^{-3}$. Among the seven observation areas, due to the establishment of some factories and an industrial zone in Mailiao Township, it has gradually become a major industrial township in Taiwan and has been accompanied with the highest $\mathrm{PM}_{10}$ levels. Taisi Township is located in the western part of Taiwan, which is close to the sea, where the strong winds and rain from the sea favor the dispersion and deposition of $\mathrm{PM}_{10}$, thus it has the lowest $\mathrm{PM}_{10}$ levels. The average $\mathrm{PM}_{10}$ concentrations for the three years under observation were $65,58,57,52,47,54$, and $70 \mu \mathrm{g} \mathrm{m}^{-3}$ in Puzih City, Singang Township, Chiayi County, Douliou City, Taisi Township, Lunbei Township, and Mailiao Township, respectively. Although the observed $\mathrm{PM}_{10}$ levels in western Taiwan were lower than those in Wuhu $\left(82 \mu \mathrm{g} \mathrm{m}^{-3}\right)$ and Bengbu $\left(95 \mu \mathrm{g} \mathrm{m}^{-3}\right)$, two central cities in China, they were still approximately $2.35-3.50$ times higher than the WHO standard $\left(20 \mu \mathrm{g} \mathrm{m}^{-3}\right)$. A previous study indicated that $\mathrm{PM}_{10}$ is an important major atmospheric air pollutant that has a large regional impact on AQI (Liu et al., 2002). Thus, further control of $\mathrm{PM}_{10}$ is of great significance to improve the air quality in western Taiwan.

An examination of the seasonal $\mathrm{PM}_{10}$ concentration characteristics indicated that the values were between 44 (Taisi Township) and $70 \mu \mathrm{g} \mathrm{m}^{-3}$ (Mailiao Township) in spring, were between 29 (Taisi Township) and $46 \mu \mathrm{g} \mathrm{m}^{-3}$ (Mailiao Township) in summer, ranged from 52 (Taisi Township) to $78 \mu \mathrm{g} \mathrm{m}^{-3}$ (Mailiao Township) in fall, and were between 65 (Taisi Township) and $96 \mu \mathrm{g} \mathrm{m}^{-3}$ (Mailiao Township) in winter, respectively, in 2015. These values ranged between 51 (Taisi Township) and $66 \mu \mathrm{g} \mathrm{m}^{-3}$ (Mailiao Township) in spring, were between 31 (Taisi Township) and $47 \mu \mathrm{g} \mathrm{m}^{-3}$ (Mailiao Township) in summer, ranged from 45 (Taisi Township) to $70 \mu \mathrm{g} \mathrm{m}^{-3}$ (Mailiao Township) in fall, and were between 54 (Taisi Township) and $80 \mu \mathrm{g} \mathrm{m}^{-3}$ (Mailiao Township) in winter, respectively, in 2016. These values ranged between 53 (Taisi Township) and $72 \mu \mathrm{g} \mathrm{m}^{-3}$ (Mailiao Township) in spring, were between 29 (Taisi Township) and $41 \mu \mathrm{g} \mathrm{m}^{-3}$ (Mailiao Township) in summer, ranged from 52 (Douliou City) to $77 \mu \mathrm{g} \mathrm{m}^{-3}$ (Mailiao Township) in fall, and were between 59 (Taisi Township) and $93 \mu \mathrm{g} \mathrm{m}^{-3}$ (Mailiao Township) in winter, respectively, in 2017. $\mathrm{PM}_{10}$ levels exhibit notable seasonal distinctions. The average values in summer with the lowest levels $\left(36 \mu \mathrm{g} \mathrm{m}^{-3}\right)$ were $52.0 \%$ in magnitude lower than those in winter, when the highest levels $\left(75 \mu \mathrm{g} \mathrm{m}^{-3}\right)$ were observed. Spring had similar levels to those in the fall, and both were in the middle levels $\left(60 \mu \mathrm{g} \mathrm{m}^{-3}\right.$ in spring and $61 \mu \mathrm{g} \mathrm{m}^{-3}$ in fall, respectively). In Taiwan, the airflow with low temperature and moisture from the north in winter favors enhancement of the level of $\mathrm{PM}_{10}$. This result was consistent with the seasonal distribution of $\mathrm{PM}_{10}$ found in Wuhu and Bengbu (Shang et al., 2018; Wang et al., 2018b). Taiwan is surrounded by the sea and has abundant rainfall, which is very beneficial to the removal of $\mathrm{PM}_{10}$ from the atmosphere by wet deposition; thus its overall $\mathrm{PM}_{10}$ levels were lower than those for Wuhu and Bengbu. 
Table 1(a)-1. Monthly average atmospheric $\mathrm{PM}_{10}$ concentrations in Puzih City, Singang Township, and Chiayi County in 2015 .

\begin{tabular}{|c|c|c|c|c|c|c|c|c|c|}
\hline \multirow[b]{2}{*}{ Month } & \multicolumn{3}{|c|}{ Puzih City } & \multicolumn{3}{|c|}{ Singang Township } & \multicolumn{3}{|c|}{ Chiayi County } \\
\hline & $\begin{array}{l}\text { Range } \\
\left(\mu \mathrm{g} \mathrm{m}^{-3}\right)\end{array}$ & $\begin{array}{l}\text { Mean } \\
\left(\mu \mathrm{g} \mathrm{m}^{-3}\right)\end{array}$ & $\begin{array}{l}\text { R.S.D } \\
(\%)\end{array}$ & $\begin{array}{l}\text { Range } \\
\left(\mu \mathrm{g} \mathrm{m}^{-3}\right)\end{array}$ & $\begin{array}{l}\text { Mean } \\
\left(\mu \mathrm{g} \mathrm{m}^{-3}\right)\end{array}$ & $\begin{array}{l}\text { R.S.D } \\
(\%)\end{array}$ & $\begin{array}{l}\text { Range } \\
\left(\mu \mathrm{g} \mathrm{m}^{-3}\right)\end{array}$ & $\begin{array}{l}\text { Mean } \\
\left(\mu \mathrm{g} \mathrm{m}^{-3}\right)\end{array}$ & $\begin{array}{l}\text { R.S.D } \\
(\%)\end{array}$ \\
\hline Jan. & $29-147$ & 100 & 27 & $29-147$ & 93 & 29 & $30-147$ & 91 & 25 \\
\hline Feb. & $50-176$ & 91 & 36 & $51-164$ & 85 & 35 & $45-136$ & 91 & 30 \\
\hline Mar. & $41-115$ & 79 & 25 & $43-112$ & 73 & 28 & $45-118$ & 75 & 27 \\
\hline Apr. & $40-103$ & 66 & 28 & 29-89 & 58 & 31 & $28-101$ & 57 & 32 \\
\hline May & $21-107$ & 49 & 40 & $9-77$ & 39 & 51 & $12-77$ & 39 & 44 \\
\hline June & $29-54$ & 42 & 13 & $20-61$ & 33 & 27 & $21-41$ & 30 & 16 \\
\hline July & $21-75$ & 43 & 28 & $14-61$ & 35 & 34 & $18-67$ & 33 & 35 \\
\hline Aug. & $20-122$ & 43 & 51 & $8-77$ & 33 & 53 & $13-84$ & 35 & 47 \\
\hline Sep. & $39-88$ & 61 & 24 & $22-73$ & 47 & 35 & $18-72$ & 46 & 37 \\
\hline Oct. & $31-114$ & 73 & 22 & $21-96$ & 62 & 26 & $25-103$ & 65 & 27 \\
\hline Nov. & 54-139 & 85 & 23 & $46-117$ & 81 & 23 & $46-115$ & 75 & 22 \\
\hline Dec. & $24-167$ & 78 & 32 & $25-142$ & 72 & 29 & 29-139 & 79 & 28 \\
\hline Annual & $33-117$ & 68 & 29 & $26-101$ & 59 & 34 & $28-100$ & 60 & 31 \\
\hline
\end{tabular}

Table 1(a)-2. Monthly average atmospheric $\mathrm{PM}_{10}$ concentrations in Douliou City, Taisi Township, Lunbei Township, and Mailiao Township in 2015.

\begin{tabular}{|c|c|c|c|c|c|c|c|c|c|c|c|c|}
\hline \multirow[b]{2}{*}{ Month } & \multicolumn{3}{|c|}{ Douliou City } & \multicolumn{3}{|c|}{ Taisi Township } & \multicolumn{3}{|c|}{ Lunbei Township } & \multicolumn{3}{|c|}{ Mailiao Township } \\
\hline & $\begin{array}{l}\text { Range } \\
\left(\mu \mathrm{g} \mathrm{m}^{-3}\right)\end{array}$ & $\begin{array}{l}\text { Mean } \\
\left(\mu \mathrm{g} \mathrm{m}^{-3}\right)\end{array}$ & $\begin{array}{l}\text { R.S.D } \\
(\%)\end{array}$ & $\begin{array}{l}\text { Range } \\
\left(\mu \mathrm{g} \mathrm{m}^{-3}\right)\end{array}$ & $\begin{array}{l}\text { Mean } \\
\left(\mu \mathrm{g} \mathrm{m}^{-3}\right)\end{array}$ & $\begin{array}{l}\text { R.S.D } \\
(\%)\end{array}$ & $\begin{array}{l}\text { Range } \\
\left(\mu \mathrm{g} \mathrm{m}^{-3}\right)\end{array}$ & $\begin{array}{l}\text { Mean } \\
\left(\mu \mathrm{g} \mathrm{m}^{-3}\right)\end{array}$ & $\begin{array}{l}\text { R.S.D } \\
(\%)\end{array}$ & $\begin{array}{l}\text { Range } \\
\left(\mu \mathrm{g} \mathrm{m}^{-3}\right)\end{array}$ & $\begin{array}{l}\text { Mean } \\
\left(\mu \mathrm{g} \mathrm{m}^{-3}\right)\end{array}$ & $\begin{array}{l}\text { R.S.D } \\
(\%)\end{array}$ \\
\hline Jan. & $23-133$ & 80 & 28.4 & $28-143$ & 71 & 40.6 & $23-119$ & 79 & 30.9 & $40-202$ & 105 & 32.6 \\
\hline Feb. & $39-139$ & 81 & 32.6 & $31-163$ & 67 & 48.6 & $36-176$ & 77 & 46.1 & $52-224$ & 97 & 45.8 \\
\hline Mar. & $42-118$ & 70 & 28.6 & $28-85$ & 54 & 34.1 & $33-104$ & 64 & 30.8 & $40-160$ & 85 & 30.8 \\
\hline Apr. & $32-88$ & 55 & 28.9 & $22-73$ & 44 & 35.4 & $25-80$ & 54 & 32.5 & $40-134$ & 72 & 29.9 \\
\hline May & $14-78$ & 40 & 44.2 & $8-64$ & 34 & 45.3 & $8-72$ & 37 & 45.5 & $23-90$ & 54 & 32.4 \\
\hline June & $21-53$ & 32 & 22.6 & $16-43$ & 26 & 23.8 & $17-49$ & 27 & 25.3 & $33-55$ & 41 & 13.5 \\
\hline July & $19-66$ & 35 & 39.9 & $16-49$ & 33 & 28.7 & $15-69$ & 37 & 40.1 & $26-99$ & 50 & 30.0 \\
\hline Aug. & $13-62$ & 27 & 43.1 & $9-59$ & 26 & 54.0 & $9-63$ & 27 & 50.0 & $12-217$ & 45 & 83.9 \\
\hline Sep. & $21-67$ & 45 & 31.6 & $18-63$ & 41 & 29.1 & $20-104$ & 48 & 37.9 & $30-122$ & 66 & 33.0 \\
\hline Oct. & $26-94$ & 60 & 28.4 & $20-90$ & 56 & 28.7 & $22-88$ & 58 & 25.5 & $42-127$ & 81 & 22.5 \\
\hline Nov. & $35-131$ & 76 & 28.7 & 25-139 & 59 & 36.1 & $42-227$ & 74 & 44.7 & $62-190$ & 86 & 27.5 \\
\hline Dec. & $27-117$ & 65 & 30.4 & $17-158$ & 56 & 51.0 & $23-181$ & 65 & 44.5 & $32-169$ & 86 & 36.6 \\
\hline Annual & $26-95$ & 56 & 32.3 & 20-94 & 47 & 38.0 & $23-111$ & 54 & 37.8 & $36-149$ & 72 & 34.9 \\
\hline
\end{tabular}

Table 1(b)-1. Monthly average atmospheric $\mathrm{PM}_{10}$ concentrations in Puzih City, Singang Township, and Chiayi County in 2016

\begin{tabular}{|c|c|c|c|c|c|c|c|c|c|}
\hline \multirow[b]{2}{*}{ Month } & \multicolumn{3}{|c|}{ Puzih City } & \multicolumn{3}{|c|}{ Singang Township } & \multicolumn{3}{|c|}{ Chiayi County } \\
\hline & $\begin{array}{l}\text { Range } \\
\left(\mu \mathrm{g} \mathrm{m}^{-3}\right)\end{array}$ & $\begin{array}{l}\text { Mean } \\
\left(\mu \mathrm{g} \mathrm{m}^{-3}\right)\end{array}$ & $\begin{array}{l}\text { R.S.D } \\
(\%)\end{array}$ & $\begin{array}{l}\text { Range } \\
\left(\mu \mathrm{g} \mathrm{m}^{-3}\right)\end{array}$ & $\begin{array}{l}\text { Mean } \\
\left(\mu \mathrm{g} \mathrm{m}^{-3}\right)\end{array}$ & $\begin{array}{l}\text { R.S.D } \\
(\%)\end{array}$ & $\begin{array}{l}\text { Range } \\
\left(\mu \mathrm{g} \mathrm{m}^{-3}\right)\end{array}$ & $\begin{array}{l}\text { Mean } \\
\left(\mu \mathrm{g} \mathrm{m}^{-3}\right)\end{array}$ & $\begin{array}{l}\text { R.S.D } \\
(\%)\end{array}$ \\
\hline Jan. & $35-109$ & 63 & 31 & $32-101$ & 58 & 34 & $28-102$ & 61 & 32 \\
\hline Feb. & $34-179$ & 81 & 41 & $25-151$ & 70 & 45 & $26-143$ & 72 & 39 \\
\hline Mar. & $32-135$ & 78 & 32 & $20-140$ & 74 & 36 & $25-113$ & 71 & 33 \\
\hline Apr. & $34-169$ & 68 & 42 & $35-157$ & 69 & 42 & $29-137$ & 61 & 49 \\
\hline May & $35-103$ & 52 & 33 & $28-99$ & 49 & 35 & $25-89$ & 45 & 37 \\
\hline June & $28-55$ & 40 & 16 & $15-57$ & 35 & 29 & $17-39$ & 29 & 19 \\
\hline July & $22-61$ & 38 & 25 & $13-56$ & 32 & 34 & $15-49$ & 31 & 27 \\
\hline Aug. & $27-81$ & 48 & 32 & $20-75$ & 40 & 36 & $18-67$ & 40 & 31 \\
\hline Sep. & $14-78$ & 45 & 42 & $12-68$ & 37 & 45 & $20-74$ & 41 & 46 \\
\hline Oct. & $25-139$ & 63 & 39 & $24-121$ & 58 & 38 & 18-94 & 55 & 33 \\
\hline Nov. & $26-141$ & 74 & 38 & $24-146$ & 72 & 44 & $17-111$ & 66 & 38 \\
\hline Dec. & $40-168$ & 83 & 29 & 29-95 & 73 & 22 & $37-113$ & 79 & 21 \\
\hline Annual & $29-118$ & 61 & 33 & $23-106$ & 56 & 37 & 23-94 & 54 & 34 \\
\hline
\end{tabular}


Table 1(b)-2. Monthly average atmospheric $\mathrm{PM}_{10}$ concentrations in Douliou City, Taisi Township, Lunbei Township, and Mailiao Township in 2016.

\begin{tabular}{|c|c|c|c|c|c|c|c|c|c|c|c|c|}
\hline \multirow[b]{2}{*}{ Month } & \multicolumn{3}{|c|}{ Douliou City } & \multicolumn{3}{|c|}{ Taisi Township } & \multicolumn{3}{|c|}{ Lunbei Township } & \multicolumn{3}{|c|}{ Mailiao Township } \\
\hline & $\begin{array}{l}\text { Range } \\
\left(\mu \mathrm{g} \mathrm{m}^{-3}\right)\end{array}$ & $\begin{array}{l}\text { Mean } \\
\left(\mu \mathrm{g} \mathrm{m}^{-3}\right)\end{array}$ & $\begin{array}{l}\text { R.S.D } \\
(\%)\end{array}$ & $\begin{array}{l}\text { Range } \\
\left(\mu \mathrm{g} \mathrm{m}^{-3}\right)\end{array}$ & $\begin{array}{l}\text { Mean } \\
\left(\mu \mathrm{g} \mathrm{m}^{-3}\right)\end{array}$ & $\begin{array}{l}\text { R.S.D } \\
(\%)\end{array}$ & $\begin{array}{l}\text { Range } \\
\left(\mu \mathrm{g} \mathrm{m}^{-3}\right)\end{array}$ & $\begin{array}{l}\text { Mean } \\
\left(\mu \mathrm{g} \mathrm{m}^{-3}\right)\end{array}$ & $\begin{array}{l}\text { R.S.D } \\
(\%)\end{array}$ & $\begin{array}{l}\text { Range } \\
\left(\mu \mathrm{g} \mathrm{m}^{-3}\right)\end{array}$ & $\begin{array}{l}\text { Mean } \\
\left(\mu \mathrm{g} \mathrm{m}^{-3}\right)\end{array}$ & $\begin{array}{l}\text { R.S.D } \\
(\%)\end{array}$ \\
\hline Jan. & $21-87$ & 48 & 34.9 & $23-76$ & 46 & 34.2 & $24-85$ & 49 & 35.7 & $35-115$ & 65 & 31.4 \\
\hline Feb. & $18-119$ & 57 & 44.5 & $24-114$ & 54 & 45.0 & $19-143$ & 64 & 46.3 & $36-191$ & 76 & 44.5 \\
\hline Mar. & $21-105$ & 62 & 35.6 & $19-106$ & 58 & 35.9 & $19-122$ & 63 & 36.8 & $27-138$ & 75 & 33.7 \\
\hline Apr. & $30-127$ & 58 & 46.3 & $28-113$ & 52 & 38.4 & $33-160$ & 59 & 46.0 & $40-145$ & 68 & 34.3 \\
\hline May & $25-78$ & 42 & 33.4 & $21-83$ & 43 & 35.1 & $21-82$ & 42 & 36.1 & $32-90$ & 55 & 28.8 \\
\hline June & $17-44$ & 30 & 20.5 & $10-44$ & 29 & 26.0 & $15-47$ & 31 & 24.2 & $22-61$ & 42 & 18.9 \\
\hline July & $14-52$ & 31 & 29.3 & $14-52$ & 30 & 30.9 & $13-60$ & 32 & 33.8 & $25-81$ & 44 & 29.0 \\
\hline Aug. & $19-68$ & 38 & 32.3 & $17-62$ & 35 & 34.8 & $19-65$ & 37 & 35.8 & $32-105$ & 54 & 31.2 \\
\hline Sep. & $13-64$ & 37 & 46.0 & $8-57$ & 31 & 44.9 & $11-62$ & 38 & 44.9 & $12-91$ & 53 & 39.6 \\
\hline Oct. & $22-94$ & 53 & 34.1 & $17-92$ & 47 & 40.7 & $22-128$ & 57 & 44.0 & $34-128$ & 74 & 30.6 \\
\hline Nov. & $18-101$ & 60 & 39.6 & $19-105$ & 57 & 41.6 & $17-124$ & 63 & 42.9 & $34-143$ & 82 & 36.1 \\
\hline Dec. & 27-93 & 65 & 22.9 & $34-114$ & 61 & 34.0 & $31-238$ & 71 & 50.9 & $48-217$ & 99 & 39.6 \\
\hline Annual & $20-86$ & 48 & 35.0 & $19-85$ & 45 & 36.8 & $20-110$ & 50 & 39.8 & $31-125$ & 66 & 33.1 \\
\hline
\end{tabular}

Table 1(c)-1. Monthly average atmospheric $\mathrm{PM}_{10}$ concentrations in Puzih City, Singang Township, and Chiayi County in 2017.

\begin{tabular}{|c|c|c|c|c|c|c|c|c|c|}
\hline \multirow[b]{2}{*}{ Month } & \multicolumn{3}{|c|}{ Puzih City } & \multicolumn{3}{|c|}{ Singang Township } & \multicolumn{3}{|c|}{ Chiayi County } \\
\hline & $\begin{array}{l}\text { Range } \\
\left(\mu \mathrm{g} \mathrm{m}^{-3}\right)\end{array}$ & $\begin{array}{l}\text { Mean } \\
\left(\mu \mathrm{g} \mathrm{m}^{-3}\right)\end{array}$ & $\begin{array}{l}\text { R.S.D } \\
(\%)\end{array}$ & $\begin{array}{l}\text { Range } \\
\left(\mu \mathrm{g} \mathrm{m}^{-3}\right)\end{array}$ & $\begin{array}{l}\text { Mean } \\
\left(\mu \mathrm{g} \mathrm{m}^{-3}\right)\end{array}$ & $\begin{array}{l}\text { R.S.D } \\
(\%)\end{array}$ & $\begin{array}{l}\text { Range } \\
\left(\mu \mathrm{g} \mathrm{m}^{-3}\right)\end{array}$ & $\begin{array}{l}\text { Mean } \\
\left(\mu \mathrm{g} \mathrm{m}^{-3}\right)\end{array}$ & $\begin{array}{l}\text { R.S.D } \\
(\%)\end{array}$ \\
\hline Jan. & $50-115$ & 82 & 22 & $40-109$ & 74 & 25 & $43-108$ & 75 & 23 \\
\hline Feb. & $37-138$ & 87 & 28 & $31-126$ & 77 & 31 & $39-109$ & 75 & 25 \\
\hline Mar. & $50-140$ & 83 & 24 & $46-115$ & 78 & 24 & $46-107$ & 76 & 19 \\
\hline Apr. & $33-106$ & 65 & 29 & $28-111$ & 59 & 35 & $29-107$ & 56 & 31 \\
\hline May & $33-110$ & 58 & 30 & $24-104$ & 54 & 32 & $26-82$ & 50 & 31 \\
\hline June & $24-53$ & 37 & 20 & $19-61$ & 33 & 31 & $17-41$ & 29 & 23 \\
\hline July & $27-56$ & 40 & 21 & $20-56$ & 37 & 24 & $19-54$ & 35 & 27 \\
\hline Aug. & $26-74$ & 38 & 29 & $16-74$ & 31 & 38 & $22-76$ & 35 & 32 \\
\hline Sep. & 29-99 & 54 & 35 & $22-80$ & 46 & 38 & $25-78$ & 46 & 31 \\
\hline Oct. & $17-189$ & 81 & 47 & $19-110$ & 60 & 33 & $16-104$ & 60 & 33 \\
\hline Nov. & $45-170$ & 86 & 37 & $37-121$ & 72 & 33 & $42-108$ & 68 & 27 \\
\hline Dec. & $38-186$ & 93 & 36 & $40-126$ & 76 & 31 & $40-116$ & 72 & 28 \\
\hline Annual & $34-120$ & 67 & 30 & 28-99 & 58 & 31 & $30-91$ & 56 & 28 \\
\hline
\end{tabular}

Table 1(c)-2. Monthly average atmospheric $\mathrm{PM}_{10}$ concentrations in Douliou City, Taisi Township, Lunbei Township, and Mailiao Township in 2017.

\begin{tabular}{|c|c|c|c|c|c|c|c|c|c|c|c|c|}
\hline \multirow[b]{2}{*}{ Month } & \multicolumn{3}{|c|}{ Douliou City } & \multicolumn{3}{|c|}{ Taisi Township } & \multicolumn{3}{|c|}{ Lunbei Township } & \multicolumn{3}{|c|}{ Mailiao Township } \\
\hline & $\begin{array}{l}\text { Range } \\
\left(\mu \mathrm{g} \mathrm{m}^{-3}\right)\end{array}$ & $\begin{array}{l}\text { Mean } \\
\left(\mu \mathrm{g} \mathrm{m}^{-3}\right)\end{array}$ & $\begin{array}{l}\text { R.S.D } \\
(\%)\end{array}$ & $\begin{array}{l}\text { Range } \\
\left(\mu \mathrm{g} \mathrm{m}^{-3}\right)\end{array}$ & $\begin{array}{l}\text { Mean } \\
\left(\mu \mathrm{g} \mathrm{m}^{-3}\right)\end{array}$ & $\begin{array}{l}\text { R.S.D } \\
(\%)\end{array}$ & $\begin{array}{l}\text { Range } \\
\left(\mu \mathrm{g} \mathrm{m}^{-3}\right)\end{array}$ & $\begin{array}{l}\text { Mean } \\
\left(\mu \mathrm{g} \mathrm{m}^{-3}\right)\end{array}$ & $\begin{array}{l}\text { R.S.D } \\
(\%)\end{array}$ & $\begin{array}{l}\text { Range } \\
\left(\mu \mathrm{g} \mathrm{m}^{-3}\right)\end{array}$ & $\begin{array}{l}\text { Mean } \\
\left(\mu \mathrm{g} \mathrm{m}^{-3}\right)\end{array}$ & $\begin{array}{l}\text { R.S.D } \\
(\%)\end{array}$ \\
\hline Jan. & $30-98$ & 61 & 27.3 & $35-80$ & 52 & 26.2 & $30-96$ & 61 & 26.3 & $61-192$ & 96 & 32.7 \\
\hline Feb. & $28-109$ & 66 & 31.5 & $24-122$ & 60 & 34.3 & $20-104$ & 65 & 31.0 & $36-185$ & 97 & 36.6 \\
\hline Mar. & $38-96$ & 67 & 22.6 & $32-104$ & 60 & 32.8 & $39-107$ & 67 & 26.7 & $47-194$ & 87 & 32.0 \\
\hline Apr. & $26-114$ & 54 & 34.1 & $25-90$ & 53 & 34.4 & $23-89$ & 56 & 32.5 & $37-110$ & 68 & 28.3 \\
\hline May & $25-84$ & 50 & 28.8 & $19-121$ & 47 & 42.9 & $19-98$ & 47 & 36.5 & $31-117$ & 61 & 31.1 \\
\hline June & $14-47$ & 28 & 27.4 & $11-45$ & 24 & 33.1 & $19-59$ & 30 & 34.2 & $22-55$ & 34 & 23.2 \\
\hline July & $22-60$ & 33 & 28.8 & $21-44$ & 33 & 20.7 & $19-59$ & 35 & 27.3 & $28-67$ & 43 & 23.8 \\
\hline Aug. & $20-59$ & 34 & 27.9 & $17-63$ & 31 & 38.2 & $19-60$ & 32 & 34.1 & $27-140$ & 45 & 46.4 \\
\hline Sep. & $26-74$ & 45 & 30.3 & $20-111$ & 45 & 43.5 & $21-127$ & 49 & 45.1 & $33-109$ & 59 & 34.0 \\
\hline Oct. & $15-78$ & 53 & 28.4 & $26-154$ & 65 & 49.4 & $16-239$ & 82 & 73.6 & $28-208$ & 85 & 42.9 \\
\hline Nov. & $36-112$ & 58 & 33.9 & $26-167$ & 52 & 54.4 & $35-211$ & 77 & 52.2 & $45-190$ & 86 & 41.4 \\
\hline Dec. & $30-108$ & 63 & 34.8 & $27-142$ & 65 & 43.7 & $31-184$ & 88 & 48.0 & $40-165$ & 85 & 33.6 \\
\hline Annual & $26-87$ & 51 & 29.6 & 24-104 & 49 & 37.8 & 24-119 & 57 & 39.0 & $36-144$ & 71 & 33.8 \\
\hline
\end{tabular}


Coarse particles $\left(\mathrm{PM}_{10}\right)$ are mainly due to natural and anthropogenic processes, including dust storms, local soil re-suspension, road dust, and various industrial processes (Querol et al., 2004; Xu et al., 2017). The $\mathrm{PM}_{2.5} / \mathrm{PM}_{10}$ ratio is a useful index by which to determine the most likely atmospheric processes leading to accumulation due to the diverse sources of $\mathrm{PM}_{2.5}$ and $\mathrm{PM}_{10}$. It can thus be used to reflect the status of air quality (Speranza et al., 2014; Blancobecerra et al., 2015; Xu et al., 2017; Wang et al., 2018b). Previous studies have found that the $\mathrm{PM}_{2.5} / \mathrm{PM}_{10}$ ratio varies from seasons to season, where the dry season is lower than the wet season, which is mainly due to the contribution of dust re-suspension (Akinlade et al., 2014; Speranza et al., 2014; Wang et al., 2018a). Some studies have also reported that due to the effect of re-suspended coarse road dust, there is negative correlation between the number of vehicles and the $\mathrm{PM}_{2.5} / \mathrm{PM}_{10}$ ratio (Querol et al., 2001; Evagelopoulos et al., 2006).

\section{$\mathrm{SO}_{2}$ Concentration}

Anthropogenic activities (including the burning of biomass, fossil fuel combustion, and metal smelting) and natural processes (including volcanic eruption, soil oxidation, and hydrogen sulfide oxidation) generate and emit sulfur dioxide $\left(\mathrm{SO}_{2}\right)$ into the atmosphere (Kettle and Andreae, 2000; Dong et al., 2002; Halmer et al., 2002; Vijay et al., 2004; Dentener et al., 2006; Lee et al., 2008; Lin et al., 2010; Khattak et al., 2013). Thus, atmospheric $\mathrm{SO}_{2}$ irritates the respiratory tract and injures the cardiovascular system of living things (Lovati et al., 1996). $\mathrm{SO}_{2}$ in the atmosphere is absorbed by water aerosol droplets, such as clouds, fog, and rains, where acid rain forms in this process and increases the risk of harm to ecological systems (Ferrari and Salisbury, 1999; Chen et al., 2001; Goncalves et al., 2002; Chen et al., 2011). $\mathrm{SO}_{2}$ is a noticeable air pollutant that will damage human health and the environment (Aneja et al., 2001; Chen et al., 2011). Figs. 2(a)-1, 2(b)-1, 2(c)-1 show the monthly average $\mathrm{SO}_{2}$ concentration) from 2015 2017 in Puzih City, Singang Township, and Chiayi County, respectively, and Figs. 2(a)-2, 2(b)-2, 2(c)-2 show the monthly average $\mathrm{SO}_{2}$ concentration in Douliou City, Taisi Township, Lunbei Township, and Mailiao Township, respectively.

The highest annual average $\mathrm{SO}_{2}$ concentration among the seven cities and townships occurred in Taisi Township (9.89 ppb), ranging from 4.44-14.4 ppb, and the lowest level occurred in Douliou City (5.54 ppb), ranging from 4.19-6.58 ppb in 2015. In 2016, the maximum annual $\mathrm{SO}_{2}$ value was found in Taisi Township (8.49 ppb), ranging from $4.60-12.2 \mathrm{ppb}$, and the lowest value was found in Douliou City (5.25 ppb), ranging from 4.00-5.92 ppb. In 2017, the maximum annual $\mathrm{SO}_{2}$ level was found in Taisi Township (7.28 ppb), ranging from 4.30-10.0 ppb, and the lowest value was found in Douliou City (4.94 ppb), ranging from 3.98-5.96 ppb. During the period 20152017, the highest concentration of $\mathrm{SO}_{2}$ always was in Taisi Township, and the lowest values were always in Douliou City. The three-year mean $\mathrm{SO}_{2}$ concentrations in Puzih City, Singang Township, Chiayi County, Douliou City,
Taisi Township, Lunbei Township and Mailiao Township were $5.51,5.66,6.20,5.24,8.55,5.85$, and $6.69 \mathrm{ppb}$, respectively. With the exception of Taisi Township, the levels of $\mathrm{SO}_{2}$ in other six observed regions were slightly lower than the WHO standard of $7.00 \mathrm{ppb}$. This result was similar to that found for Wuhu City (6.54 ppb) and Bengbu City (7.88 ppb) (Wang et al., 2018b). Some studies have indicated that volcanic eruptions are the major contributors to the natural sources of $\mathrm{SO}_{2}$ in the atmosphere (Andres and Kasdnoc et al., 1998; Halmer et al., 2002; Kato et al., 2016). Although there are several volcanoes in Taiwan, including Datunshan volcano, Keelung volcano, and Penghu volcano, these are all extinct volcanoes and will not increase atmospheric $\mathrm{SO}_{2}$ concentration in the region.

The seasonal variations in atmospheric $\mathrm{SO}_{2}$ are discussed as follows: In 2015, the average $\mathrm{SO}_{2}$ concentrations were $4.71 \mathrm{ppb}$ (Puzih City)-8.16 ppb (Taisi Township), $4.23 \mathrm{ppb}$ (Lunbei Township)-6.69 ppb (Taisi Township), $5.79 \mathrm{ppb}$ (Singang Township)-13.07 ppb (Taisi Township), $6.44 \mathrm{ppb}$ (Douliou City)-11.7 ppb (Taisi Township) in spring, summer, fall, and winter, respectively. In 2016, these values were $5.52 \mathrm{ppb}$ (Douliou City)-10.2 ppb (Taisi Township), $4.05 \mathrm{ppb}$ (Lunbei Township)-5.26 ppb (Singang Township), $5.48 \mathrm{ppb}$ (Puzih City)-9.06 ppb (Taisi Township), 5.18 ppb (Douliou City)-8.73 ppb (Taisi Township) in spring, summer, fall, and winter, respectively. In 2017, these values were $5.46 \mathrm{ppb}$ (Douliou City)-8.29 ppb (Taisi Township), 3.91 ppb (Lunbei Township)-6.18 ppb (Taisi Township), $5.13 \mathrm{ppb}$ (Douliou City)-8.01 ppb (Taisi Township), 4.75 ppb (Douliou City)7.79 ppb (Chiayi County) in spring, summer, fall and winter, respectively. This indicated that summer had the minimum $\mathrm{SO}_{2}$ values, followed by spring, fall and winter, when similar levels were observed. Generally, the average $\mathrm{SO}_{2}$ concentration of these seven areas in summer (4.86 ppb) was $26.1 \%$ lower than that in other seasons $(6.40,6.58$, and $6.75 \mathrm{ppb}$ in spring, fall and winter, respectively). This may be attributed to the fact that Taiwan has a monsoon climate with strong rainfall intensity in summer, so some of the $\mathrm{SO}_{2}$ was scavenged from the ambient air through wet deposition (Chen et al., 2011). This result was compared with those found for Wuhu and Bengbu, where the $\mathrm{SO}_{2}$ concentrations in winter were slightly higher than in the other seasons, and where without the requirement of fuel combustion for heating and less effect of polluted airflow from north China in the winter in Taiwan lead to this distinction.

\section{$\mathrm{NO}_{2}$ Concentration}

Anthropogenic activities of industrial facilities and traffic emissions are the main sources of atmospheric nitrogen dioxide (Cheng et al., 2018). $\mathrm{NO}_{2}$ participates in a complex photochemical reaction, where as the corresponding oxidation products are incorporated into ambient aerosols, they have adverse effects on visibility (Anttila et al., 2011; He et al., 2014). $\mathrm{NO}_{2}$ is also the crucial precursor of ozone and acid rain, which can acidize ecosystems and impact the human respiratory system (Bowman et al., 1994; Plaisance et al., 2002; Cox et al., 2003; An et al., 2006; Khokhar et al., 2016). Based on air quality guidelines established by WHO, 


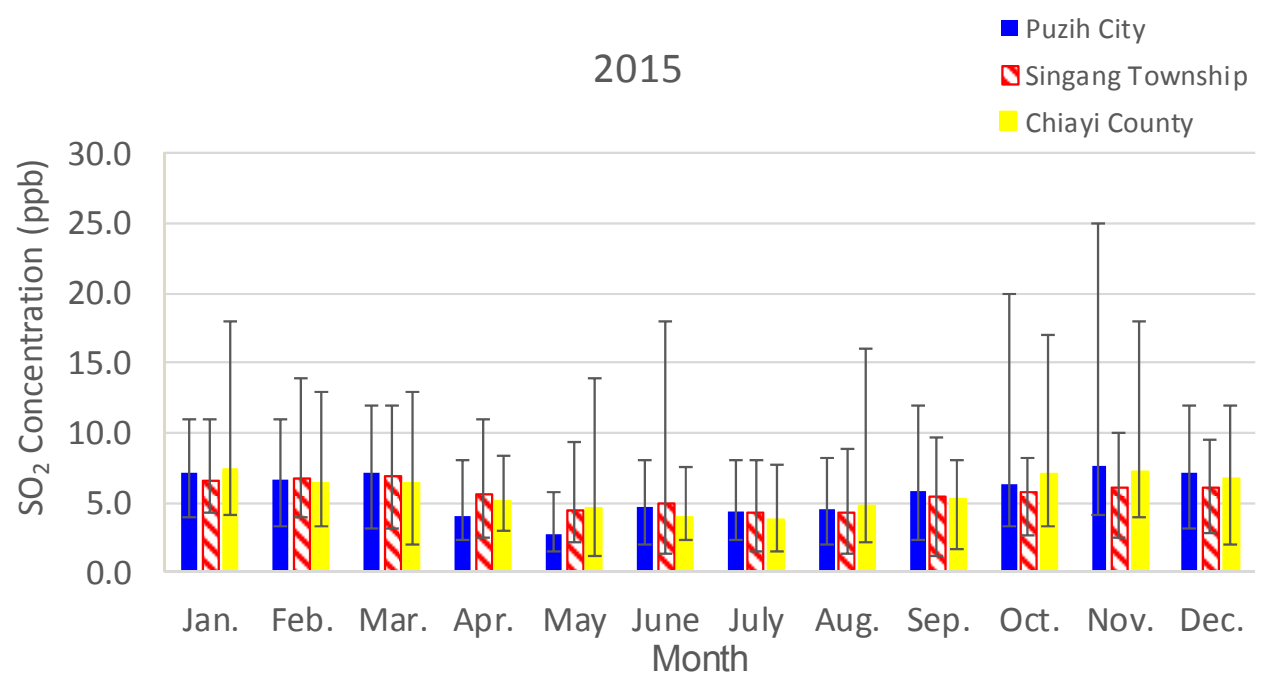

Fig. 2(a)-1. Monthly average atmospheric $\mathrm{SO}_{2}$ concentrations in Puzih City, Singang Township, and Chiayi County in 2015.

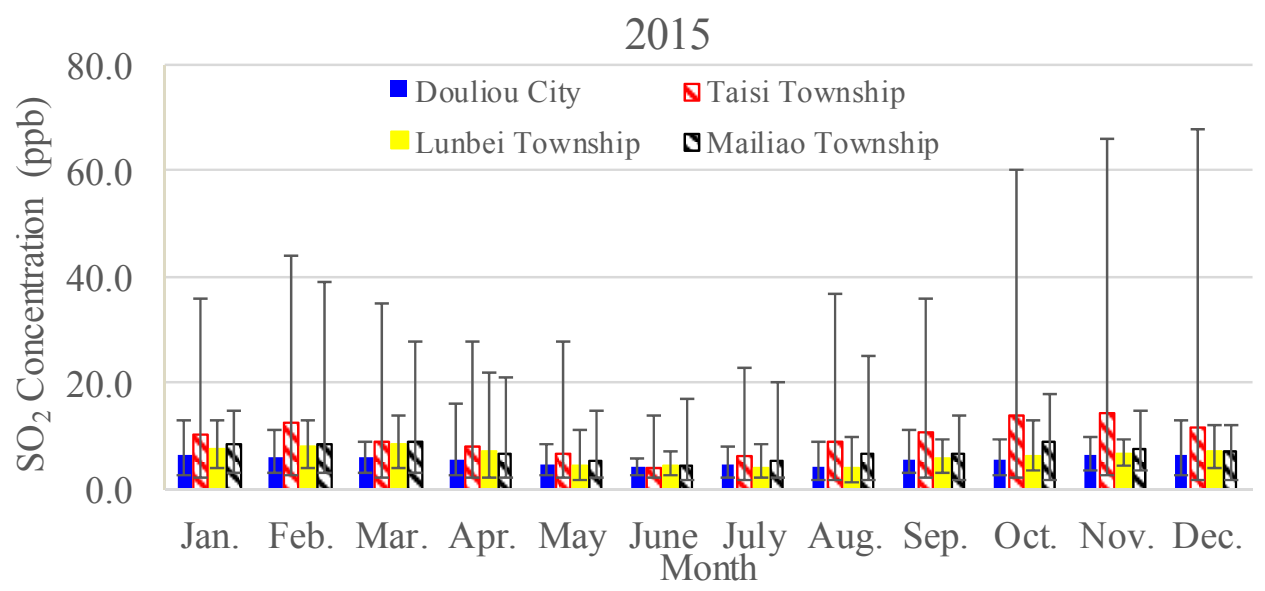

Fig. 2(a)-2. Monthly average atmospheric $\mathrm{SO}_{2}$ concentrations in Douliou City, Taisi Township, Lunbei Township, and Mailiao Township in 2015.

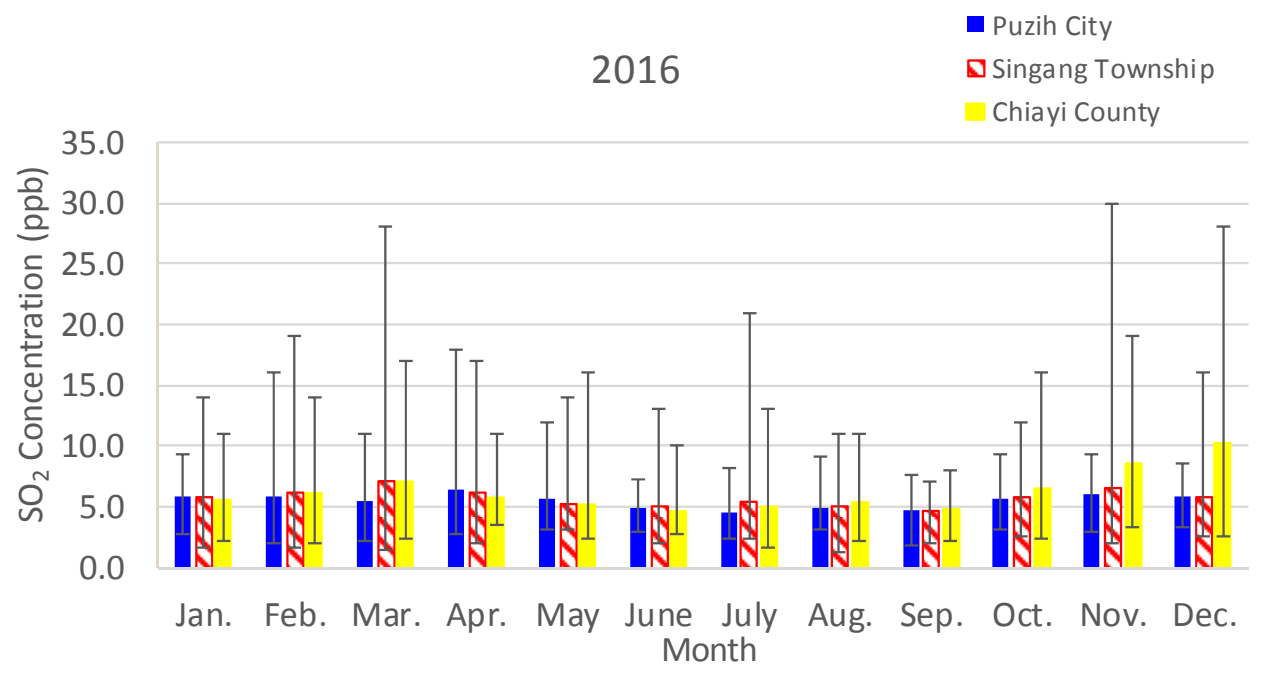

Fig. 2(b)-1. Monthly average atmospheric $\mathrm{SO}_{2}$ concentrations in Puzih City, Singang Township, and Chiayi County in 2016. 


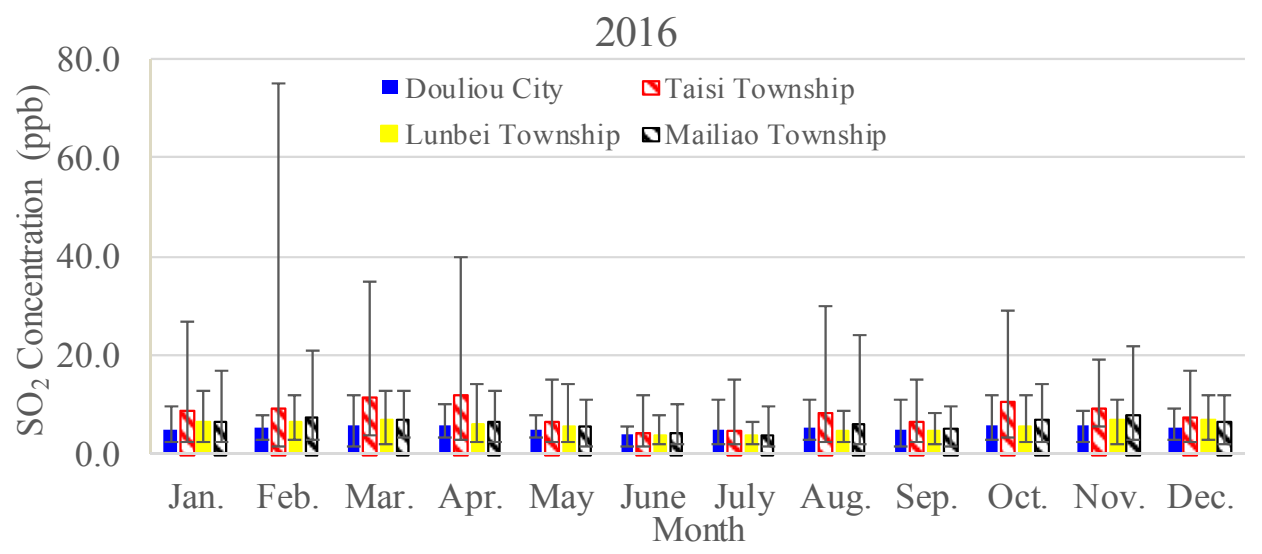

Fig. 2(b)-2. Monthly average atmospheric $\mathrm{SO}_{2}$ concentrations in Douliou City, Taisi Township, Lunbei Township, and Mailiao Township in 2016.

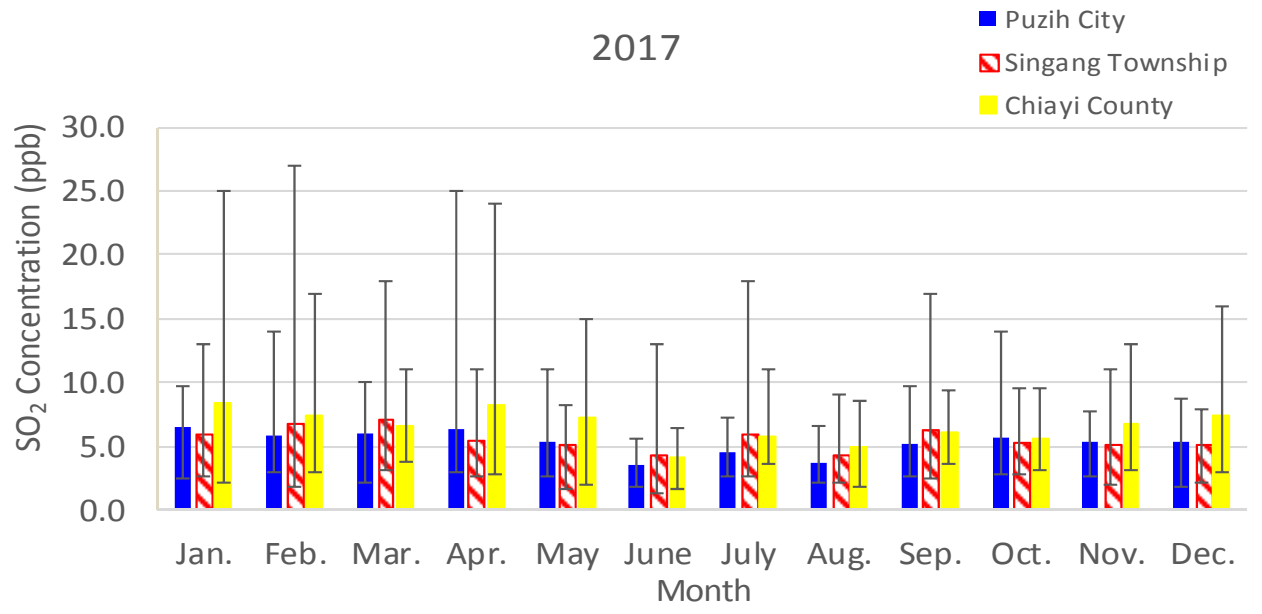

Fig. 2(c)-1. Monthly average atmospheric $\mathrm{SO}_{2}$ concentrations in Puzih City, Singang Township, and Chiayi County in 2017 .

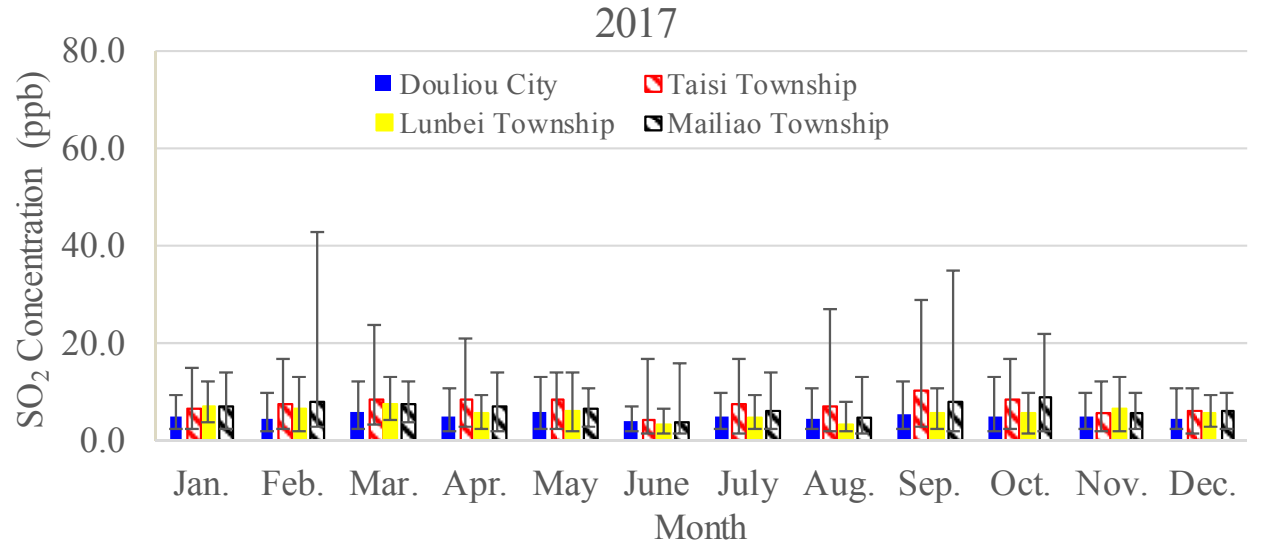

Fig. 2(c)-2. Monthly average atmospheric $\mathrm{SO}_{2}$ concentrations in Douliou City, Taisi Township, Lunbei Township, and Mailiao Township in 2017.

when evaluating the air quality index of a region, $\mathrm{NO}_{2}$ is classified as a monitored air pollutant (He et al., 2014). From 2015 to 2017, the monthly average $\mathrm{NO}_{2}$ concentrations in Puzih City, Singang Township, and Chiayi County are plotted in Figs. 3(a)-1, 3(b)-1, 3(c)-1, respectively, and the monthly average $\mathrm{NO}_{2}$ concentrations in Douliou City, Taisi Township, Lunbei Township, and Mailiao Township are plotted in Figs. 3(a)-2, 3(b)-2, 3(c)-2, respectively. 


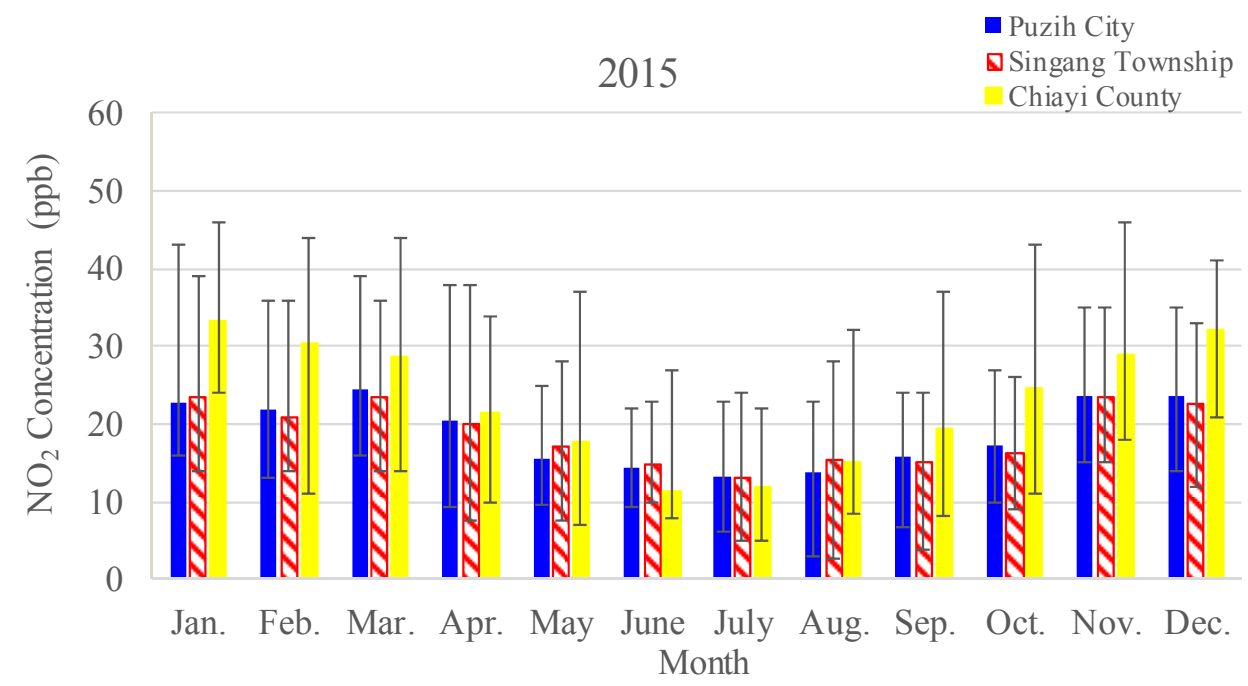

Fig. 3(a)-1. Monthly average atmospheric $\mathrm{NO}_{2}$ concentrations in Puzih City, Singang Township, and Chiayi County in 2015.

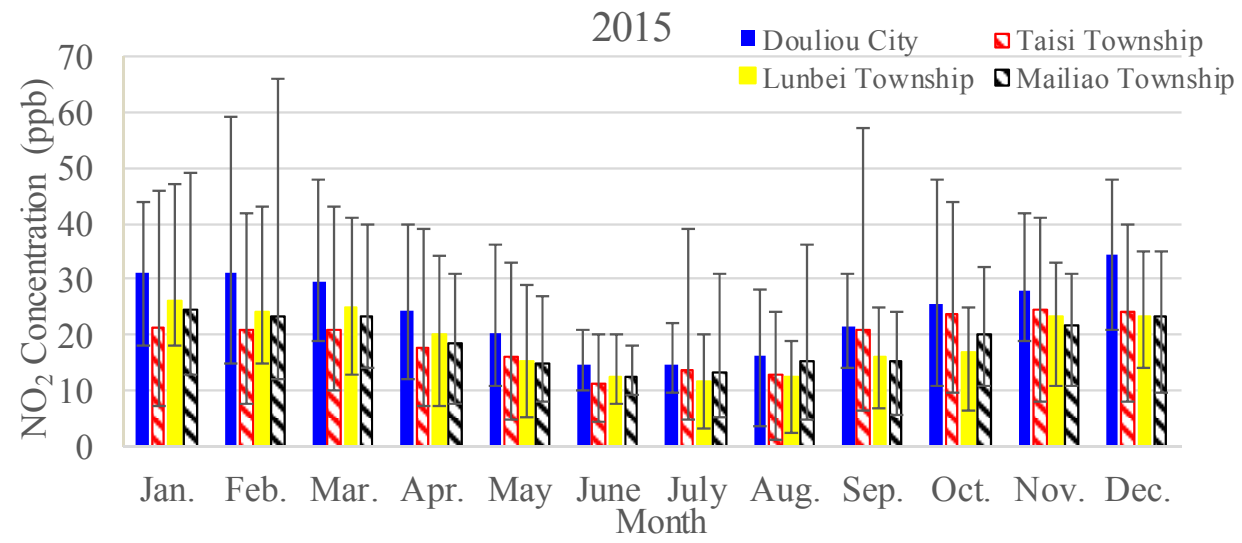

Fig. 3(a)-2. Monthly average atmospheric $\mathrm{NO}_{2}$ concentrations in Douliou City, Taisi Township, Lunbei Township, and Mailiao Township in 2015.

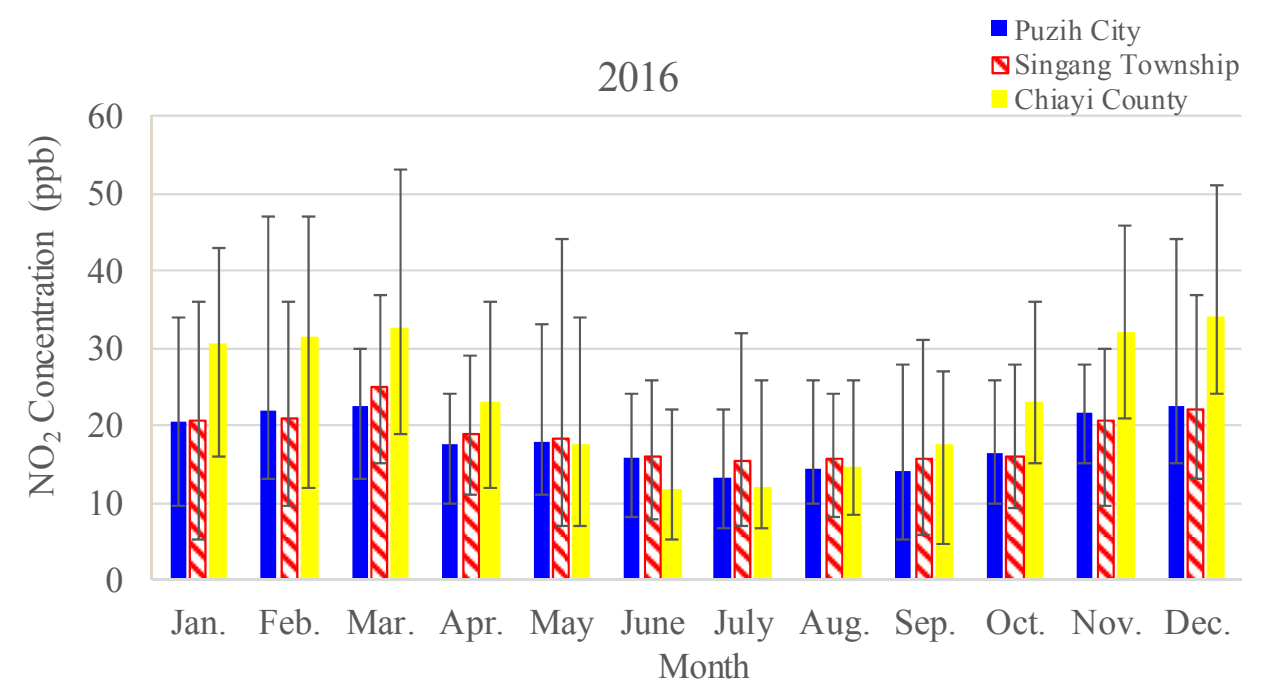

Fig. 3(b)-1. Monthly average atmospheric $\mathrm{NO}_{2}$ concentrations in Puzih City, Singang Township, and Chiayi County in 2016. 


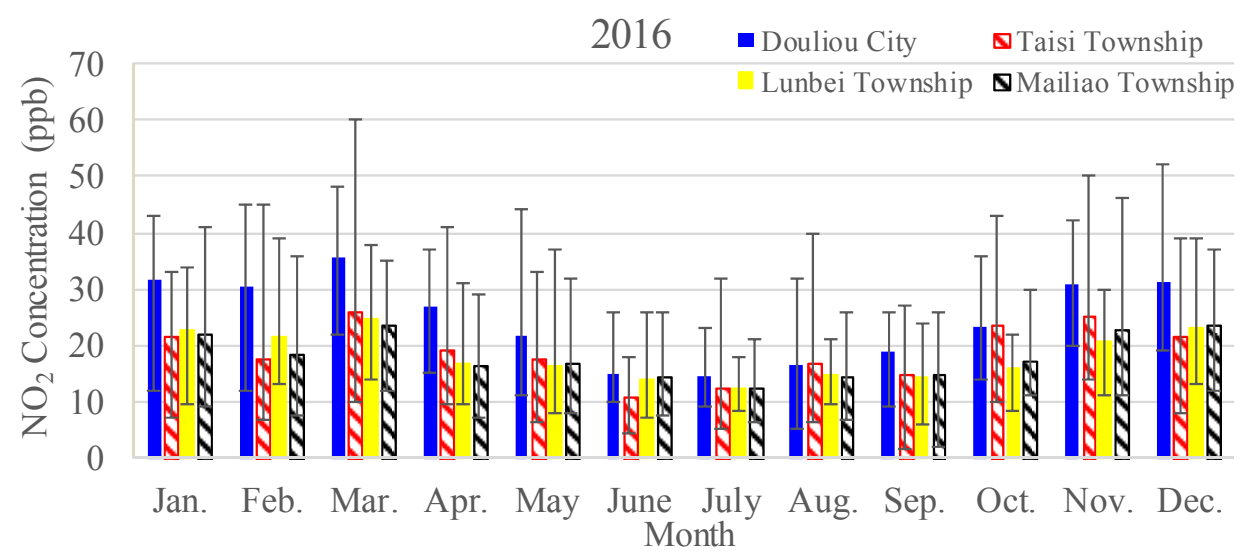

Fig. 3(b)-2. Monthly average atmospheric $\mathrm{NO}_{2}$ concentrations in Douliou City, Taisi Township, Lunbei Township, and Mailiao Township in 2016.

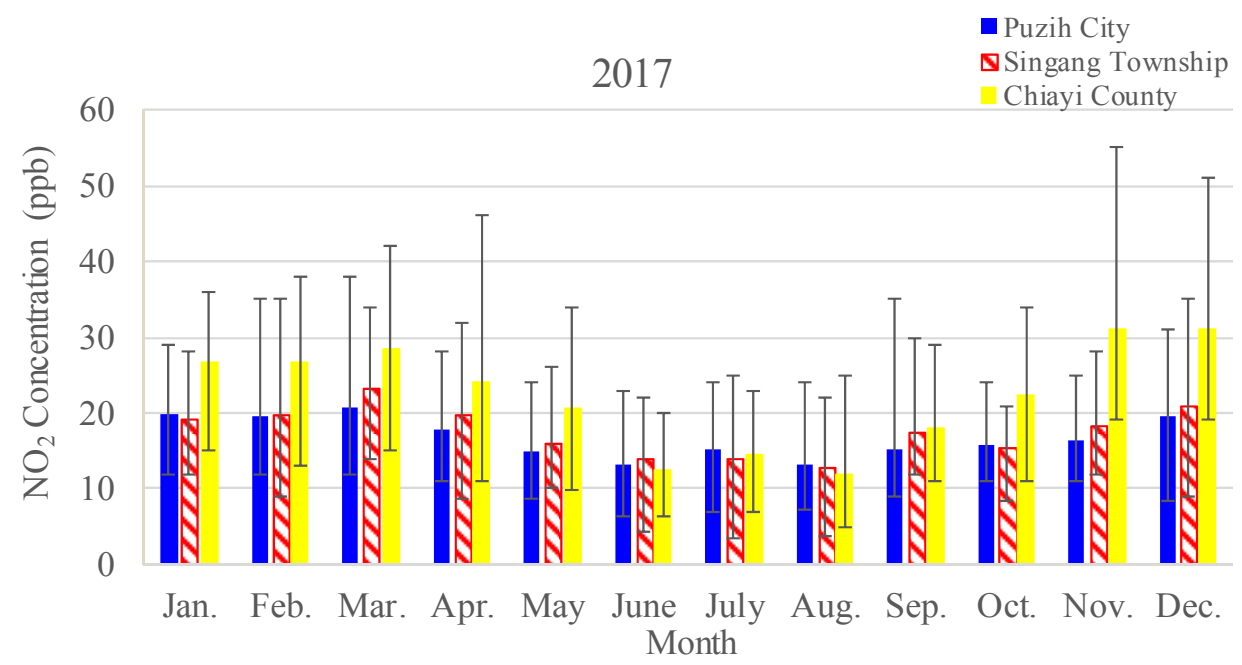

Fig. 3(c)-1. Monthly average atmospheric $\mathrm{NO}_{2}$ concentrations in Puzih City, Singang Township, and Chiayi County in 2017.

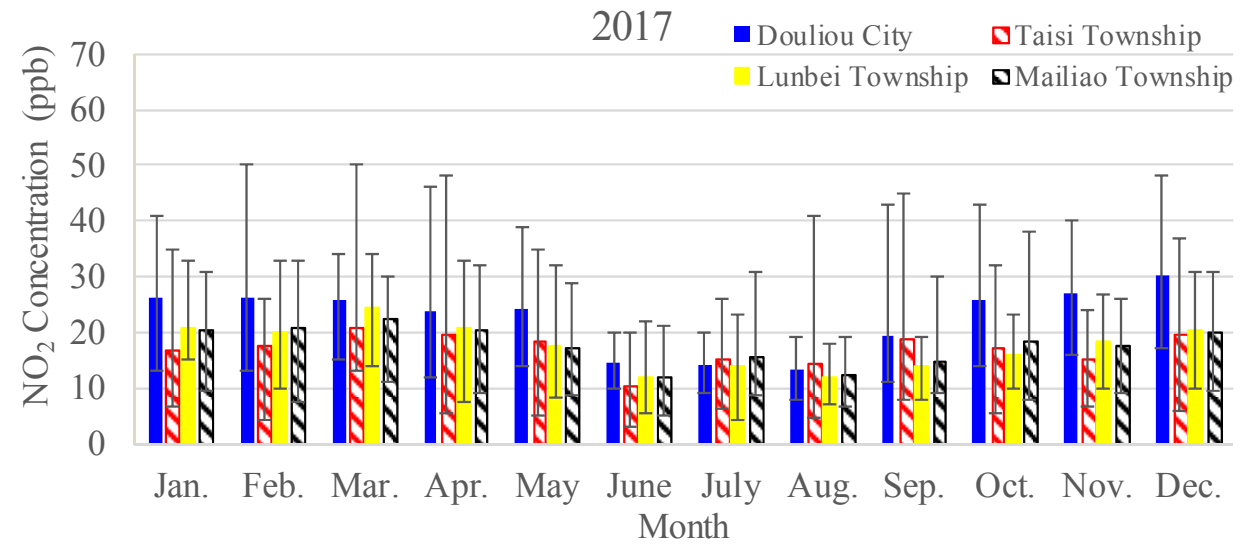

Fig. 3(c)-2. Monthly average atmospheric $\mathrm{NO}_{2}$ concentrations in Douliou City, Taisi Township, Lunbei Township, and Mailiao Township in 2017.

Comparing the annual mean $\mathrm{NO}_{2}$ concentration in the seven observed areas during the period 2015-2017, Douliou was the city with the highest levels of $\mathrm{NO}_{2}$, which were
24.3, 24.7, and 22.6 ppb in 2015, 2016, and 2017, for which the corresponding ranges were $14.6-34.3 \mathrm{ppb}, 14.5-35.5 \mathrm{ppb}$, and $13.2-30.1 \mathrm{ppb}$, respectively. The lowest levels were 
found in Singang Township (18.9 ppb), Lunbei Township (18.1 ppb), and Puzih City (16.8 ppb) in 2015, 2016, and 2017, for which the corresponding ranges were 13.2$23.6 \mathrm{ppb}, 12.3-24.8 \mathrm{ppb}$, and $13.2-20.8 \mathrm{ppb}$, respectively. In general, with the exception of Chiayi County and Douliou City, where the $\mathrm{NO}_{2}$ concentration rose slightly in 2016 (the annual mean values of Chiayi County were 22.9, 23.3 and $22.4 \mathrm{ppb}$ in 2015,2016 , and 2017, respectively, those of Douliou City were 24.3, 24.7 and 22.6 ppb in 2015, 2016 , and 2017, respectively), the other five showed a clear annual tendency to decline, decreasing by $0.524 \%-4.23 \%$ from 2015 to 2016 , and by $3.85 \%-11.6 \%$ from 2016 to 2017 .

As a whole, during these recent three years (2015-2017), the average $\mathrm{NO}_{2}$ concentration in Puzih City, Singang Township, Chiayi County, Douliou City, Taisi Township, Lunbei Township, and Mailiao Township were 18.0, 18.4, $22.9,23.9,18.3,18.2$ and $18.2 \mathrm{ppb}$, respectively. It can be seen that the $\mathrm{NO}_{2}$ levels in Chiayi County and Douliou City were slightly higher than the WHO standard of $19.6 \mathrm{ppb}$ and that the others were slightly lower than the WHO standard. The overall levels in the surveyed regions were comparable to those of Wuhu (21.4 ppb) and Bengbu (18.0 ppb) (Wang et al., 2018b). Fu et al. (2000) and Cheng et al. (2018) pointed out that due to recent economic development and rapid urbanization, motor vehicles have become the major emission source of $\mathrm{NO}_{2}$. The human population of Chiayi County $(274,051)$ and Douliou City $(108,231)$ is far above that of Puzih City $(44,234)$, Singang Township (35,347), Taisi Township $(25,116)$, Lunbei Township (28,003), and Mailiao Township $(34,014)$, where it can be inferred that the former urbanization rate was higher than that occurring later. Thus, a larger number of vehicles are emitting $\mathrm{NO}_{2}$ into the ambient air, which results in the higher $\mathrm{NO}_{2}$ concentration in Chiayi County and Douliou City.

In 2015 , the seasonal $\mathrm{NO}_{2}$ concentrations were $18.4 \mathrm{ppb}$ (Taisi Township)-24.9 ppb (Douliou City), 12.3 ppb (Lunbei Township)-15.2 ppb (Douliou City), $18.2 \mathrm{ppb}$ (Singang Township)-25.0 ppb (Douliou City), 22.2 ppb (Taisi Township)-32.2 ppb (Douliou City) in spring, summer, fall, and winter, respectively. In 2016, these values were $19.0 \mathrm{ppb}$ (Mailiao Township)-28.0 ppb (Douliou City), 12.7 ppb (Chiayi County)-15.7 ppb (Singang Township), $17.0 \mathrm{ppb}$ (Lunbei Township)-24.3 ppb (Douliou City), $20.3 \mathrm{ppb}$ (Taisi Township)-32.0 ppb (Chiayi County) in spring, summer, fall, and winter, respectively. In 2017, these values were $17.9 \mathrm{ppb}$ (Puzih City)-24.7 ppb (Douliou City), 12.6 ppb (Lunbei Township)-14.0 ppb (Douliou City), 15.8 ppb (Puzih City)-24.2 ppb (Douliou City), 17.8 ppb (Taisi Township)-28.2 ppb (Chiayi County) in spring, summer, fall, and winter, respectively. As for the spatial distribution, Douliou City usually had with the maximum $\mathrm{NO}_{2}$ levels, which may be tightly related to vehicle emissions. In terms of the temporal distribution, the minimum $\mathrm{NO}_{2}$ concentration always occurred in summer, and the maximum values occurred in winter, with three-year average values in summer (13.7 ppb) that were $43.2 \%$ lower than those in winter $(24.1 \mathrm{ppb})$, while the $\mathrm{NO}_{2}$ levels for spring and fall were between those of summer and winter, and that of spring (21.1 ppb) was slightly higher than fall (19.9 ppb). This seasonal distribution is attributed to distinct meteorological conditions in different seasons, where there is a hot summer and a cold winter. The high ground temperature in summer and the severe winter are conducive to the transport of $\mathrm{NO}_{2}$, and the abundant rainfall favors the deposition of $\mathrm{NO}_{2}$ (Wang et al., 2018b). Thus, the $\mathrm{NO}_{2}$ levels are lowest in summer and highest in winter.

The above results indicate that atmospheric $\mathrm{NO}_{2}$ concentrations are determined by both emissions and meteorological conditions. Therefore, when implementing control of industrial and vehicle emissions, it is necessary to pay attention to restricting $\mathrm{NO}_{2}$ concentrations during seasons without favorable weather conditions (Cheng et al., 2018).

\section{CO Concentration}

During the combustion process, carbon monoxide (CO) is emitted along with $\mathrm{NO}_{\mathrm{x}}$ and volatile organic compounds (VOCs) and into the ambient air. CO can exist longer than one month and remain at high concentrations after being transported for a long distance (Kato et al., 2016). Therefore, $\mathrm{CO}$ is an important indicator of air pollution to understand the air quality of a region. During the period 2015-2017, the monthly average CO concentrations in Puzih City, Singang Township, and Chiayi County are given in Tables 2(a)-1, 2(b)-1, 2(c)-1, respectively, and the monthly average CO concentrations in Douliou City, Taisi Township, Lunbei Township and Mailiao Township are given in Tables 2(a)2, 2(b)-2, 2(c)-2, respectively.

From 2015-2017, comparing the annual mean CO concentration among the seven districts, the highest levels of $\mathrm{CO}$ were found in Chiayi County, which were 0.514, 0.506 , and $0.478 \mathrm{ppm}$ in 2015,2016 , and 2017 , for which the corresponding ranges were $0.295-0.793$ ppm, $0.307-$ $0.797 \mathrm{ppm}$, and $0.293-0.899 \mathrm{ppm}$, respectively. Taisi was the Township with the lowest CO levels, which were $0.332,0.324$, and $0.296 \mathrm{ppm}$ in 2015,2016 , and 2017 , for which corresponding ranges were $0.151-0.611 \mathrm{ppm}$, $0.168-0.567 \mathrm{ppm}$, and $0.145-0.498 \mathrm{ppm}$, respectively. Generally, it can be inferred that the CO levels of these studied locations were significantly lower than those in Wuhu (0.532-1.21 ppm, with an average of $0.831 \mathrm{ppm})$ and Bengbu (0.465-1.16 ppm, with an average of $0.720 \mathrm{ppm}$ ), two middle latitude cities in China. Furthermore, a comparison the annual average $\mathrm{CO}$ concentration of the seven areas during the three years under observation (2015-2017) indicates that these values all decreased annually. The levels in 2015 reduced by $1.10-7.15 \%$ as compared with those observed in 2016 and went down by 5.62-10.8\% from 2016 to 2017 . As a whole, during the three years under observation (2015-2017), the mean CO concentrations in Puzih City, Singang Township, Chiayi County, Douliou City, Taisi Township, Lunbei Township, and Mailiao Township were 0.384, 0.413, 0.499, 0.437, $0.317,0.377$, and $0.374 \mathrm{ppm}$, respectively. The WHO air quality eight-hour average regulated standard of $\mathrm{CO}$ is $8.00 \mathrm{ppm}$, while the CO concentrations in these seven 
Table 2(a)-1. Monthly average atmospheric CO concentrations in Puzih City, Singang Township, and Chiayi County in 2015.

\begin{tabular}{|c|c|c|c|c|c|c|c|c|c|}
\hline \multirow[b]{2}{*}{ Month } & \multicolumn{3}{|c|}{ Puzih City } & \multicolumn{3}{|c|}{ Singang Township } & \multicolumn{3}{|c|}{ Chiayi County } \\
\hline & Range (ppm) & $\begin{array}{l}\text { Mean } \\
\text { (ppm) }\end{array}$ & $\begin{array}{l}\text { R.S.D } \\
(\%)\end{array}$ & Range (ppm) & $\begin{array}{l}\text { Mean } \\
(\mathrm{ppm})\end{array}$ & $\begin{array}{l}\text { R.S.D } \\
(\%)\end{array}$ & Range (ppm) & $\begin{array}{l}\text { Mean } \\
\text { (ppm) }\end{array}$ & $\begin{array}{l}\text { R.S.D } \\
(\%)\end{array}$ \\
\hline Jan. & $0.340-0.856$ & 0.531 & 24.7 & $0.318-0.889$ & 0.578 & 25.6 & $0.459-0.918$ & 0.742 & 14.7 \\
\hline Feb. & $0.285-0.760$ & 0.518 & 26.1 & $0.323-0.804$ & 0.567 & 23.6 & $0.469-1.038$ & 0.723 & 22.1 \\
\hline Mar. & $0.330-0.775$ & 0.501 & 21.4 & $0.293-0.815$ & 0.536 & 20.6 & $0.319-1.015$ & 0.660 & 20.5 \\
\hline Apr. & $0.278-0.577$ & 0.385 & 19.0 & $0.161-0.670$ & 0.383 & 25.1 & $0.210-0.718$ & 0.449 & 26.2 \\
\hline May & $0.220-1.410$ & 0.374 & 57.4 & $0.164-0.690$ & 0.343 & 33.4 & $0.185-0.671$ & 0.371 & 43.9 \\
\hline June & $0.193-0.388$ & 0.267 & 15.6 & $0.148-0.537$ & 0.258 & 32.5 & $0.168-0.495$ & 0.237 & 25.5 \\
\hline July & $0.153-0.373$ & 0.262 & 21.5 & $0.148-0.354$ & 0.251 & 22.6 & $0.139-0.410$ & 0.282 & 26.6 \\
\hline Aug. & $0.166-0.580$ & 0.323 & 32.5 & $0.100-0.544$ & 0.291 & 32.0 & $0.146-0.753$ & 0.335 & 32.7 \\
\hline Sep. & $0.190-0.486$ & 0.364 & 17.2 & $0.239-0.499$ & 0.402 & 16.1 & $0.236-0.591$ & 0.461 & 17.9 \\
\hline Oct. & $0.259-0.634$ & 0.408 & 25.8 & $0.289-0.630$ & 0.430 & 21.0 & $0.304-0.860$ & 0.548 & 22.7 \\
\hline Nov. & $0.274-0.668$ & 0.467 & 21.8 & $0.294-0.775$ & 0.542 & 23.9 & $0.429-0.860$ & 0.630 & 19.3 \\
\hline Dec. & $0.225-0.830$ & 0.491 & 26.0 & $0.230-0.918$ & 0.557 & 26.9 & $0.483-1.193$ & 0.735 & 21.4 \\
\hline Annual & $0.243-0.695$ & 0.408 & 25.7 & $0.225-0.677$ & 0.428 & 25.3 & $0.295-0.793$ & 0.514 & 24.4 \\
\hline
\end{tabular}

Table 2(a)-2. Monthly average atmospheric CO concentrations in Douliou City, Taisi Township, Lunbei Township, and Mailiao Township in 2015.

\begin{tabular}{|c|c|c|c|c|c|c|c|c|c|c|c|c|}
\hline \multirow[b]{2}{*}{ Month } & \multicolumn{3}{|c|}{ Douliou City } & \multicolumn{3}{|c|}{ Taisi Township } & \multicolumn{3}{|c|}{ Lunbei Township } & \multicolumn{3}{|c|}{ Mailiao Township } \\
\hline & $\begin{array}{l}\text { Range } \\
(\mathrm{ppm})\end{array}$ & $\begin{array}{l}\text { Mean } \\
(\mathrm{ppm})\end{array}$ & $\begin{array}{l}\text { R.S.D } \\
(\%)\end{array}$ & $\begin{array}{l}\text { Range } \\
(\mathrm{ppm})\end{array}$ & $\begin{array}{l}\text { Mean } \\
(\mathrm{ppm})\end{array}$ & $\begin{array}{l}\text { R.S.D } \\
(\%)\end{array}$ & $\begin{array}{l}\text { Range } \\
(\mathrm{ppm})\end{array}$ & $\begin{array}{l}\text { Mean } \\
(\mathrm{ppm})\end{array}$ & $\begin{array}{l}\text { R.S.D } \\
(\%)\end{array}$ & $\begin{array}{l}\text { Range } \\
(\mathrm{ppm})\end{array}$ & $\begin{array}{l}\text { Mean } \\
(\mathrm{ppm})\end{array}$ & $\begin{array}{l}\text { R.S.D } \\
(\%)\end{array}$ \\
\hline Jan. & $0.337-0.799$ & 0.621 & 18.5 & $0.176-0.906$ & 0.461 & 38.7 & $0.370-0.945$ & 0.585 & 24.2 & $0.224-0.945$ & 0.512 & 32.6 \\
\hline Feb. & $0.366-0.829$ & 0.590 & 23.2 & $0.185-0.663$ & 0.427 & 30.9 & $0.289-0.780$ & 0.549 & 22.7 & $0.240-0.704$ & 0.491 & 26.9 \\
\hline Mar. & $0.404-0.884$ & 0.559 & 23.0 & $0.157-0.733$ & 0.389 & 31.2 & $0.238-0.880$ & 0.546 & 20.3 & $0.280-0.675$ & 0.457 & 24.7 \\
\hline Apr. & $0.301-0.563$ & 0.416 & 13.9 & $0.151-0.554$ & 0.303 & 33.0 & $0.134-0.633$ & 0.389 & 29.5 & $0.190-0.620$ & 0.363 & 27.4 \\
\hline May & $0.269-0.667$ & 0.402 & 26.7 & $0.110-0.780$ & 0.257 & 48.3 & $0.148-0.747$ & 0.322 & 41.2 & $0.169-0.763$ & 0.325 & 34.2 \\
\hline June & $0.231-0.434$ & 0.325 & 13.7 & $0.123-0.361$ & 0.178 & 32.1 & $0.152-0.373$ & 0.220 & 27.0 & $0.189-0.486$ & 0.263 & 25.7 \\
\hline July & $0.204-0.444$ & 0.316 & 17.7 & $0.111-0.308$ & 0.190 & 23.4 & $0.125-0.319$ & 0.211 & 26.3 & $0.150-0.409$ & 0.248 & 23.0 \\
\hline Aug. & $0.108-0.668$ & 0.350 & 28.1 & $0.055-0.326$ & 0.187 & 34.3 & $0.080-0.344$ & 0.219 & 31.9 & $0.170-0.500$ & 0.280 & 27.1 \\
\hline Sep. & $0.326-0.539$ & 0.421 & 14.7 & $0.169-0.541$ & 0.334 & 27.8 & $0.203-0.488$ & 0.361 & 21.9 & $0.182-0.545$ & 0.376 & 22.1 \\
\hline Oct. & $0.344-0.735$ & 0.490 & 20.7 & $0.185-0.625$ & 0.372 & 28.8 & $0.244-0.624$ & 0.418 & 26.2 & $0.238-0.698$ & 0.430 & 25.6 \\
\hline Nov. & $0.315-0.765$ & 0.542 & 20.2 & $0.209-0.727$ & 0.446 & 29.1 & $0.271-0.735$ & 0.504 & 24.4 & $0.301-0.765$ & 0.476 & 25.1 \\
\hline Dec. & $0.362-0.909$ & 0.601 & 24.6 & $0.183-0.805$ & 0.441 & 31.5 & $0.240-0.904$ & 0.522 & 27.3 & $0.245-0.867$ & 0.474 & 29.6 \\
\hline Annual & $0.297-0.686$ & 0.469 & 20.4 & $0.151-0.611$ & 0.332 & 32.4 & $0.208-0.648$ & 0.404 & 26.9 & $0.215-0.665$ & 0.391 & 27.0 \\
\hline
\end{tabular}

Table 2(b)-1. Monthly average atmospheric CO concentrations in Puzih City, Singang Township, and Chiayi County in 2016.

\begin{tabular}{|c|c|c|c|c|c|c|c|c|c|}
\hline \multirow[b]{2}{*}{ Month } & \multicolumn{3}{|c|}{ Puzih City } & \multicolumn{3}{|c|}{ Singang Township } & \multicolumn{3}{|c|}{ Chiayi County } \\
\hline & Range (ppm) & $\begin{array}{l}\text { Mean } \\
(\mathrm{ppm})\end{array}$ & $\begin{array}{l}\text { R.S.D } \\
(\%)\end{array}$ & Range (ppm) & $\begin{array}{l}\text { Mean } \\
(\mathrm{ppm})\end{array}$ & $\begin{array}{l}\text { R.S.D } \\
(\%)\end{array}$ & Range (ppm) & $\begin{array}{l}\text { Mean } \\
\text { (ppm) }\end{array}$ & $\begin{array}{l}\text { R.S.D } \\
(\%)\end{array}$ \\
\hline Jan. & $0.319-0.831$ & 0.501 & 26.8 & $0.351-0.736$ & 0.529 & 20.6 & $0.412-1.010$ & 0.733 & 20.2 \\
\hline Feb. & $0.315-0.690$ & 0.504 & 20.5 & $0.301-0.803$ & 0.545 & 21.8 & $0.388-1.024$ & 0.675 & 20.8 \\
\hline Mar. & $0.282-0.766$ & 0.482 & 24.7 & $0.286-0.771$ & 0.540 & 22.7 & $0.479-1.211$ & 0.701 & 22.2 \\
\hline Apr. & $0.266-0.863$ & 0.458 & 27.7 & $0.251-2.968$ & 0.596 & 82.3 & $0.256-0.810$ & 0.522 & 30.5 \\
\hline May & $0.217-0.753$ & 0.385 & 34.7 & $0.153-0.725$ & 0.393 & 40.1 & $0.167-0.845$ & 0.390 & 47.4 \\
\hline June & $0.190-0.331$ & 0.266 & 13.3 & $0.158-0.371$ & 0.258 & 24.3 & $0.163-0.465$ & 0.251 & 27.1 \\
\hline July & $0.139-0.332$ & 0.231 & 20.2 & $0.165-0.429$ & 0.245 & 24.7 & $0.141-0.414$ & 0.258 & 27.8 \\
\hline Aug. & $0.166-0.531$ & 0.299 & 25.4 & $0.178-0.526$ & 0.321 & 24.1 & $0.208-0.529$ & 0.358 & 22.8 \\
\hline Sep. & $0.074-0.446$ & 0.321 & 27.3 & $0.114-0.475$ & 0.329 & 26.2 & $0.206-0.536$ & 0.389 & 24.7 \\
\hline Oct. & $0.220-0.620$ & 0.349 & 27.8 & $0.220-0.634$ & 0.387 & 25.5 & $0.346-0.793$ & 0.503 & 21.2 \\
\hline Nov. & $0.265-0.644$ & 0.429 & 23.2 & $0.278-0.715$ & 0.464 & 25.7 & $0.433-0.958$ & 0.626 & 20.3 \\
\hline Dec. & $0.268-0.693$ & 0.434 & 26.8 & $0.274-0.836$ & 0.475 & 26.0 & $0.488-0.971$ & 0.667 & 18.4 \\
\hline Annual & $0.227-0.625$ & 0.388 & 24.9 & $0.227-0.832$ & 0.424 & 30.3 & $0.307-0.797$ & 0.506 & 25.3 \\
\hline
\end{tabular}


Table 2(b)-2. Monthly average atmospheric CO concentrations in Douliou City, Taisi Township, Lunbei Township, and Mailiao Township in 2016.

\begin{tabular}{|c|c|c|c|c|c|c|c|c|c|c|c|c|}
\hline \multirow[b]{2}{*}{ Month } & \multicolumn{3}{|c|}{ Douliou City } & \multicolumn{3}{|c|}{ Taisi Township } & \multicolumn{3}{|c|}{ Lunbei Township } & \multicolumn{3}{|c|}{ Mailiao Township } \\
\hline & $\begin{array}{l}\text { Range } \\
(\mathrm{ppm})\end{array}$ & $\begin{array}{l}\text { Mean } \\
(\mathrm{ppm})\end{array}$ & $\begin{array}{l}\text { R.S.D } \\
(\%)\end{array}$ & $\begin{array}{l}\text { Range } \\
\text { (ppm) }\end{array}$ & $\begin{array}{l}\text { Mean } \\
(\mathrm{ppm})\end{array}$ & $\begin{array}{l}\text { R.S.D } \\
(\%)\end{array}$ & $\begin{array}{l}\text { Range } \\
(\mathrm{ppm})\end{array}$ & $\begin{array}{l}\text { Mean } \\
(\mathrm{ppm})\end{array}$ & $\begin{array}{l}\text { R.S.D } \\
(\%)\end{array}$ & $\begin{array}{l}\text { Range } \\
(\mathrm{ppm})\end{array}$ & $\begin{array}{l}\text { Mean } \\
(\mathrm{ppm})\end{array}$ & $\begin{array}{l}\text { R.S.D } \\
(\%)\end{array}$ \\
\hline Jan. & $0.358-0.881$ & 0.608 & 21.4 & $0.270-0.714$ & 0.428 & 26.4 & $0.312-0.819$ & 0.500 & 22.6 & $0.320-0.743$ & 0.472 & 24.8 \\
\hline Feb. & $0.420-0.895$ & 0.573 & 23.5 & $0.210-0.568$ & 0.388 & 25.7 & $0.305-0.644$ & 0.500 & 17.3 & $0.220-0.598$ & 0.430 & 24.6 \\
\hline Mar. & $0.339-0.928$ & 0.585 & 22.3 & $0.250-0.701$ & 0.422 & 26.0 & $0.250-0.746$ & 0.505 & 24.3 & $0.285-0.789$ & 0.467 & 24.9 \\
\hline Apr. & $0.305-0.725$ & 0.513 & 22.3 & $0.179-0.898$ & 0.388 & 36.6 & $0.191-0.937$ & 0.434 & 36.5 & $0.274-0.923$ & 0.441 & 30.5 \\
\hline May & $0.254-0.739$ & 0.393 & 26.9 & $0.136-0.699$ & 0.333 & 46.8 & $0.140-0.791$ & 0.354 & 47.3 & $0.158-0.758$ & 0.378 & 41.8 \\
\hline June & $0.208-0.535$ & 0.289 & 22.8 & $0.106-0.303$ & 0.191 & 27.4 & 0.108 & 0.203 & 25.5 & $0.166-0.335$ & 0.257 & 17.4 \\
\hline July & 0.18 & 0.284 & 19.2 & $0.094-0.270$ & 0.170 & 28.8 & 0.10 & 0.185 & 24.7 & $0.151-0.323$ & 0.224 & 18.7 \\
\hline Aug. & $0.211-0.519$ & 0.343 & 21.3 & $0.133-0.458$ & 0.242 & 32.0 & $0.130-0.516$ & 0.279 & 32.4 & $0.141-0.521$ & 0.303 & 27.1 \\
\hline Sep. & $0.135-0.525$ & 0.364 & 21.8 & $0.090-0.449$ & 0.259 & 36.5 & $0.090-0.465$ & 0.285 & 38.2 & $0.060-0.489$ & 0.323 & 31.5 \\
\hline Oct. & $0.265-0.689$ & 0.407 & 23.0 & $0.182-0.506$ & 0.321 & 24.1 & $0.188-0.639$ & 0.362 & 29.0 & $0.228-0.626$ & 0.379 & 24.3 \\
\hline Nov. & $0.269-0.711$ & 0.468 & 23.7 & $0.184-0.638$ & 0.391 & 29.0 & $0.258-0.704$ & 0.436 & 23.5 & $0.225-0.654$ & 0.425 & 24.6 \\
\hline Dec. & $0.339-0.716$ & 0.509 & 19.1 & $0.178-0.605$ & 0.359 & 33.2 & $0.288-0.705$ & 0.454 & 26.1 & $0.245-0.690$ & 0.422 & 26.5 \\
\hline Annual & $0.274-0.690$ & 0.445 & 22.3 & $0.168-0.567$ & 0.324 & 31.0 & $0.197-0.630$ & 0.375 & 29.0 & $0.206-0.621$ & 0.377 & 26.4 \\
\hline
\end{tabular}

Table 2(c)-1. Monthly average atmospheric CO concentrations in Puzih City, Singang Township, and Chiayi County in 2017.

\begin{tabular}{|c|c|c|c|c|c|c|c|c|c|}
\hline \multirow[b]{2}{*}{ Month } & \multicolumn{3}{|c|}{ Puzih City } & \multicolumn{3}{|c|}{ Singang Township } & \multicolumn{3}{|c|}{ Chiayi County } \\
\hline & Range (ppm) & $\begin{array}{l}\text { Mean } \\
(\mathrm{ppm})\end{array}$ & $\begin{array}{l}\text { R.S.D } \\
(\%)\end{array}$ & Range (ppm) & $\begin{array}{l}\text { Mean } \\
(\mathrm{ppm})\end{array}$ & $\begin{array}{l}\text { R.S.D } \\
(\%)\end{array}$ & Range (ppm) & $\begin{array}{l}\text { Mean } \\
(\mathrm{ppm})\end{array}$ & $\begin{array}{l}\text { R.S.D } \\
(\%)\end{array}$ \\
\hline Jan. & $0.265-0.659$ & 0.446 & 23.0 & $0.305-0.618$ & 0.483 & 22.3 & $0.410-0.864$ & 0.640 & 16.9 \\
\hline Feb. & $0.249-0.600$ & 0.429 & 22.8 & $0.284-0.618$ & 0.470 & 22.0 & $0.429-0.826$ & 0.626 & 14.4 \\
\hline Mar. & $0.296-0.684$ & 0.462 & 18.8 & $0.324-0.918$ & 0.529 & 23.4 & $0.476-1.098$ & 0.630 & 20.1 \\
\hline Apr. & $0.231-0.736$ & 0.407 & 26.8 & $0.210-0.718$ & 0.452 & 32.1 & $0.233-0.866$ & 0.505 & 35.7 \\
\hline May & $0.226-0.520$ & 0.332 & 24.6 & $0.178-0.518$ & 0.366 & 26.6 & $0.230-0.618$ & 0.433 & 27.1 \\
\hline June & $0.155-0.392$ & 0.254 & 27.6 & $0.106-0.418$ & 0.242 & 34.6 & $0.116-2.690$ & 0.339 & 134.0 \\
\hline July & $0.150-0.373$ & 0.252 & 20.3 & $0.176-0.418$ & 0.276 & 23.2 & $0.195-0.483$ & 0.305 & 26.1 \\
\hline Aug. & $0.137-0.425$ & 0.247 & 25.0 & $0.159-0.318$ & 0.250 & 21.9 & $0.136-0.442$ & 0.261 & 32.2 \\
\hline Sep. & $0.211-0.498$ & 0.304 & 25.1 & $0.190-0.518$ & 0.337 & 27.1 & $0.224-0.526$ & 0.396 & 19.4 \\
\hline Oct. & $0.181-0.504$ & 0.332 & 20.6 & $0.215-0.518$ & 0.362 & 23.7 & $0.236-0.737$ & 0.461 & 22.6 \\
\hline Nov. & $0.283-0.526$ & 0.383 & 21.8 & $0.263-0.518$ & 0.414 & 23.0 & $0.386-0.794$ & 0.547 & 18.5 \\
\hline Dec. & $0.277-0.678$ & 0.426 & 28.8 & $0.284-0.718$ & 0.470 & 31.4 & $0.445-0.843$ & 0.587 & 18.9 \\
\hline Annual & $0.222-0.550$ & 0.356 & 23.8 & $0.224-0.609$ & 0.388 & 25.9 & $0.293-0.899$ & 0.478 & 32.2 \\
\hline
\end{tabular}

Table 2(c)-2. Monthly average atmospheric CO concentrations in Douliou City, Taisi Township, Lunbei Township, and Mailiao Township in 2017.

\begin{tabular}{|c|c|c|c|c|c|c|c|c|c|c|c|c|}
\hline \multirow[b]{2}{*}{ Month } & \multicolumn{3}{|c|}{ Douliou City } & \multicolumn{3}{|c|}{ Taisi Township } & \multicolumn{3}{|c|}{ Lunbei Township } & \multicolumn{3}{|c|}{ Mailiao Township } \\
\hline & $\begin{array}{l}\text { Range } \\
(\mathrm{ppm})\end{array}$ & $\begin{array}{l}\text { Mean } \\
(\mathrm{ppm})\end{array}$ & $\begin{array}{l}\text { R.S.D } \\
(\%)\end{array}$ & $\begin{array}{l}\text { Range } \\
(\mathrm{ppm})\end{array}$ & $\begin{array}{l}\text { Mean } \\
\text { (ppm) }\end{array}$ & $\begin{array}{l}\text { R.S.D } \\
(\%)\end{array}$ & $\begin{array}{l}\text { Range } \\
(\mathrm{ppm})\end{array}$ & $\begin{array}{l}\text { Mean } \\
\text { (ppm) }\end{array}$ & $\begin{array}{l}\text { R.S.D } \\
(\%)\end{array}$ & $\begin{array}{l}\text { Range } \\
\text { (ppm) }\end{array}$ & $\begin{array}{l}\text { Mean } \\
(\mathrm{ppm})\end{array}$ & $\begin{array}{l}\text { R.S.D } \\
(\%)\end{array}$ \\
\hline Jan. & $0.328-0.727$ & 0.496 & 20.3 & $0.163-0.601$ & 0.345 & 32.3 & $0.281-0.694$ & 0.465 & 21.9 & $0.222-0.645$ & 0.400 & 30.4 \\
\hline Feb. & $0.270-0.636$ & 0.477 & 18.8 & $0.179-0.618$ & 0.381 & 30.4 & $0.284-0.627$ & 0.448 & 23.2 & $0.193-0.705$ & 0.424 & 29.5 \\
\hline Mar. & $0.333-0.745$ & 0.489 & 16.8 & $0.223-0.698$ & 0.406 & 25.6 & $0.343-0.759$ & 0.503 & 19.5 & $0.275-0.760$ & 0.470 & 25.9 \\
\hline Apr. & $0.294-0.835$ & 0.447 & 29.6 & $0.153-0.601$ & 0.370 & 31.1 & $0.166-0.681$ & 0.426 & 31.7 & $0.244-0.696$ & 0.427 & 27.4 \\
\hline May & $0.243-0.584$ & 0.389 & 21.1 & $0.138-0.540$ & 0.307 & 35.3 & $0.158-0$ & 0.356 & 29.4 & 0.180 & 0.354 & 28.9 \\
\hline June & $0.216-0.468$ & 0.284 & 19.4 & $0.086-0.293$ & 0.151 & 40.0 & $0.096-0.358$ & 0.189 & 34.6 & $0.101-0.400$ & 0.230 & 30.2 \\
\hline July & $0.190-0.340$ & 0.255 & 14.0 & $0.090-0.303$ & 0.205 & 28.4 & $0.128-0.290$ & 0.217 & 19.7 & $0.123-0.343$ & 0.249 & 21.9 \\
\hline Aug. & $0.211-0.436$ & 0.286 & 20.1 & $0.091-0.294$ & 0.173 & 31.0 & $0.105-0.324$ & 0.199 & 26.4 & $0.148-0.384$ & 0.245 & 25.4 \\
\hline Sep. & $0.225-0.539$ & 0.343 & 22.5 & $0.124-0.375$ & 0.242 & 29.1 & $0.126-0.485$ & 0.281 & 27.7 & $0.179-0.629$ & 0.310 & 30.1 \\
\hline Oct. & $0.244-0.628$ & 0.391 & 24.2 & $0.157-0.530$ & 0.311 & 29.0 & $0.186-0.517$ & 0.328 & 26.0 & $0.196-0.518$ & 0.375 & 23.2 \\
\hline Nov. & $0.286-0.599$ & 0.426 & 20.9 & $0.154-0.507$ & 0.286 & 31.7 & $0.274-0.541$ & 0.380 & 21.5 & $0.230-0.519$ & 0.344 & 23.6 \\
\hline Dec. & $0.328-0.668$ & 0.480 & 22.5 & $0.183-0.620$ & 0.373 & 29.8 & $0.259-0.751$ & 0.446 & 24.9 & $0.220-0.659$ & 0.427 & 25.8 \\
\hline Annual & $0.264-0.600$ & 0.397 & 20.9 & $0.145-0.498$ & 0.296 & 31.1 & $0.200-0.549$ & 0.353 & 25.5 & $0.192-0.566$ & 0.355 & 26.9 \\
\hline
\end{tabular}


investigated regions were all significantly lower than WHO standard, which demonstrated that atmospheric $\mathrm{CO}$ does not have a serious impact on the air quality in these areas.

As for variations in atmospheric $\mathrm{CO}$ concentration by season, in 2015, these values were $0.316 \mathrm{ppm}$ (Taisi Township)-0.493 ppm (Chiayi County), 0.185 ppm (Taisi Township)-0.330 ppm (Douliou City), 0.384 ppm (Taisi Township)-0.546 ppm (Chiayi County), 0.443 ppm (Taisi Township)-0.733 ppm (Chiayi County) in spring, summer, fall, and winter, respectively. In 2016, the values were 0.381 ppm (Taisi Township)-0.537 ppm (Chiayi County), $0.201 \mathrm{ppm}$ (Taisi Township)-0.305 ppm (Douliou City), 0.324 ppm (Taisi Township)-0.506 ppm (Chiayi County), $0.392 \mathrm{ppm}$ (Taisi Township)-0.692 ppm (Chiayi County) in spring, summer, fall, and winter, respectively. In 2017, the values were $0.361 \mathrm{ppm}$ (Taisi Township) $-0.523 \mathrm{ppm}$ (Chiayi County), 0.176 ppm (Taisi Township)-0.301 ppm (Chiayi County), 0.280 ppm (Taisi Township)-0.468 ppm (Chiayi County), 0.366 ppm (Taisi Township)-0.618 ppm (Chiayi County) in spring, summer, fall, and winter, respectively. Generally, it can be seen that the hot summer had the minimum values and the cold winter had the maximum values, while spring and fall had levels in the middle, which indicated that the $\mathrm{CO}$ values in spring were slightly higher than those in fall, especially in 2016 and 2017. The average CO concentrations in the seven researched areas in spring were all higher than those in fall. Wang et al. (2018b) reported the same result for Wuhu $(0.867,0$. 651, 0.770, with 1.04 ppm in spring, summer, fall, and winter, respectively) and for Bengbu $(0.723,0.513,0.670$, and $0.960 \mathrm{ppm}$ in spring, summer, fall, and winter, respectively). The seasonal variation may be a result of the distinct meteorological conditions occurring in different seasons, where a higher air temperature is conducive to the long-range transport of CO in the summer (Kato et al. 2016), and the lower ground air temperature in the winter can lead to an accumulation of $\mathrm{CO}$, which concurs with the seasonal distribution of $\mathrm{NO}_{2}$.

\section{$\mathrm{O}_{3}$ Concentration}

Ozone $\left(\mathrm{O}_{3}\right)$ is a secondary source of pollution that is generated through natural or anthropogenic photochemical reactions of oxides of nitrogen $\left(\mathrm{NO}_{\mathrm{x}}\right)$, volatile organic compounds (VOCs), carbon monoxide $(\mathrm{CO})$, methane $\left(\mathrm{CH}_{4}\right)$, and nonmethane hydrocarbons (NMHCs) (Seinfeld and Pandis, 1998; Tu et al., 2007; Lan et al., 2015; Wu et al., 2015; Gong et al., 2018). Atmospheric $\mathrm{NO}_{\mathrm{x}}$ and VOCs play a dramatic role in the formation of $\mathrm{O}_{3}$ in polluted atmospheres, especially unsaturated VOCs (Wang et al., $2018 b$ ). From the Air Quality Guidelines of $\mathrm{WHO}_{2005}$, the simplified photochemical reactions can be summarized as follows:

Nitrogen dioxide dissociates to form nitric oxide (NO) and an atomic oxygen radical:

$\mathrm{NO}_{2}+h v(\lambda \leq 430 \mathrm{~nm}) \rightarrow \mathrm{NO}+\mathrm{O}$

Atomic oxygen radical combines with molecular oxygen to form ozone:
$\mathrm{O}+\mathrm{O}_{2} \rightarrow \mathrm{O}_{3}$

Ozone is decomposed by reacting with nitric oxide, forming nitrogen dioxide and molecular oxygen:

$\mathrm{NO}+\mathrm{O}_{3} \rightarrow \mathrm{NO}_{2}+\mathrm{O}_{2}$

The reaction of nitric oxide with atmospheric peroxides $\left(\mathrm{RO}_{2}\right)$ is the main cause of disturbances in the photochemical equilibrium, as presented in reaction (6):

$\mathrm{NO}+\mathrm{RO}_{2} \rightarrow \mathrm{NO}_{2}+\mathrm{RO}$

Atmospheric peroxides are formed by the oxidation of VOCs as represented in the equations below, which describe the oxidation of an alkene:

$\mathrm{RCHCHR}+\mathrm{O} \rightarrow \mathrm{RCH}_{2}+\mathrm{RCO}$

(generation of free radicals)

$\mathrm{RCH}_{2}+\mathrm{O}_{2} \rightarrow \mathrm{RCH}_{2} \mathrm{O}_{2}$

(generation of peroxides)

$\mathrm{RCH}_{2} \mathrm{O}+\mathrm{O}_{2} \rightarrow \mathrm{RCHO}+\mathrm{HO}_{2}$

(generation of aldehydes)

$\mathrm{RCH}_{2} \mathrm{O}_{2}+\mathrm{NO}_{2} \rightarrow \mathrm{RCH}_{2} \mathrm{O}_{2} \mathrm{NO}_{2}$

(generation of organic nitrates)

The intensity of the sun and the concentration of $\mathrm{NO}_{\mathrm{x}}$ and VOCs are all key factors that influence ambient ozone concentrations. Some studies have also indicated that the ratio of VOCs to $\mathrm{NO}_{\mathrm{x}}$ also has an effect on the $\mathrm{O}_{3}$ formation mechanism. These studies reported that ratios in a range of 4:1 to10:1 are most favorable for formation of $\mathrm{O}_{3}$. Furthermore, meteorological factors, including air temperature, humidity, and wind speed, play an important role in the process of dispersion, transport, and dilution of $\mathrm{O}_{3}$ (Seaman, 2000; Tu et al., 2007; Jin et al., 2013; Cheng et al., 2015).

Tropospheric $\mathrm{O}_{3}$ is a crucial greenhouse gas and has a direct adverse impact on ecosystems and human health (Solomon et al., 2000; Silva et al., 2013; Lelieveld et al., 2015; Kato et al., 2016). With the impact of anthropogenic activities, including industrial emissions and transportation and meteorological conditions, the dramatic increase $\mathrm{O}_{3}$ has made it a concern, and it has become an important criteria air pollutant. From 2015 to 2017, the monthly average $\mathrm{O}_{3}$ concentration in Puzih City, Singang Township, and Chiayi County are plotted in Figs. 4(a)-1, 4(b)-1, 4(c)-1, respectively, and the monthly average $\mathrm{O}_{3}$ concentration in Douliou City, Taisi Township, Lunbei Township, and Mailiao Township are plotted in Figs. 4(a)-2, 4(b)-2, 4(c)-2, respectively.

In 2015, the highest annual mean $\mathrm{O}_{3}$ level among the seven cities and townships was found in Taisi Township (50.3 ppb), and the lowest value was in Lunbei Township (42.2 ppb), which ranged from 29.4-63.3 ppb and 27.8$55.9 \mathrm{ppb}$, respectively. In 2016, the highest annual mean $\mathrm{O}_{3}$ level among the seven cities and townships was found 


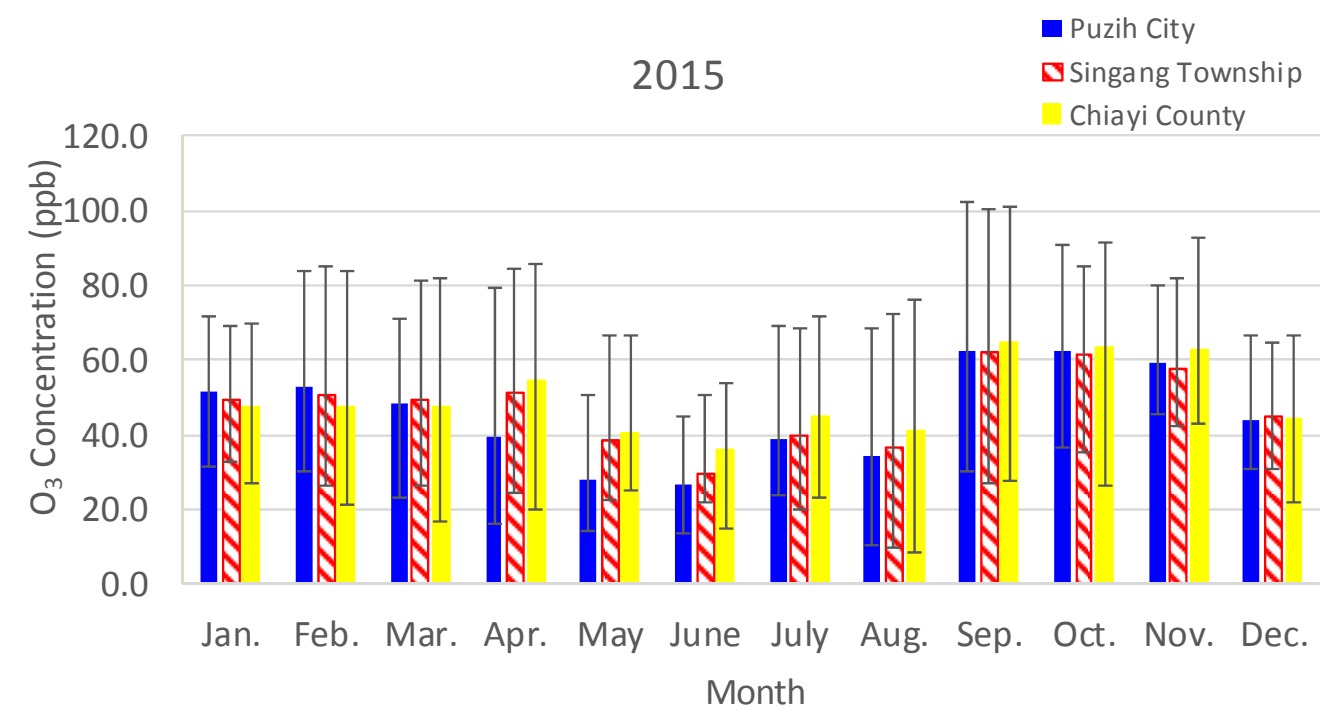

Fig. 4(a)-1. Monthly average atmospheric $\mathrm{O}_{3}$ concentrations in Puzih City, Singang Township, and Chiayi County in 2015.

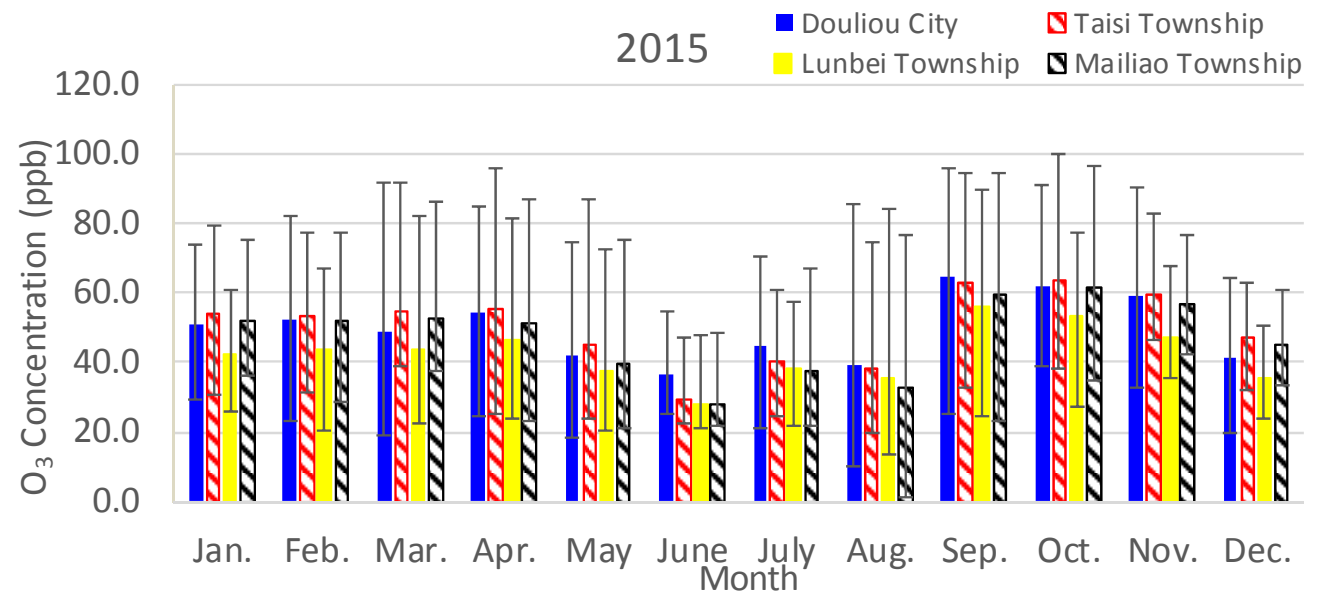

Fig. 4(a)-2. Monthly average atmospheric $\mathrm{O}_{3}$ concentrations in Douliou City, Taisi Township, Lunbei Township, and Mailiao Township in 2015.

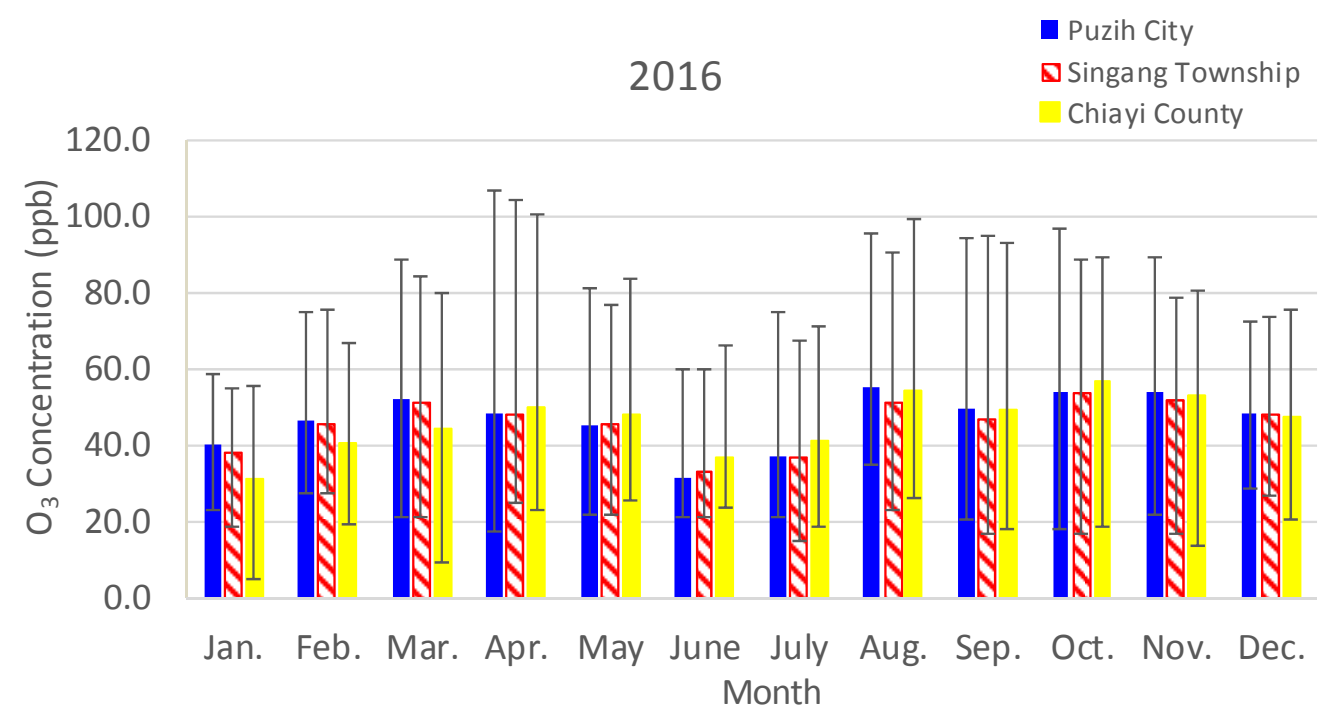

Fig. 4(b)-1. Monthly average atmospheric $\mathrm{O}_{3}$ concentrations in Puzih City, Singang Township, and Chiayi County in 2016. 


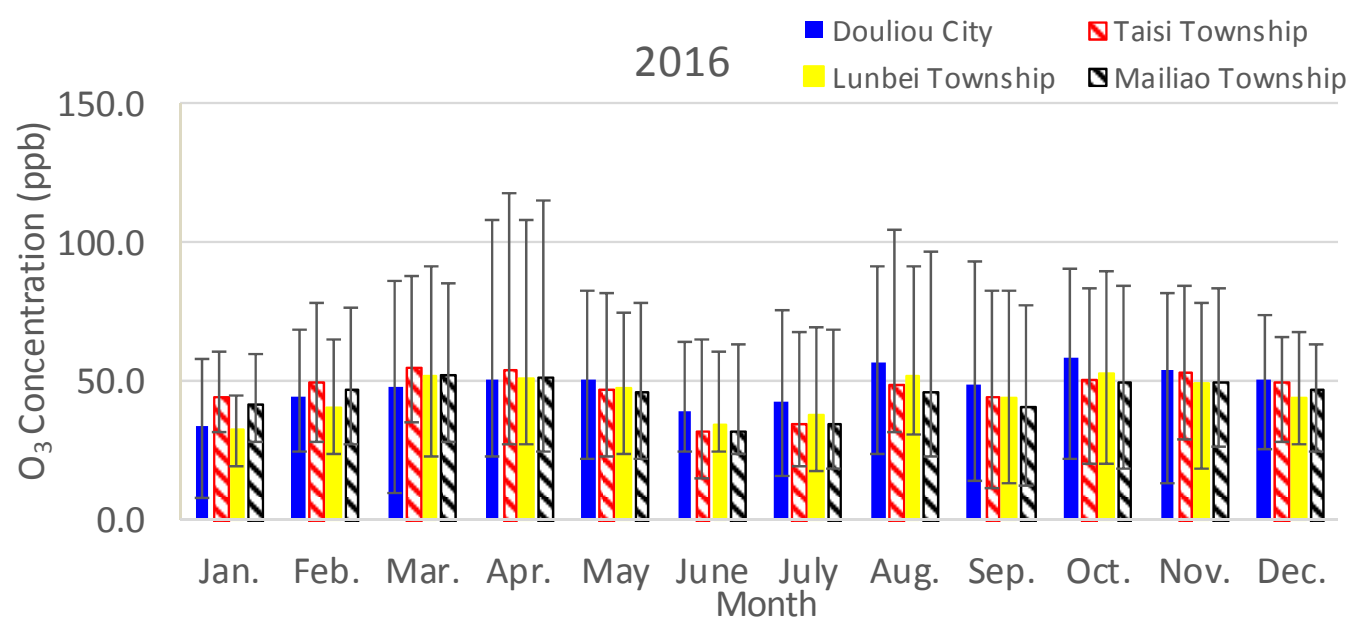

Fig. 4(b)-2. Monthly average atmospheric $\mathrm{O}_{3}$ concentrations in Douliou City, Taisi Township, Lunbei Township, and Mailiao Township in 2016.

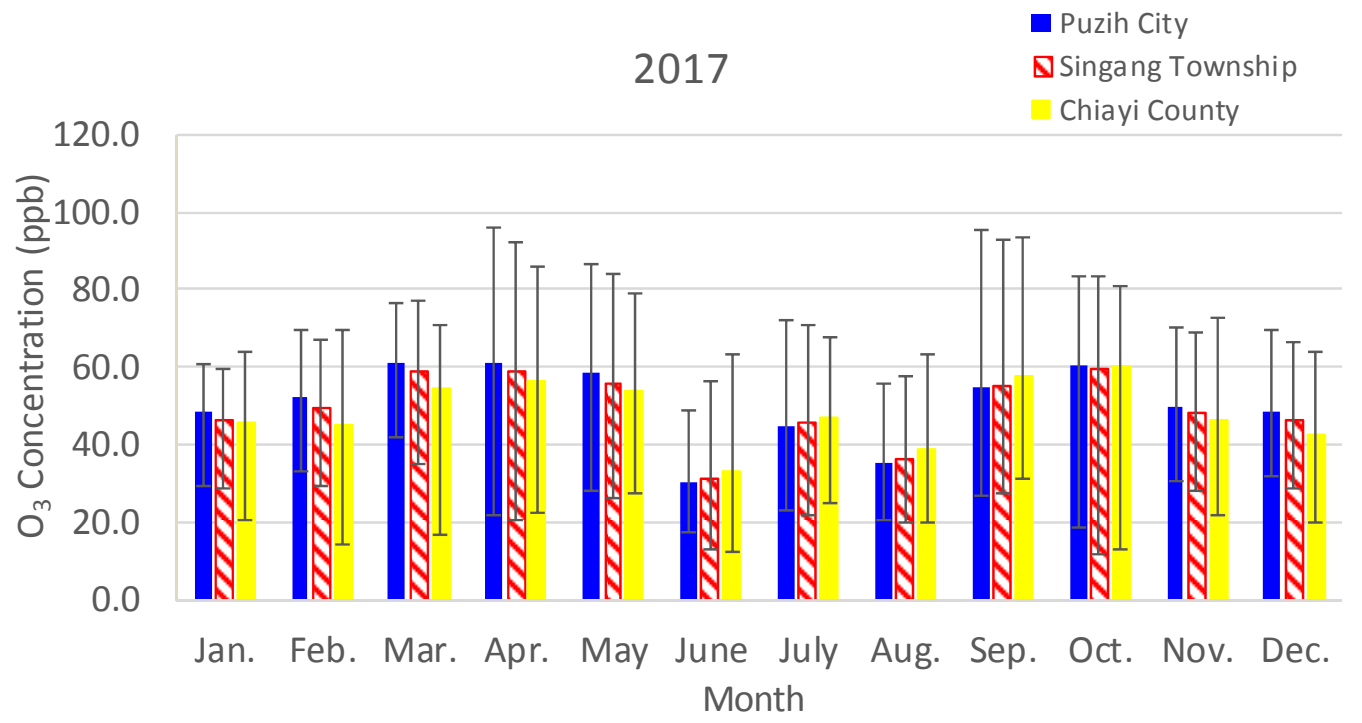

Fig. 4(c)-1. Monthly average atmospheric $\mathrm{O}_{3}$ concentrations in Puzih City, Singang Township, and Chiayi County in 2017.

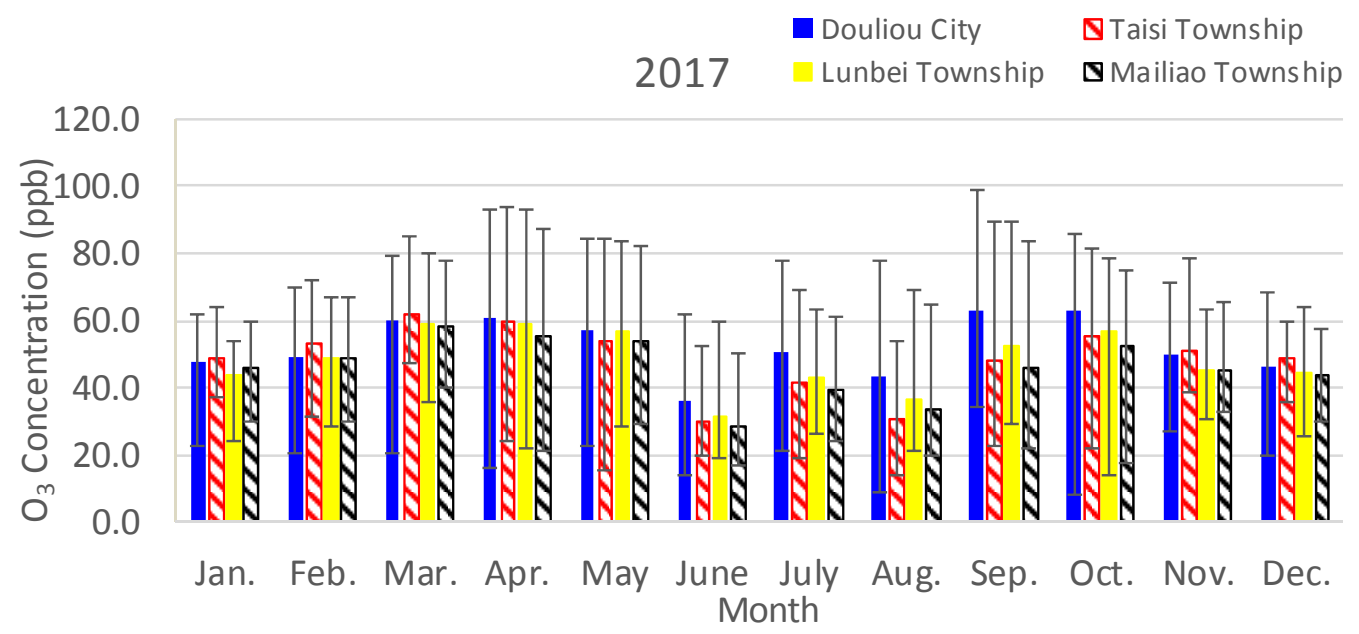

Fig. 4(c)-2. Monthly average atmospheric $\mathrm{O}_{3}$ concentrations in Douliou City, Taisi Township, Lunbei Township, and Mailiao Township in 2017. 
in Douliou City (48.1 ppb), and the lowest value was in Lunbei Township (44.7 ppb), which ranged from 33.5-58.8 $\mathrm{ppb}$ and $32.2-52.5 \mathrm{ppb}$, respectively. In 2017 , the highest annual mean $\mathrm{O}_{3}$ level among the seven cities and townships was found in Douliou City (52.3 ppb), and the lowest value was in Mailiao Township (45.6 ppb), which ranged from 36.3-63.2 ppb and 28.4-57.7 ppb, respectively. A comparison of the variation in $\mathrm{O}_{3}$ concentrations from 2015 to 2016 showed that $\mathrm{O}_{3}$ concentrations in Puzih City and Lunbei Township increased by $1.91 \%$ and $5.60 \%$, respectively, while in the others, concentrations declined by $3.07-7.76 \%$. However, the values in all the observed cities rose by $0.43-$ $7.93 \%$ in 2016 compared with those observed in 2017. This trend toward increases in $\mathrm{O}_{3}$ levels poses a serious challenge in terms of air quality and should generate more public attention.

Generally, the recent three-year (2015-2017) average $\mathrm{O}_{3}$ concentrations in Puzih City, Singang Township, Chiayi County, Douliou City, Taisi Township, Lunbei Township, and Mailiao Township were 47.7, 47.5, 48.0, 50.0, 48.7, 45.0 and $46.1 \mathrm{ppb}$, respectively. The average $\mathrm{O}_{3}$ levels in Lunbei Township and Mailiao Township met the WHO standard of $46.6 \mathrm{ppb}$, but the others were all slightly higher than WHO standard and were also higher than in Wuhu City (35.9 ppb) and Bengbu City (44.7 ppb) (Wang et al., $2018 \mathrm{~b}$ ). This result can be attributed to the sunshine intensity. The latitude of Taiwan is significantly lower than that of Wuhu and Bengbu, and with a higher solar altitude angle, low latitude areas have stronger UV radiation, which leads to the formation of $\mathrm{O}_{3}$.

As for the seasonal variations in $\mathrm{O}_{3}$, the average $\mathrm{O}_{3}$ concentrations were 38.8 ppb (Puzih City)-51.6 ppb (Taisi Township), 32.5 ppb (Mailiao Township)-40.7 ppb (Chiayi County), 52.2 ppb (Lunbei Township)-63.3 ppb (Chiayi County), 40.3 ppb (Lunbei Township)-51.6 ppb (Taisi Township) in spring, summer, fall, and winter, respectively, in 2015. In 2016, these values were 47.3 ppb (Chiayi County)$52.2 \mathrm{ppb}$ (Taisi Township), $38.3 \mathrm{ppb}$ (Mailiao Township)$46.2 \mathrm{ppb}$ (Douliou City), 47.3 ppb (Mailiao Township)53.9 ppb (Douliou City), 38.9 ppb (Lunbei Township)$48.4 \mathrm{ppb}$ (Taisi Township) in spring, summer, fall, and winter, respectively. In 2017, these values were $55.0 \mathrm{ppb}$ (Chiayi County)-60.1 ppb (Puzih City), 33.6 ppb (Mailiao Township)-43.5 ppb (Douliou City), 47.6 ppb (Mailiao Township)-58.8 ppb (Douliou City), 44.1 ppb (Chiayi County)-50.1 ppb (Taisi Township) in spring, summer, fall, and winter, respectively. Overall, the seasonal $\mathrm{O}_{3}$ concentration exhibited different patterns in the three years under observation. Firstly, all the observed cities achieved their maximum levels in fall and their minimum in summer, while spring and winter exhibited intermediate levels in 2015. Previous studies reported there to be a negative correlation between the atmospheric relative humidity and $\mathrm{O}_{3}$ concentration (Kato et al., 2016; Li et al., 2017b; Gong et al., 2018; Wang et al., 2018b), where during a dry fall season, the lower relative humidity results in higher $\mathrm{O}_{3}$ levels than those in summer and spring, and the stronger sun radiation leads to higher $\mathrm{O}_{3}$ levels than those in winter. During the summer, the high atmospheric relative humidity and low precursor concentrations are not favorable to the formation of $\mathrm{O}_{3}$. Thus, the summer in these observed areas exhibited the lowest $\mathrm{O}_{3}$ levels. Secondly, as for 2016, the maximum $\mathrm{O}_{3}$ levels typically occurred in spring or fall, and the minimum $\mathrm{O}_{3}$ levels typically occurred in summer or winter. This may be attributed to the fact that during spring and fall, the UV radiation strength in the monitored areas is stronger than in winter, and the concentrations of precursors (including $\mathrm{NO}_{\mathrm{x}}$ and VOCs) are higher than in summer in monitored areas, so the strong UV radiation and increasing precursors enhance the production of $\mathrm{O}_{3}$. Thirdly, as seen in 2017, the $\mathrm{O}_{3}$ concentrations in both spring and fall were at high levels, and those in spring were higher than those in fall, followed by winter, with the lowest in summer. This may be analyzed from the perspective of air temperature, sunshine intensity, and precursor concentrations. The temperature and sun intensity in spring and fall were higher than those in winter, which directly increases $\mathrm{O}_{3}$ production rates and thus leads to higher $\mathrm{O}_{3}$ levels. While high temperatures and wind speeds in summer are favorable to the dispersion and dilution of air pollutants, a significant lack of precursors will hinder the formation of $\mathrm{O}_{3}$. Therefore, the summer had the minimum $\mathrm{O}_{3}$ level among the four seasons. The differences in seasonal ozone distribution over the three years under observation may have been related to the different contributions of various influencing factors at different ozone levels, including the concentration of $\mathrm{NO}_{\mathrm{x}}$ and VOCs, air temperature, humidity, and wind speed.

\section{AQI Analysis}

The Air Quality Index (AQI) is a useful index for evaluating daily air quality and its health effects, which can be used to inform the government and the public about the current air quality and thus help them take proper health protection measures when necessary. From 2015-2017, the day fractions of the six AQI categories in different seasons for Puzih City, Singang Township, Chiayi County, Douliou City, Taisi Township, Lunbei Township, and Mailiao Township are plotted in Figs. 5(a)-1 to 5(g)-3, respectively, and the corresponding cumulative number of days of primary pollutants are shown in Tables 3(a)-3(g).

In 2015, the daily AQI of Puzih City, Singang Township, Chiayi County, Douliou City, Taisi Township, Lunbei Township, and Mailiao Township were 77 (19-194), 77 (15-188), 84 (19-190), 89 (17-176), 78 (18-187), 88 (20$173)$, and 80 (18-179), respectively. In 2016, these values were 80 (22-202), 77 (17-198), 82 (18-189), 85 (19-204), 76 (22-213), 85 (27-203), and 77 (23-210), respectively. In 2017 , these values were 76 (17-176), 78 (18-169), 83 (16-171), 88 (18-184), 79 (26-171), 83 (25-169), and 85 (21-160), respectively. Generally, during the three-year observation period, the annual mean levels of AQI in these observed areas were Grade II, but the daily AQI values obviously fluctuated, which may be attributed to the seasonal characteristics of air pollutant emissions and meteorological conditions.

Based on the ranges of the AQI values, air quality can be classified into six classes: Grade I: 0-50; Grade II: 51-100; Grade III: 101-150; Grade IV: 151-200; Grade V: 201-300; 

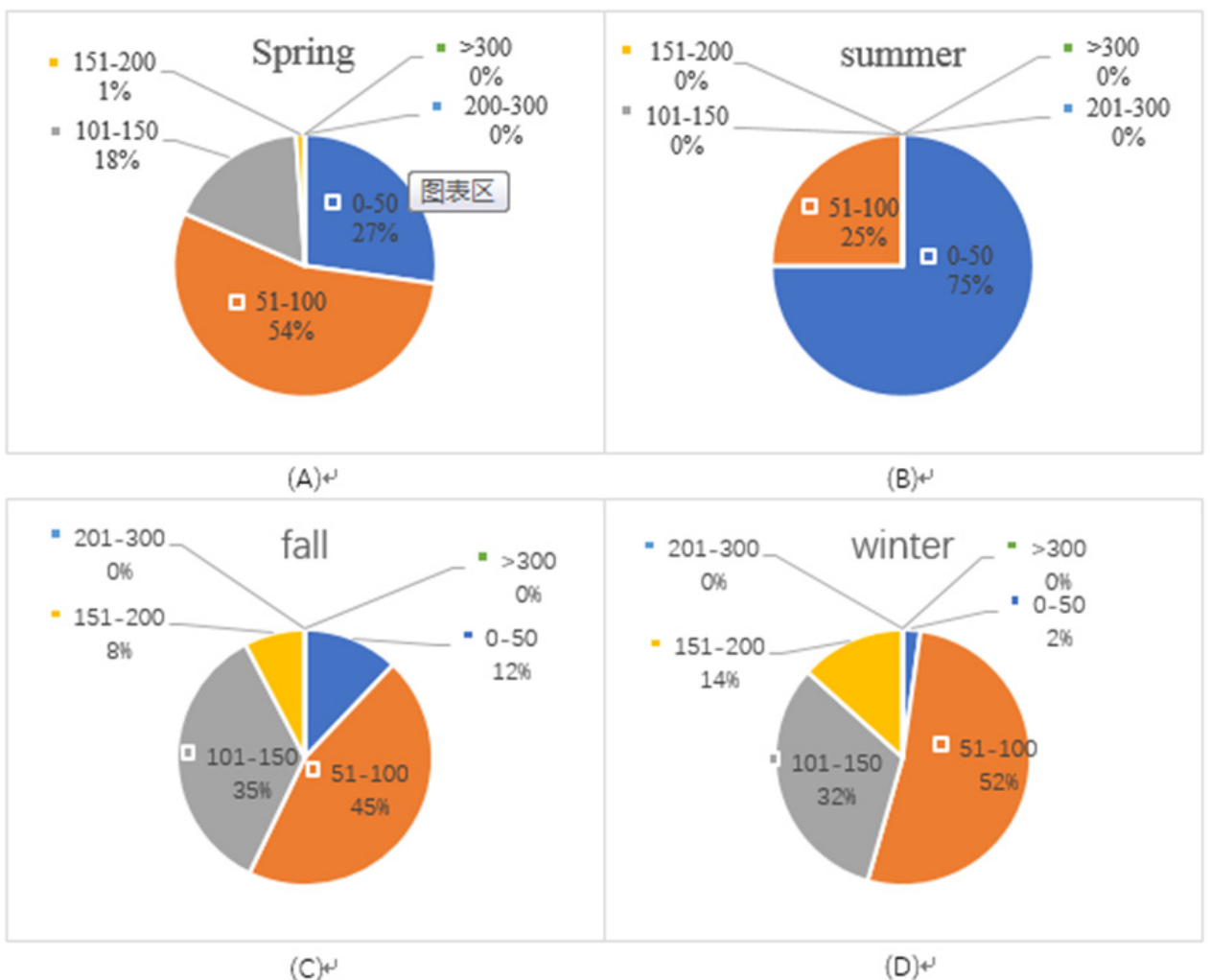

Fig. 5(a)-1. The fractions of the six AQI categories for Puzih City in (A) Spring, (B) Summer, (C) Fall, and (D) Winter in 2015 .

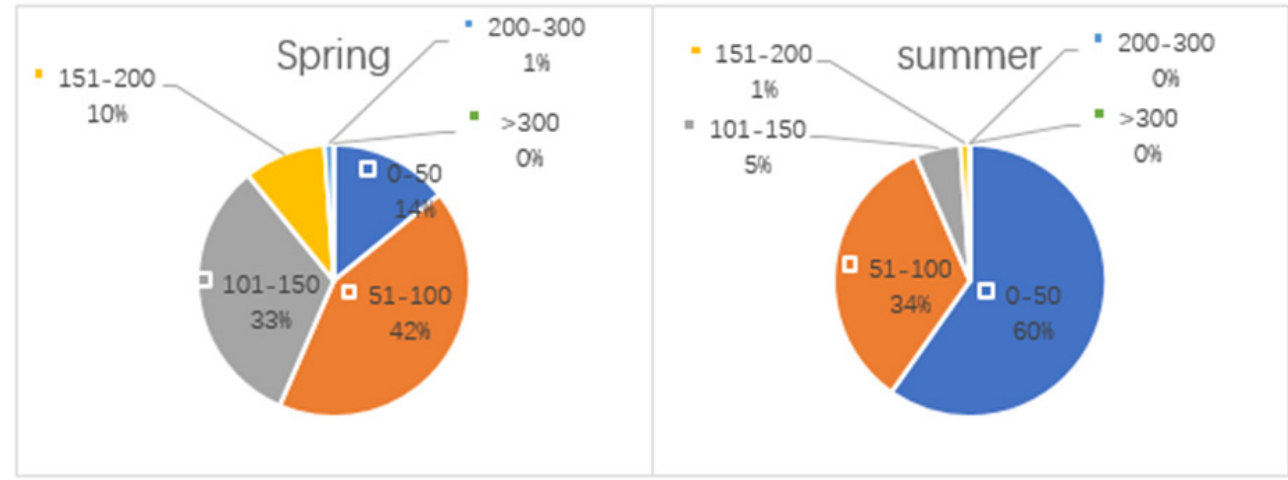

(A)

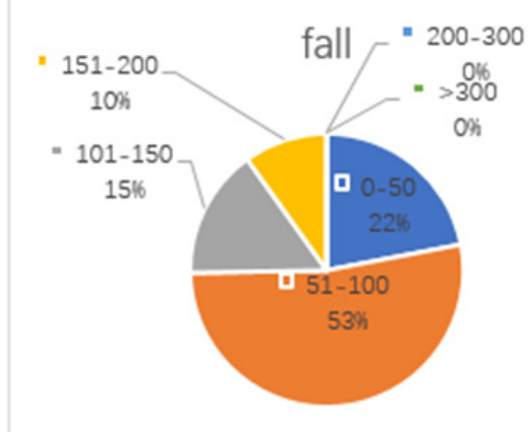

(C)
(B)

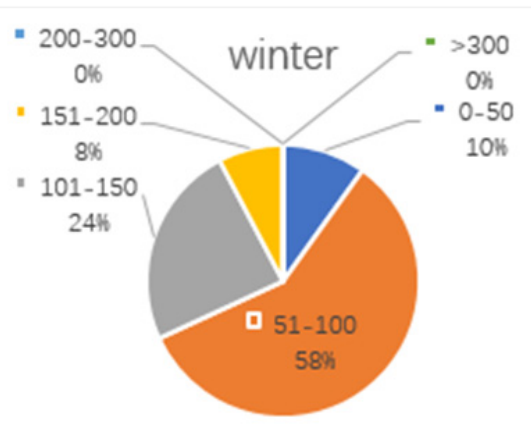

(D)

Fig. 5(a)-2. The fractions of the six AQI categories for Puzih City in (A) Spring, (B) Summer, (C) Fall, and (D) Winter in 2016 . 


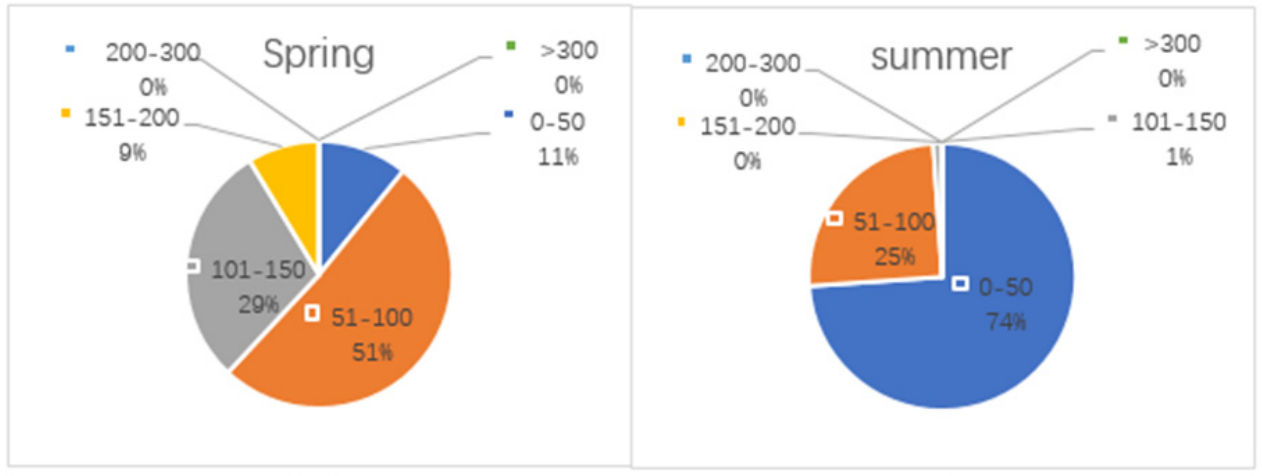

(A)

(B)+

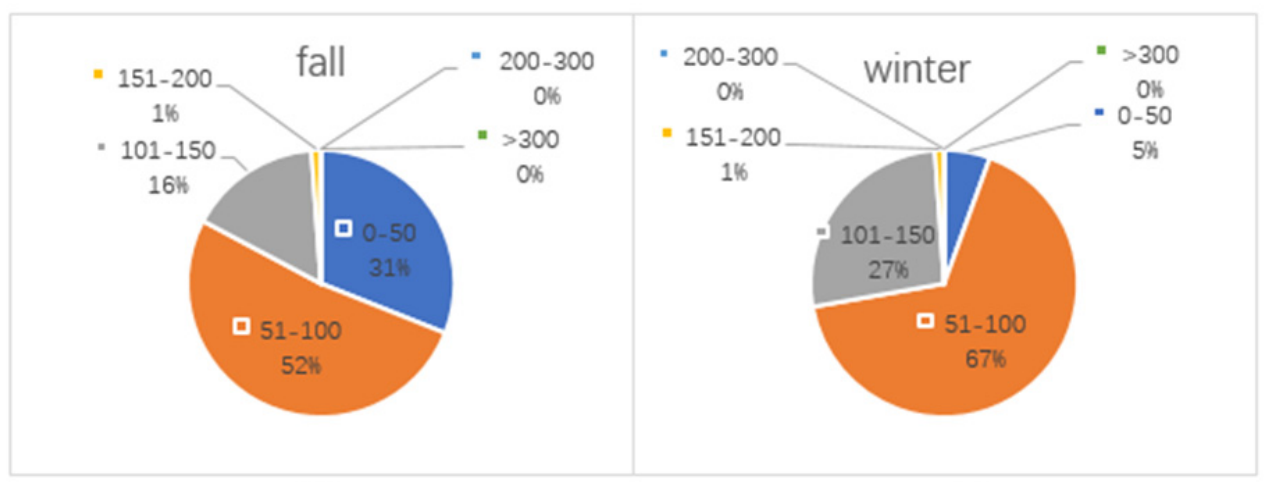

(C)

(D)

Fig. 5(a)-3. The fractions of the six AQI categories for Puzih City in (A) Spring, (B) Summer, (C) Fall, and (D) Winter in 2017.

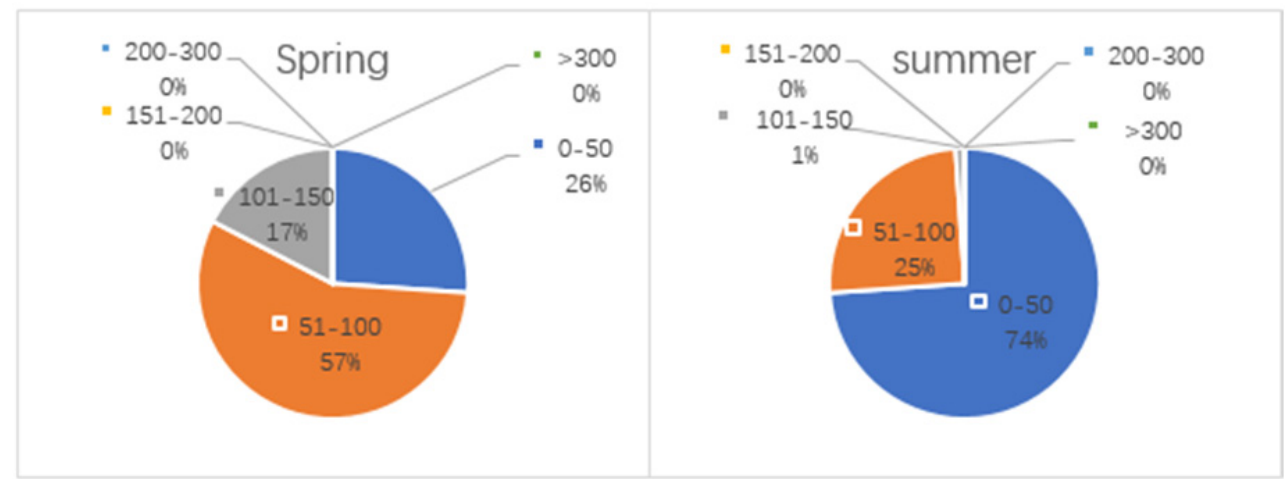

(A)

(B)

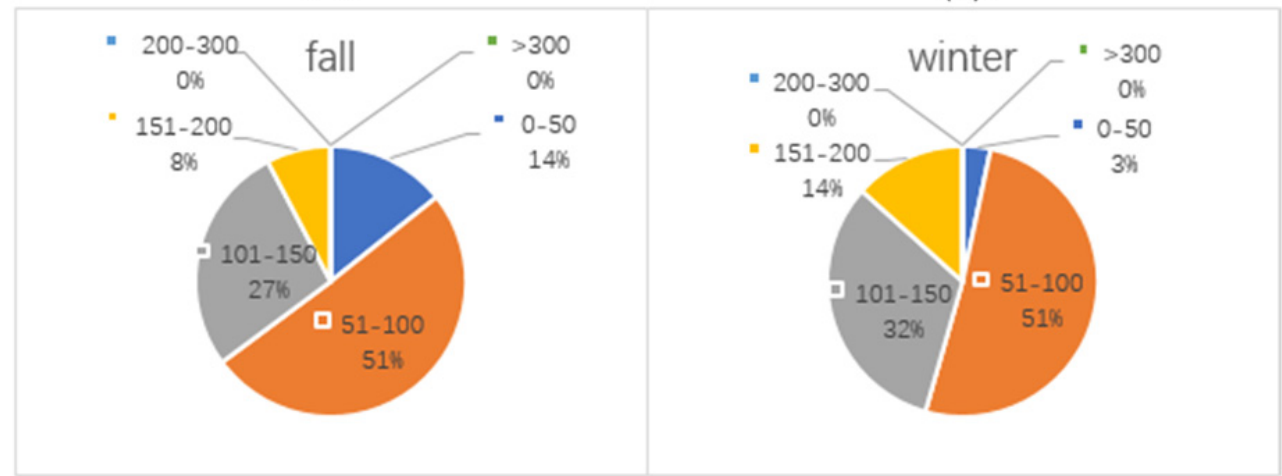

(C)

(D)

Fig. 5(b)-1. The fractions of the six AQI categories for Singang Township in (A) Spring, (B) Summer, (C) Fall, and (D) Winter in 2015. 


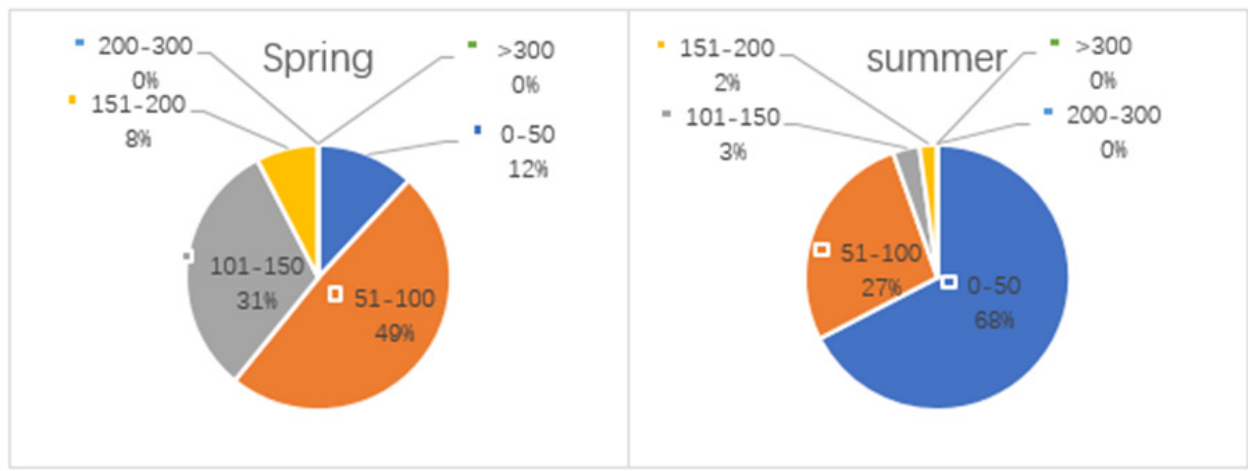

(A)

(B)

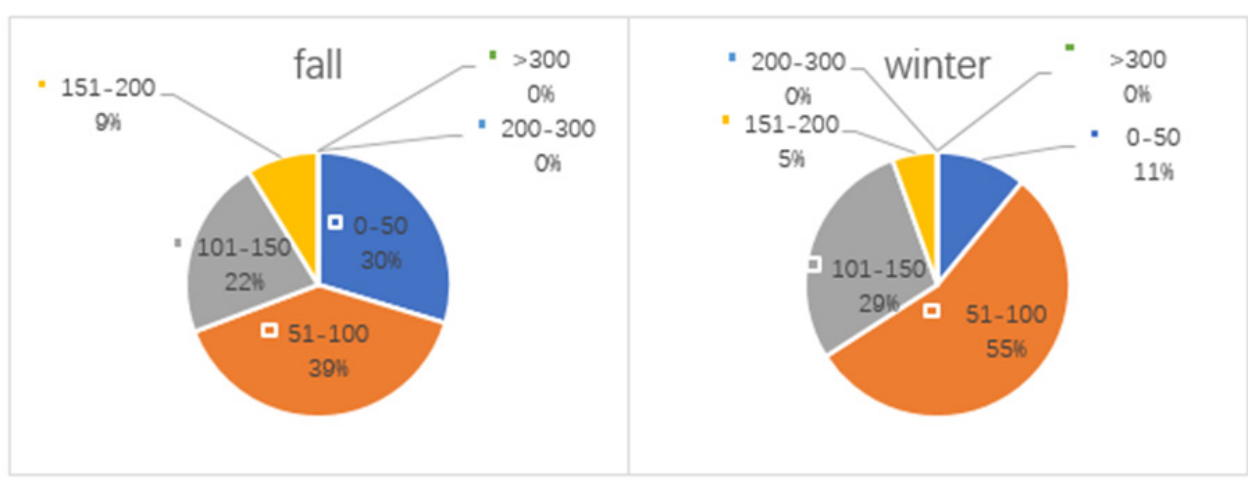

(C)

(D)

Fig. 5(b)-2. The fractions of the six AQI categories for Singang Township in (A) Spring, (B) Summer, (C) Fall, and (D) Winter in 2016.

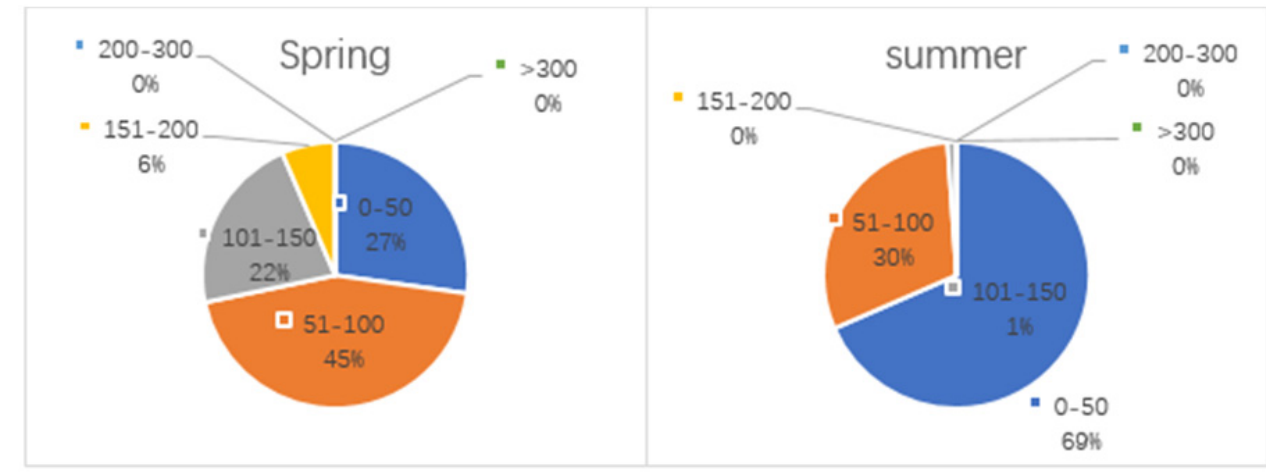

(A)

(B)

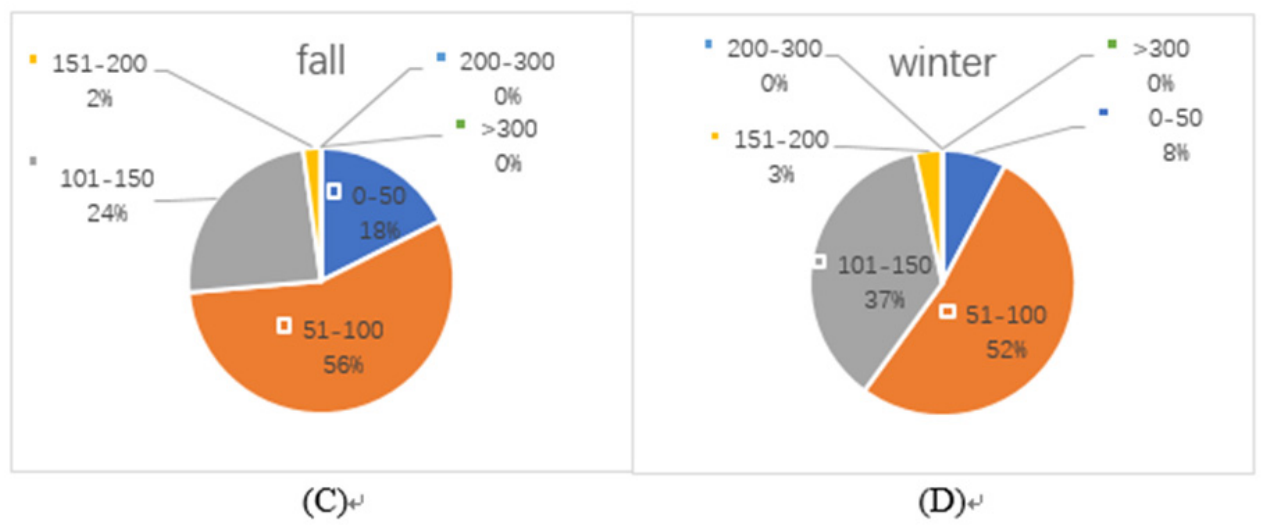

Fig. 5(b)-3. The fractions of the six AQI categories for Singang Township in (A) Spring, (B) Summer, (C) Fall, and (D) Winter in 2017. 


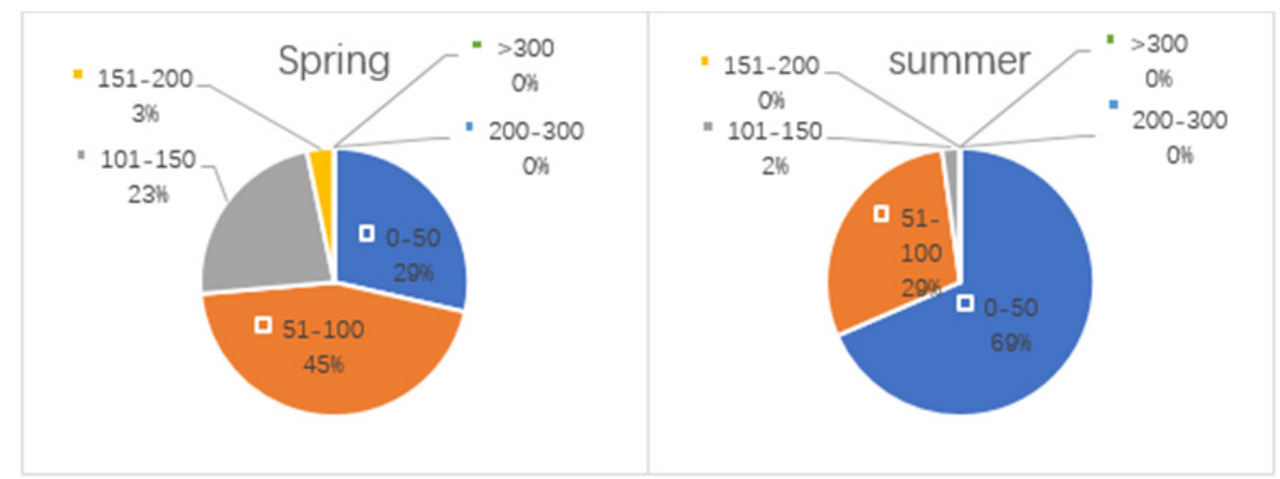

(A)

(B)

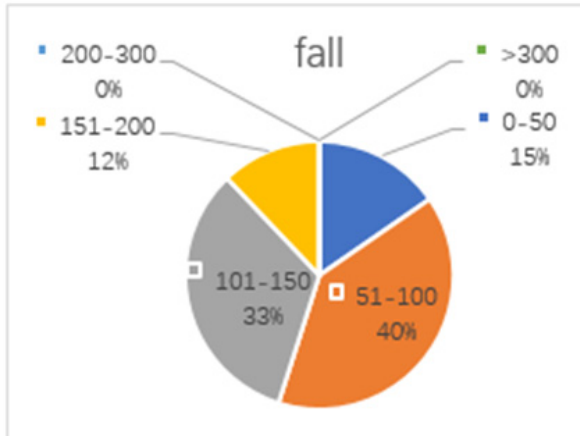

(C)

(D)

Fig. 5(c)-1. The fractions of the six AQI categories for Chiayi County in (A) Spring, (B) Summer, (C) Fall, and (D) Winter in 2015 .

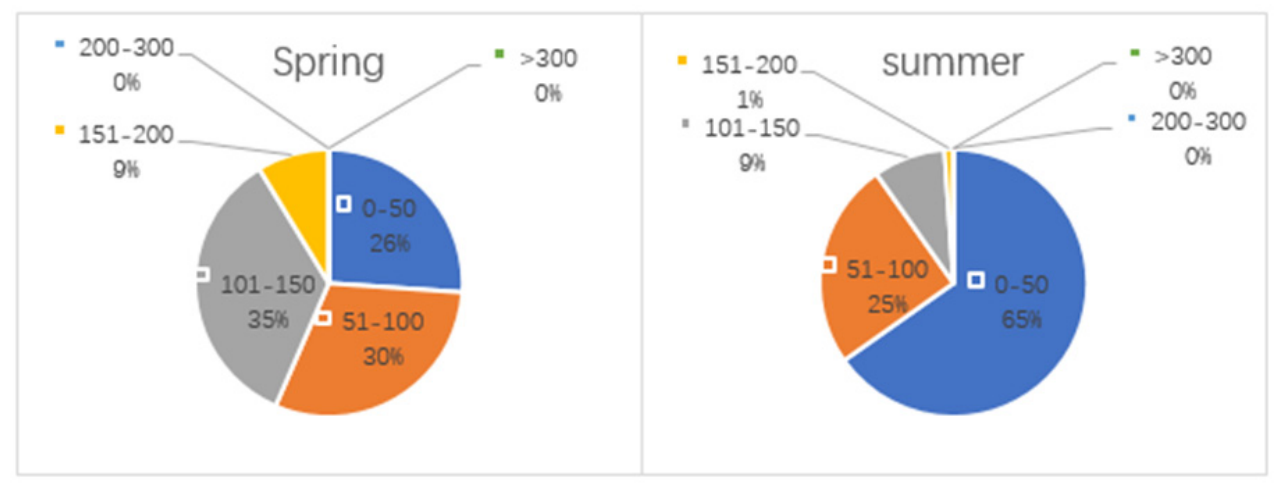

(A)

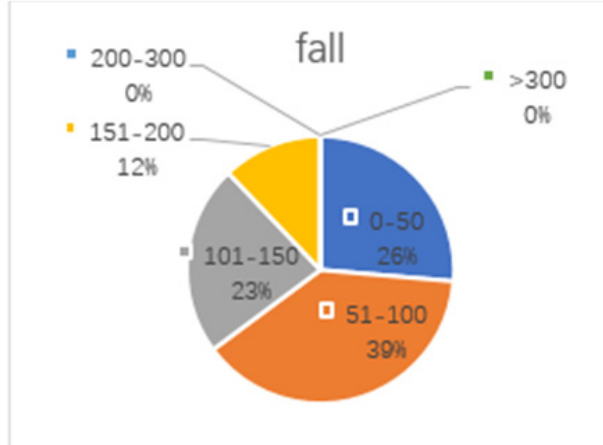

(C)
(B)

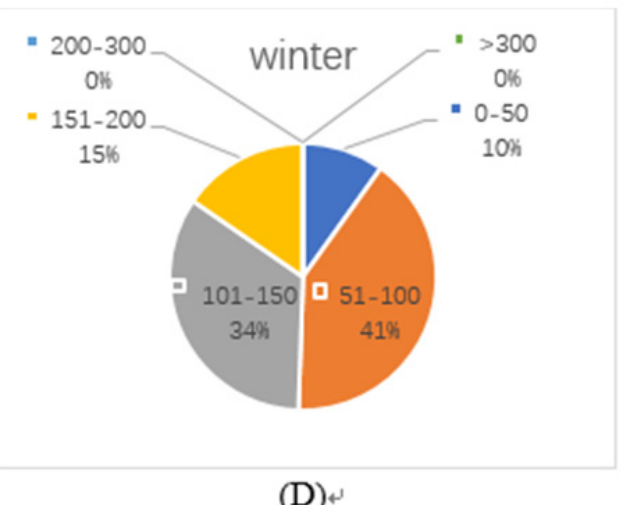

Fig. 5(c)-2. The fractions of the six AQI categories for Chiayi County in (A) Spring, (B) Summer, (C) Fall, and (D) Winter in 2016. 


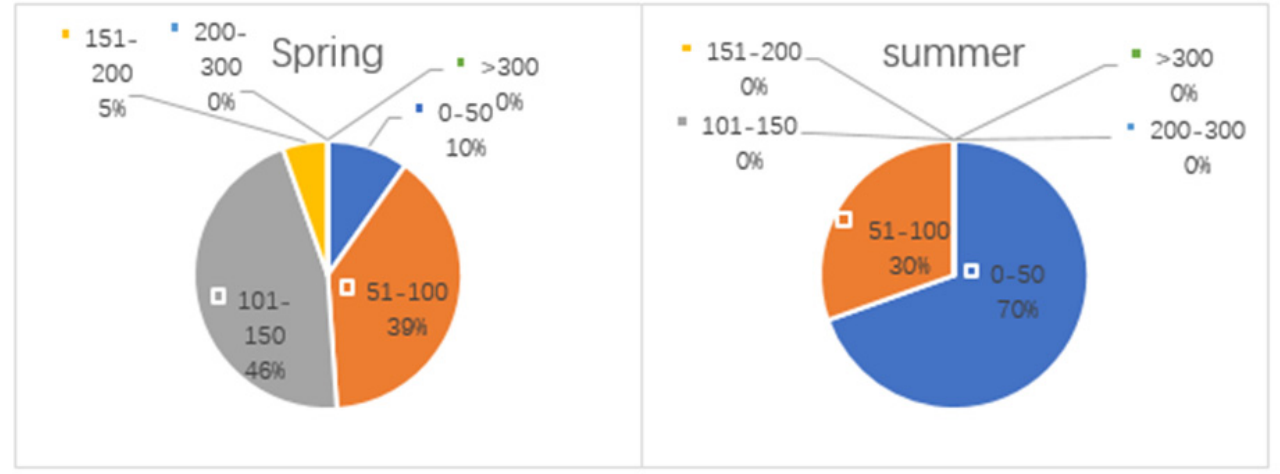

(A)

(B)

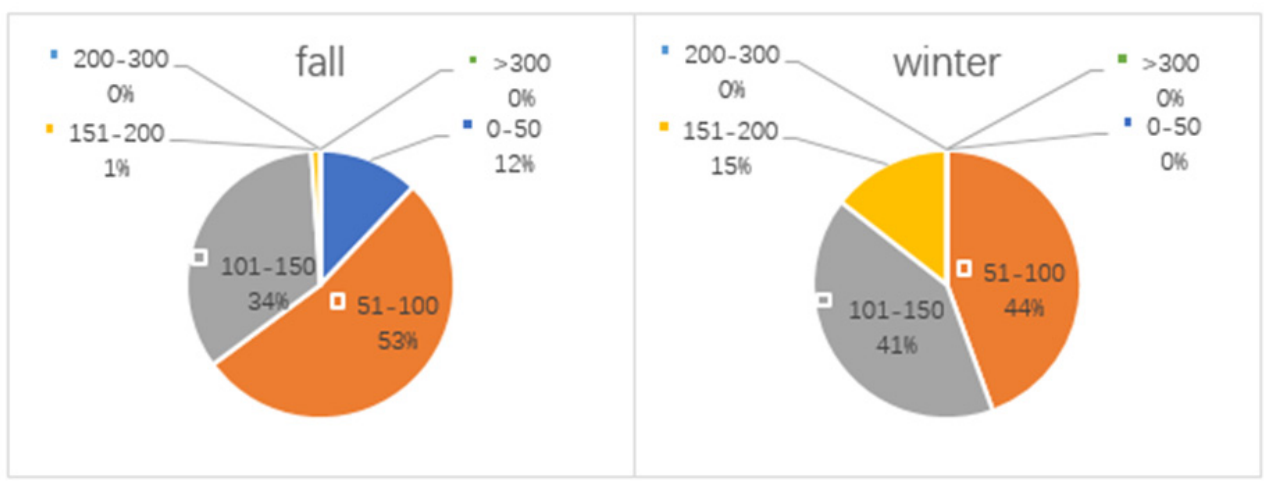

(C)

(D)

Fig. 5(c)-3. The fractions of the six AQI categories for Chiayi County in (A) Spring, (B) Summer, (C) Fall, and (D) Winter in 2017.

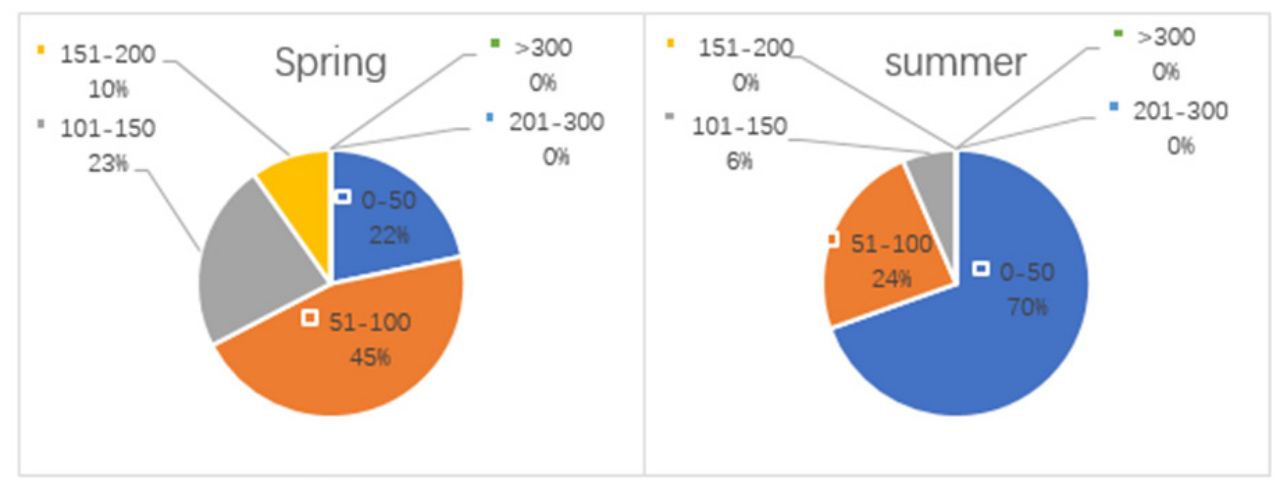

(A)

(B)

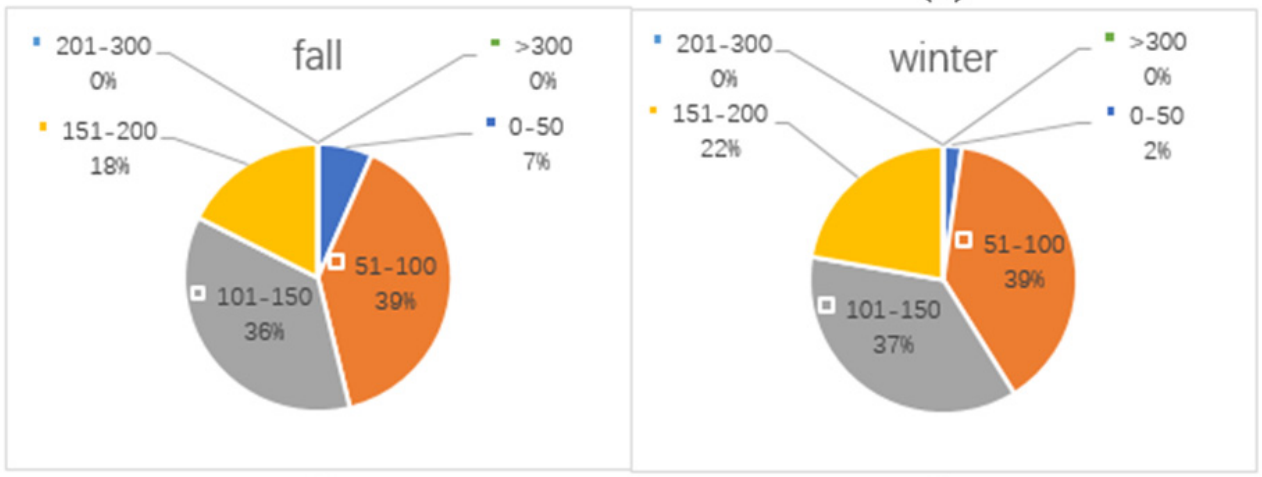

(C)

(D)

Fig. 5(d)-1. The fractions of the six AQI categories for Douliou City in (A) Spring, (B) Summer, (C) Fall, and (D) Winter in 2015 . 


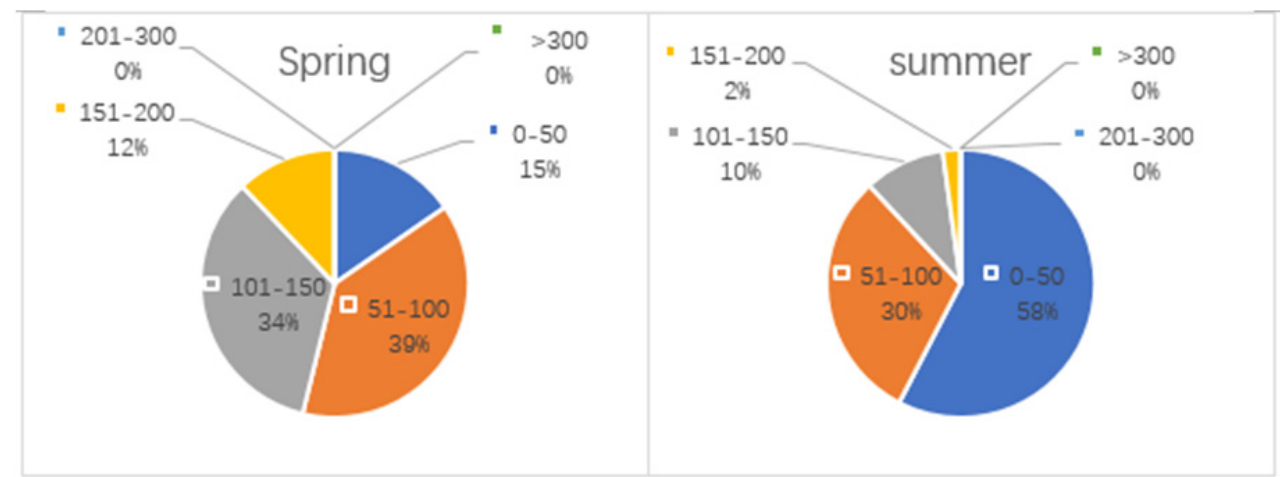

(A)

(B)

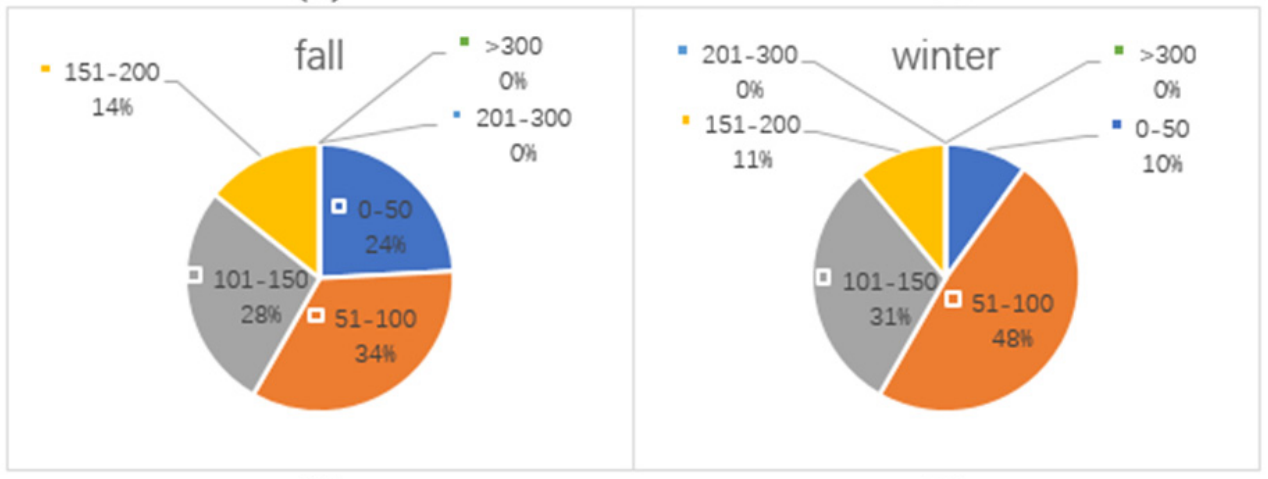

(C)

(D)

Fig. 5(d)-2. The fractions of the six AQI categories for Douliou City in (A) Spring, (B) Summer, (C) Fall, and (D) Winter in 2016.

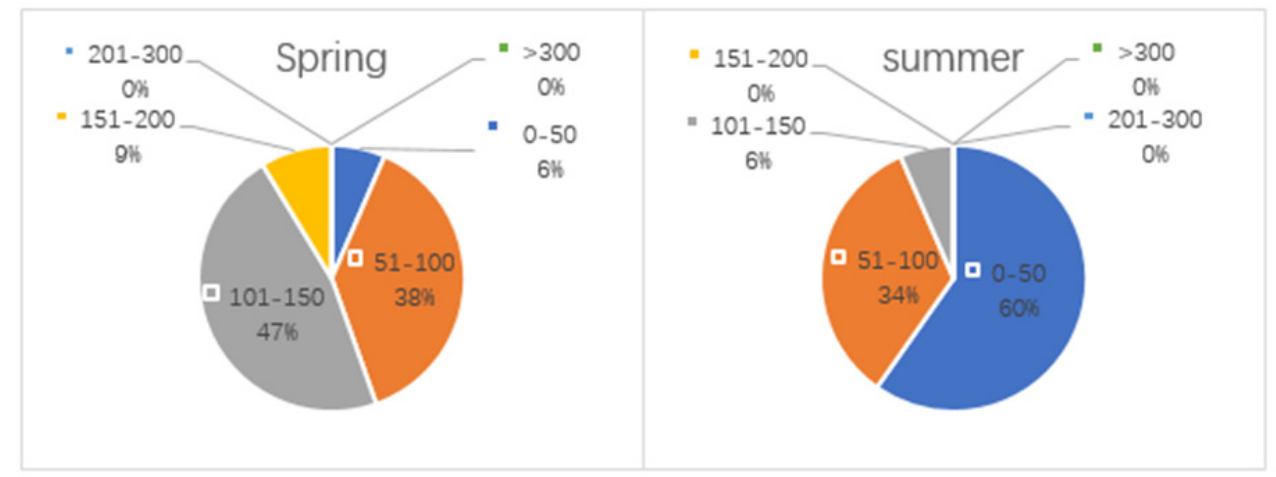

(A)

(B)

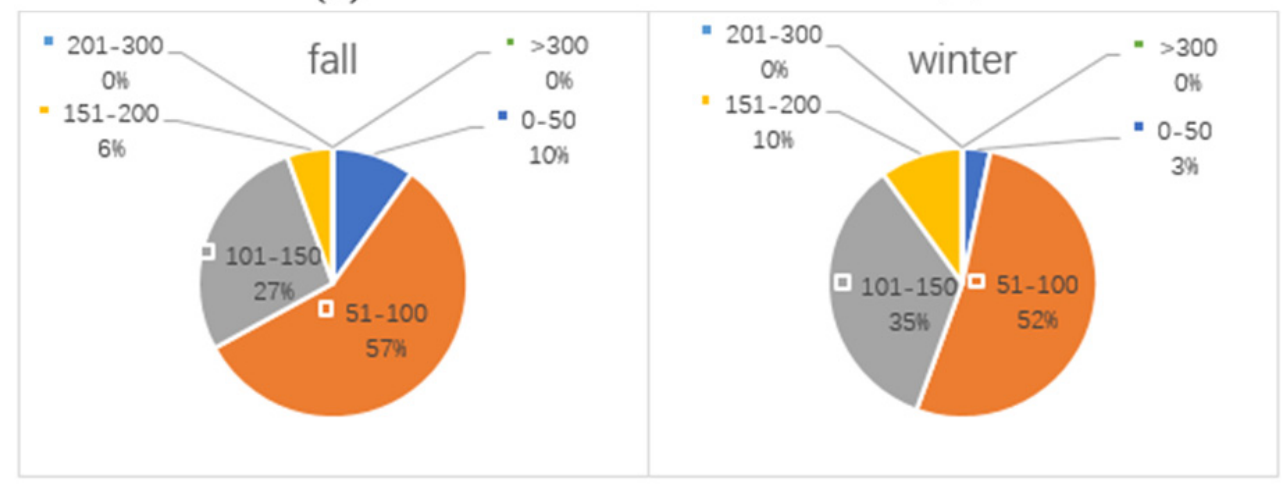

(C)

(D)

Fig. 5(d)-3. The fractions of the six AQI categories for Douliou City in (A) Spring, (B) Summer, (C) Fall, and (D) Winter in 2017. 


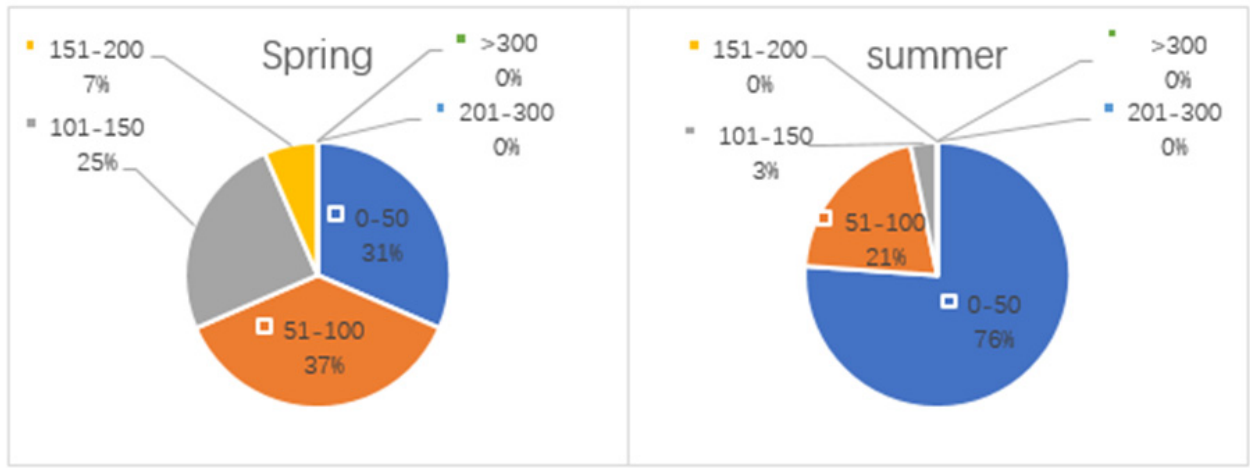

(A)

(B)

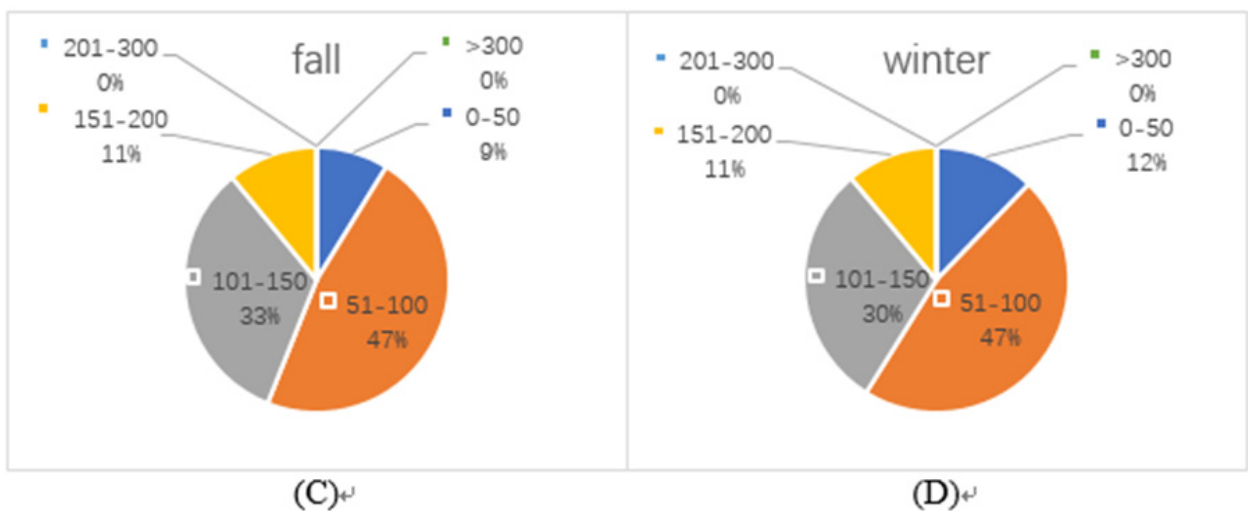

Fig. 5(e)-1. The fractions of the six AQI categories for Taisi Township in (A) Spring, (B) Summer, (C) Fall, and (D) Winter in 2015.

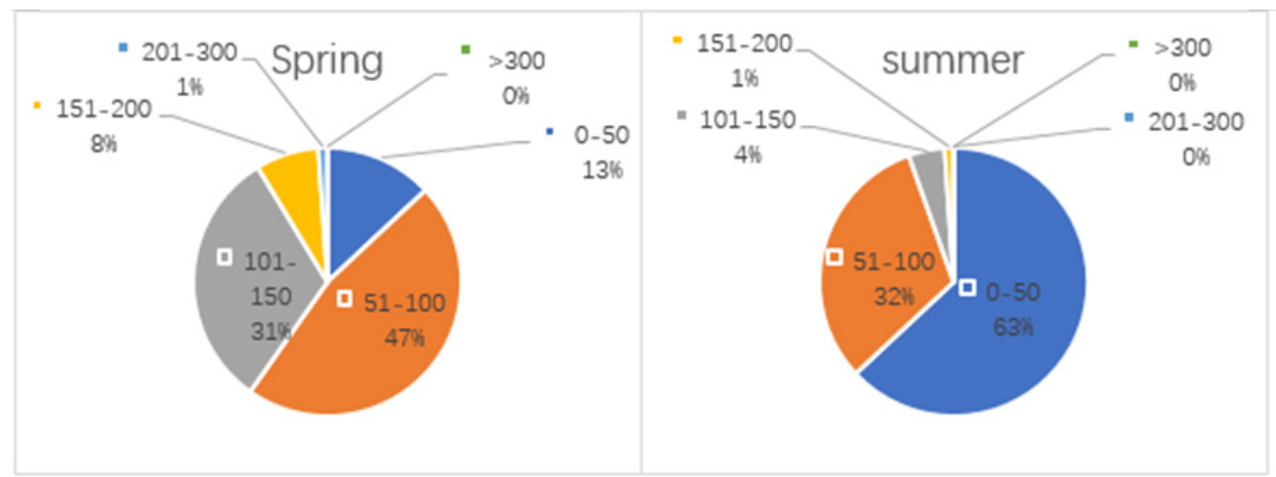

(A)

(B)

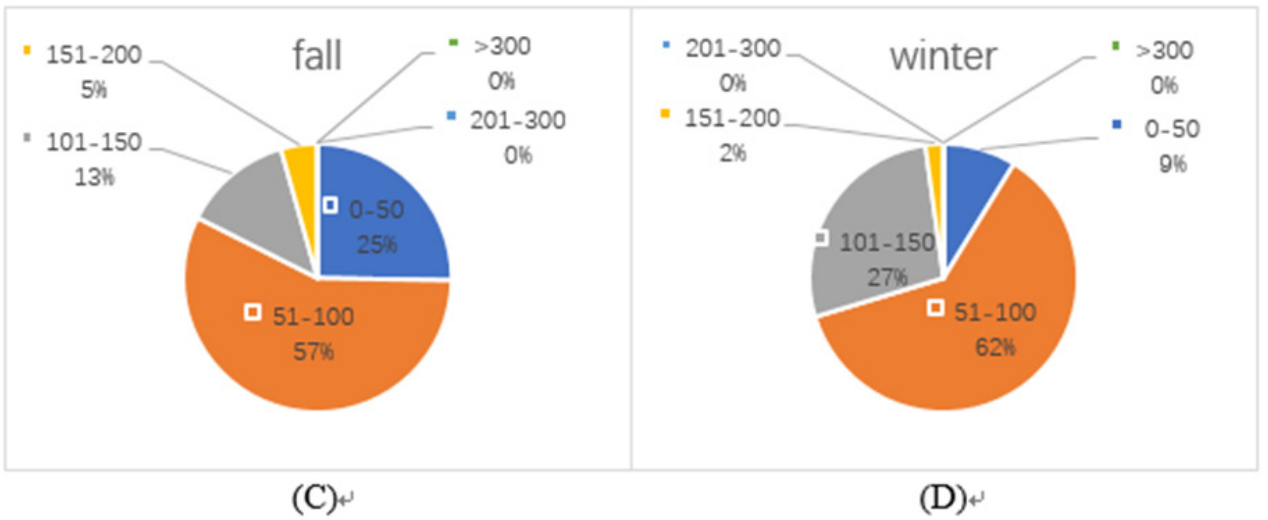

Fig. 5(e)-2. The fractions of the six AQI categories for Taisi Township in (A) Spring, (B) Summer, (C) Fall, and (D) Winter in 2016. 


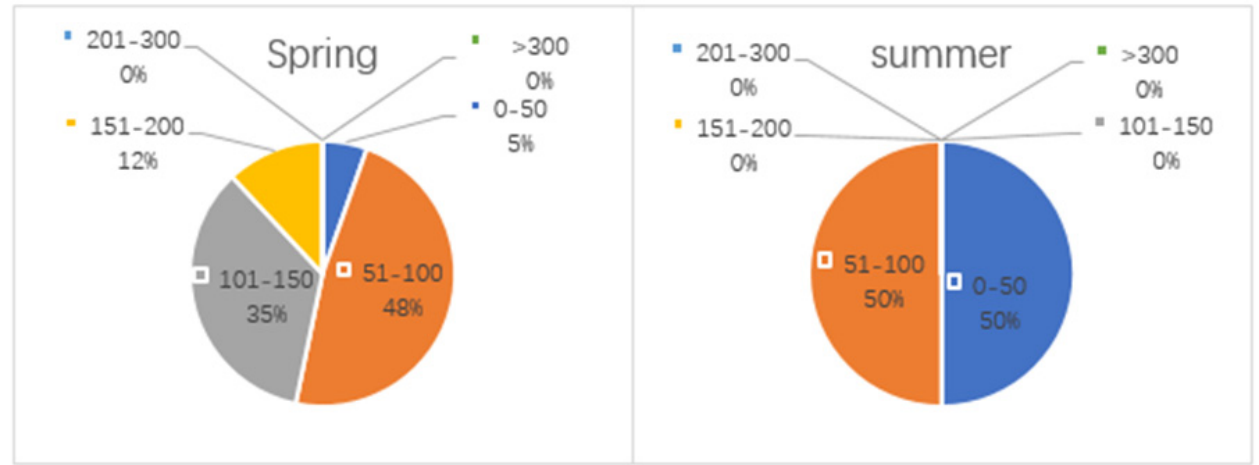

(A)

(B)

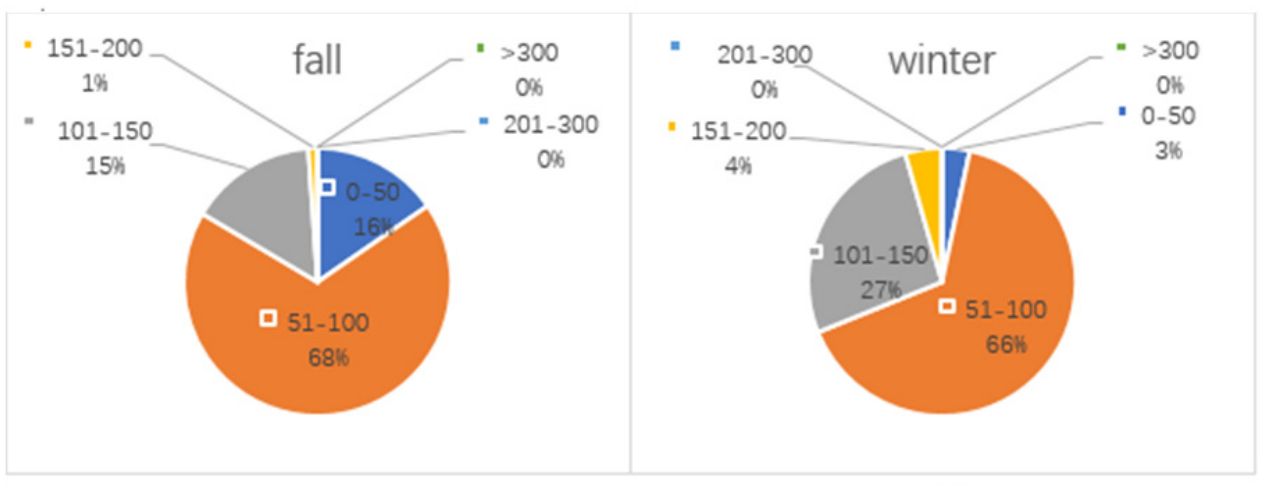

(C)

(D)

Fig. 5(e)-3. The fractions of the six AQI categories for Taisi Township in (A) Spring, (B) Summer, (C) Fall, and (D) Winter in 2017.

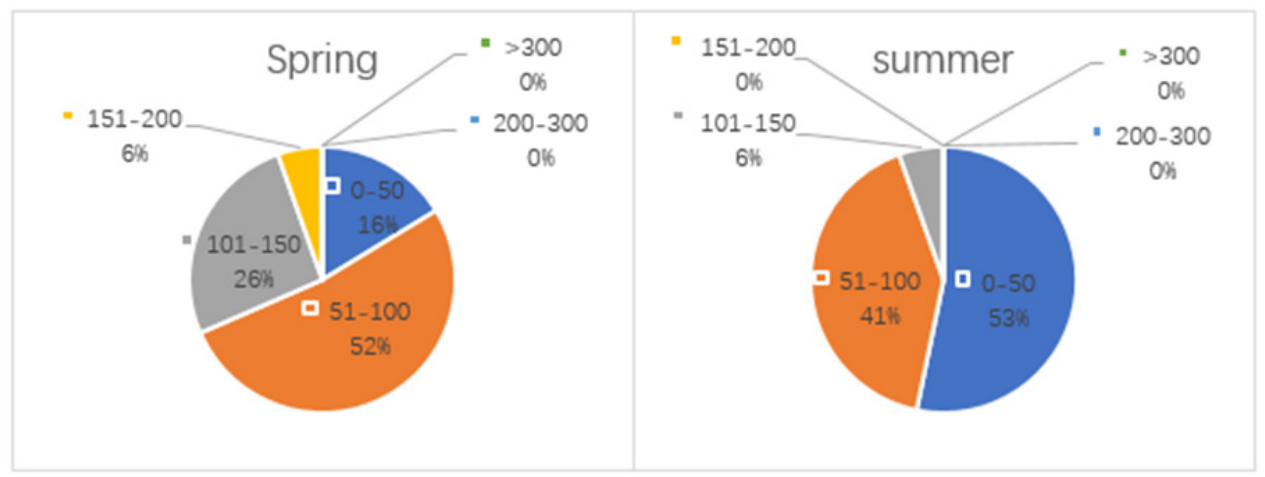

(A)

(B)

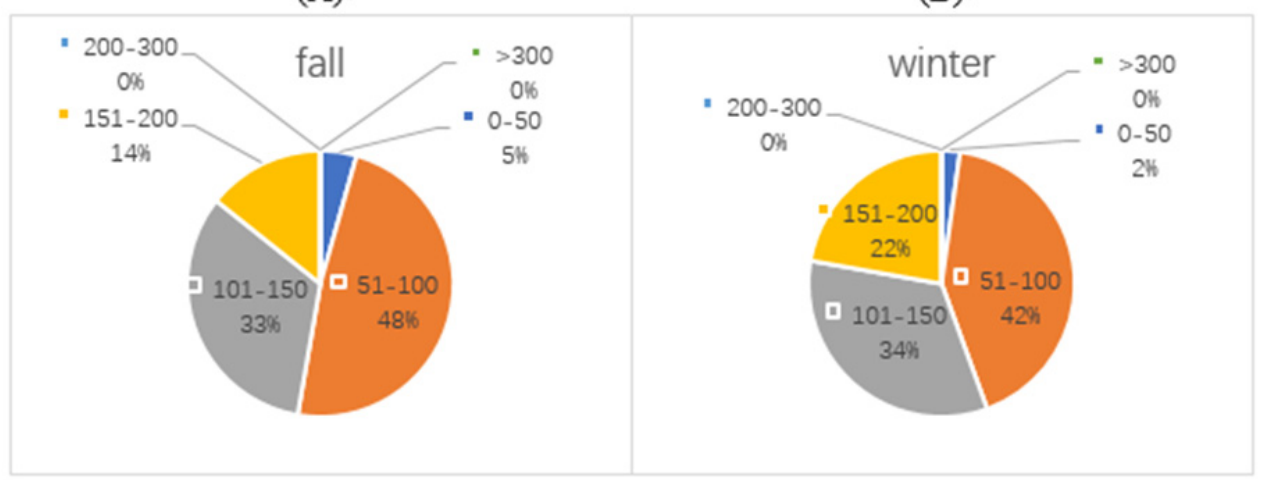

(C)

(D)

Fig. 5(f)-1. The fractions of the six AQI categories for Lunbei Township in (A) Spring, (B) Summer, (C) Fall, and (D) Winter in 2015. 


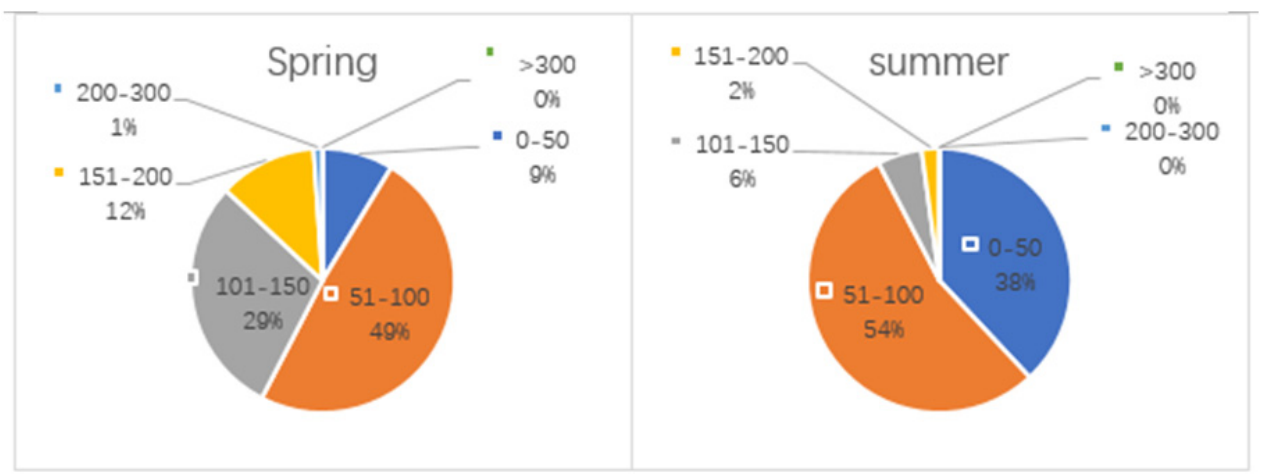

(A)

(B)

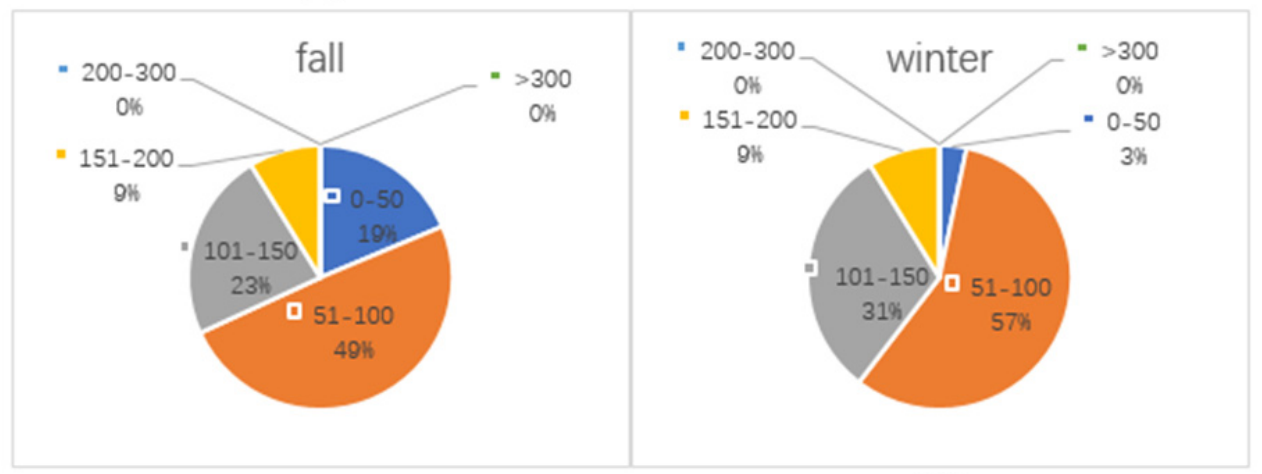

(C)

(D)

Fig. 5(f)-2. The fractions of the six AQI categories for Lunbei Township in (A) Spring, (B) Summer, (C) Fall, and (D) Winter in 2016.

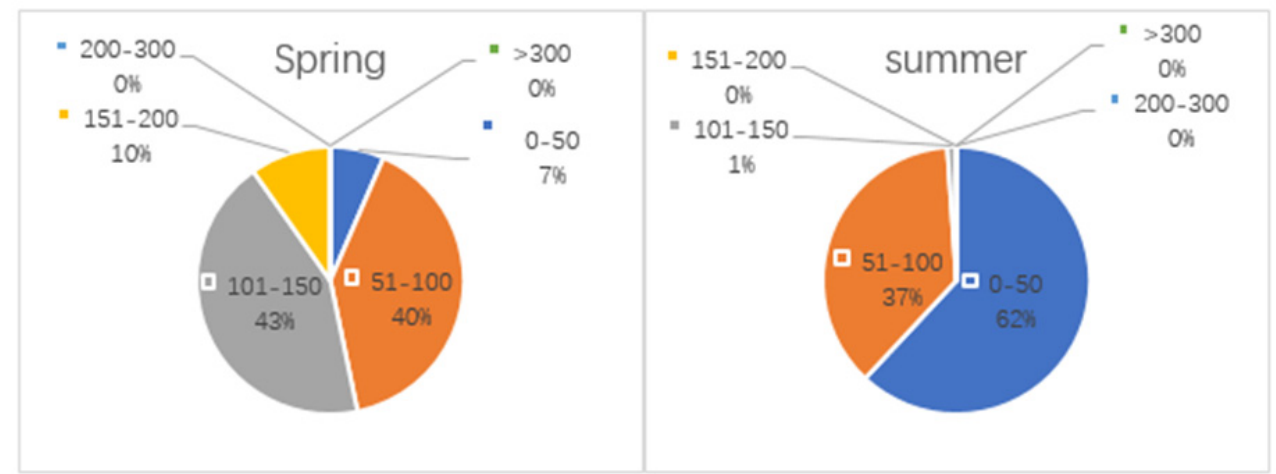

(A)

(B)

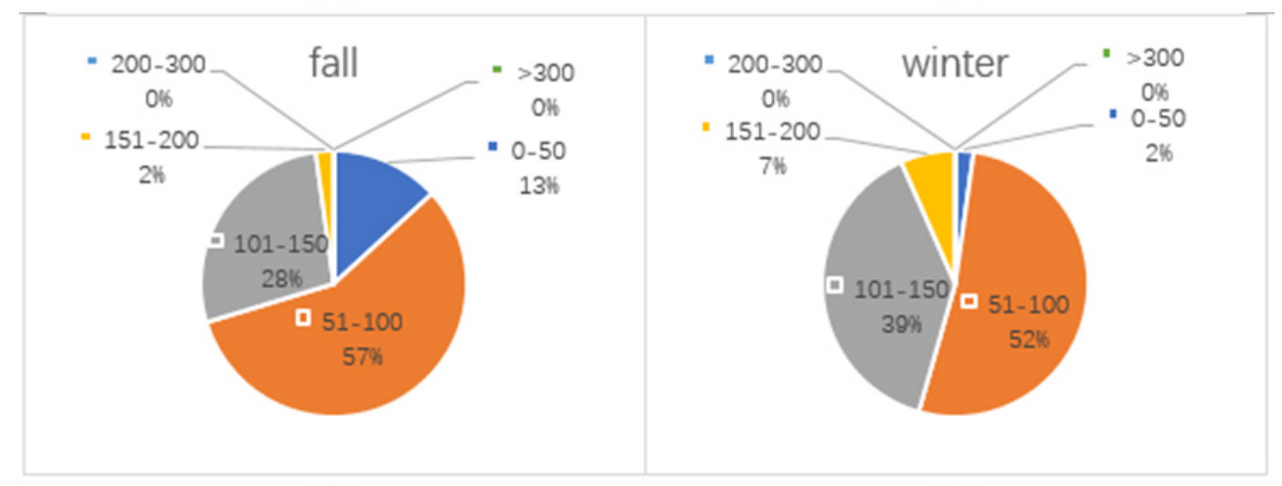

(C)

(D)

Fig. 5(f)-3. The fractions of the six AQI categories for Lunbei Township in (A) Spring, (B) Summer, (C) Fall, and (D) Winter in 2017. 


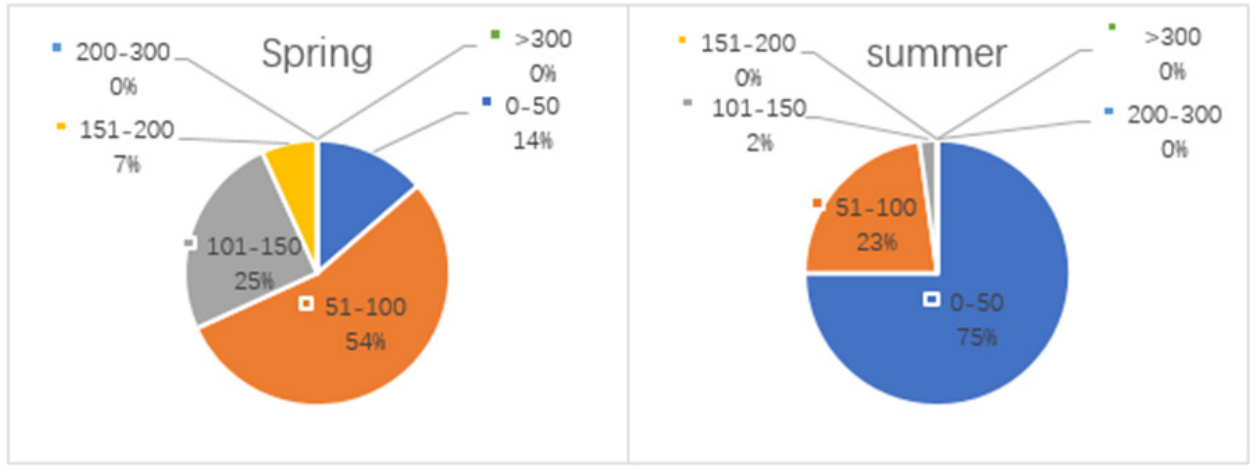

(A)

(B)

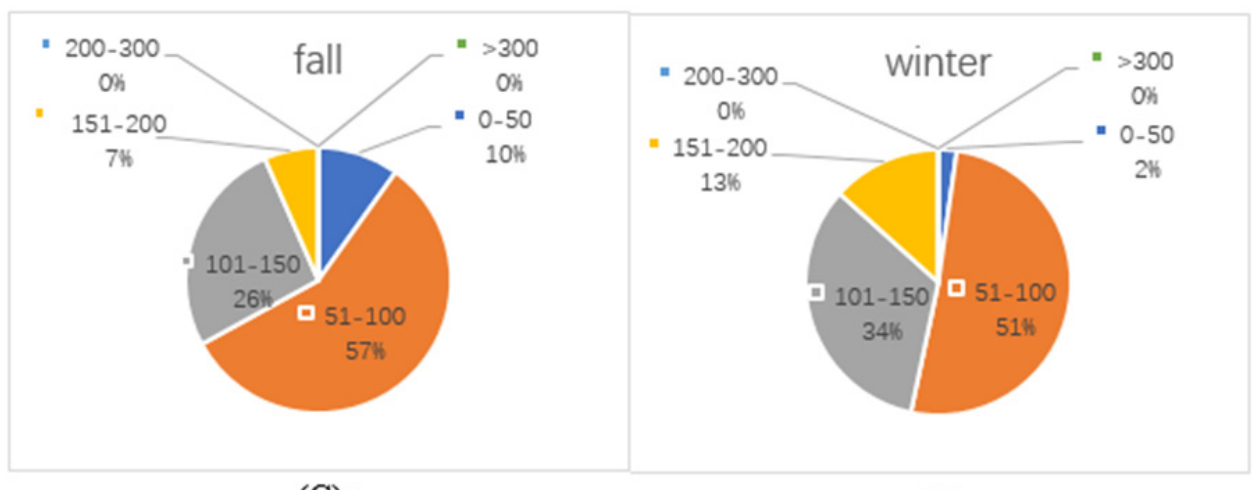

(C)

(D)

Fig. 5(g)-1. The fractions of the six AQI categories for Mailiao Township in (A) Spring, (B) Summer, (C) Fall, and (D) Winter in 2015 .

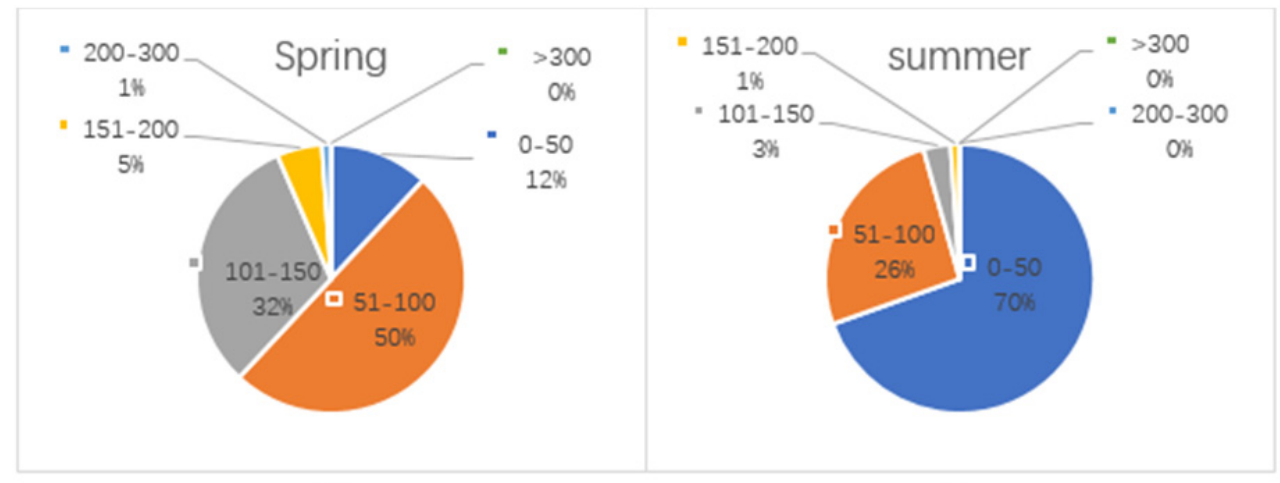

(A)

(B)

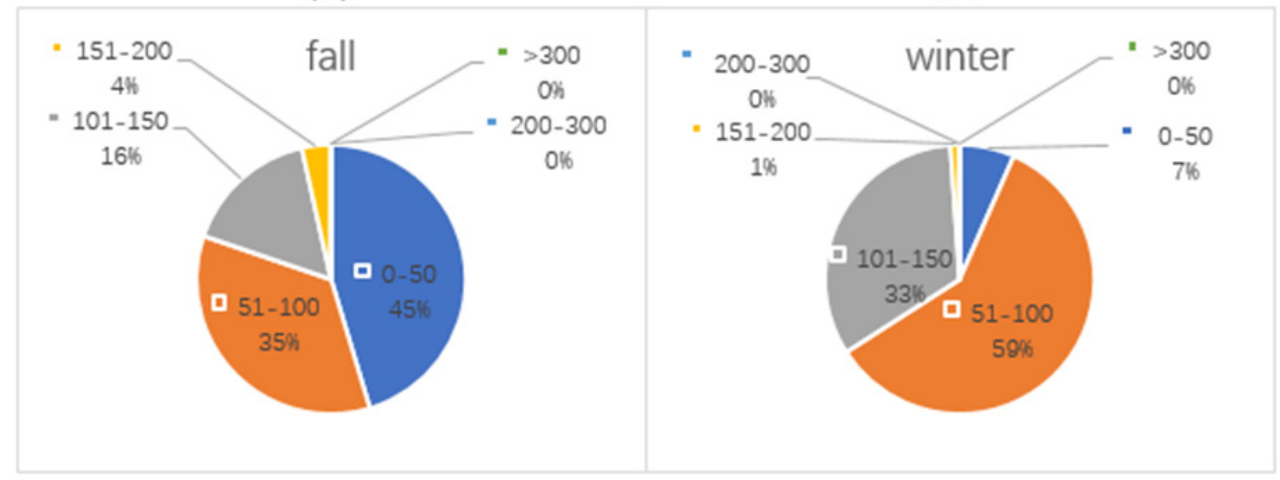

(C)

(D)

Fig. 5(g)-2. The fractions of the six AQI categories for Mailiao Township in (A) Spring, (B) Summer, (C) Fall, and (D) Winter in 2016. 


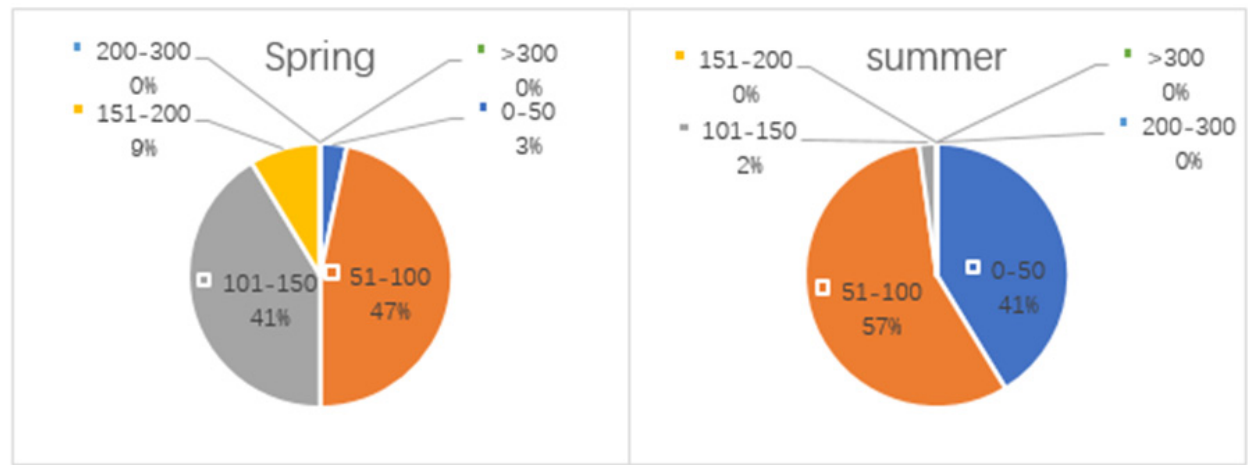

(A)

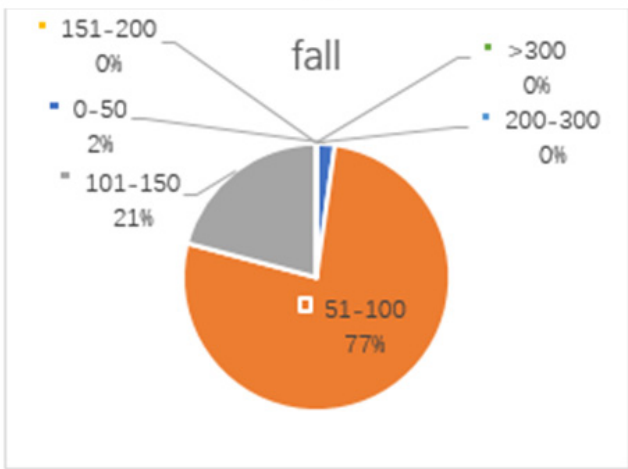

(C)
(B)

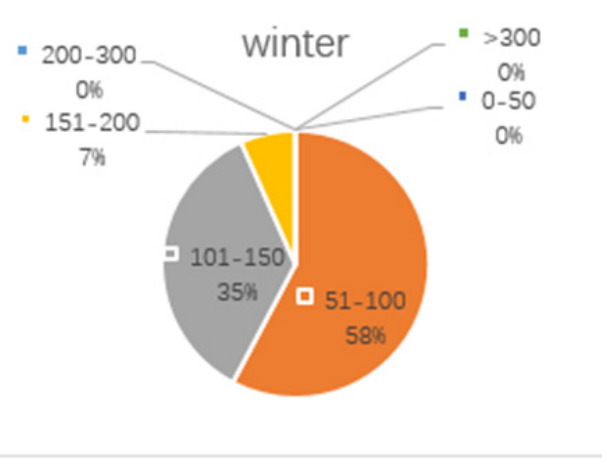

(D)

Fig. 5(g)-3. The fractions of the six AQI categories for Mailiao Township in (A) Spring, (B) Summer, (C) Fall, and (D) Winter in 2017.

Grade VI: 300-500. In terms of the seasonal proportions of different AQI classes, in the spring of 2015, the percentages of Grade I, II, III, IV, V, and VI levels ranged from 14\% (Mailiao Township)-31\% (Taisi Township), 37\% (Taisi Township)-57\% (Singang Township), 17\% (Singang Township)-26\% (Lunbei Township), 1\% (Puzih City)-10\% (Douliou City), 0\% and 0\%, respectively. In 2016, the Grade I, II, III, IV, V, and VI ranged from $9 \%$ (Lunbei Township)-26\% (Chiayi County), 30\% (Chiayi County)-50\% (Mailiao Township), 29\% (Lunbei Township)-35\% (Chiayi County), 5\% (Mailiao Township)-12\% (Douliou City and Lunbei Township), 0\%-1\% (Puzih City, Taisi Township and Mailiao Township) and $0 \%$, respectively. In 2017, the percentages of Grade I, II, III, IV, V, and VI ranged from 3\% (Mailiao Township)-27\% (Singang Township), 38\% (Douliou City)-51\% (Puzih City), 22\% (Singang Township)46\% (Chiayi County), 5\% (Chiayi County)-12\% (Taisi Township), 0\% and 0\%, respectively. From 2015-2017, the AQI Grade I classes showed a decreasing tendency, the Grade II had relatively large fractions, and the Grade IV rose slowly, while both Grade V and VI remained constant at $0 \%$ and $1 \%$. It can be seen that the air quality of these seven districts was evenly distributed in the Good (Grade I), Moderate (Grade II) and Unhealthy for Sensitive Groups (Grade III) categories; furthermore, the Moderate (Grade II) level comprised the highest proportion among the areas under consideration. The decline in the fraction of Grade I and the increasing fraction of Grade IV demonstrated that the air quality in these districts gradually deteriorated in spring. However, occurrences of Unhealthy (Grade V) and Hazardous (Grade VI) conditions were extremely rare.

In general, $\mathrm{PM}_{2.5}$ was the most frequent primary air pollutant during the three year study period, but the levels declined annually. This was followed by $\mathrm{O}_{3}$, where the days with this gaseous species as the primary air pollutant increased in various AQI classes. In 2016, Grade V levels, with $\mathrm{O}_{3}$ as the primary air pollutant, was observed in all seven areas, which means that the impact of $\mathrm{O}_{3}$ on spring pollution is increasing. Among the other four air pollutants, $\mathrm{PM}_{10}$ was an occasional primary pollutant, and none of the other pollutants were primary pollutants in spring in these regions.

In the summer of 2015, the percentages with Grade I, II, III, IV, V, and VI ranged from 53\% (Mailiao Township)76\% (Taisi Township), 21\% (Taisi Township)-41\% (Lunbei Township), 0\% (Puzih City)-6\% (Douliou City and Lunbei Township), $0 \%, 0 \%$ and $0 \%$, respectively. In 2016, the percentages with Grade I, II, III, IV, V, and VI ranged from 38\% (Lunbei Township)-70\% (Chiayi County), 25\% (Chiayi County)-54\% (Lunbei Township), 3\% (Singang Township and Mailiao Township)-10\% (Douliou City), 1\%-2\% (Singang Township, Douliou City and Lunbei Township), $0 \%$ and $0 \%$, respectively. And in 2017, the percentages with Grade I, II, III, IV, V, and VI ranged from $41 \%$ (Mailiao Township)-74\% (Puzih City), 25\% (Puzih City)57\% (Mailiao Township), 0\% (Chiayi County and Taisi Township) $-6 \%$ (Douliou City), $0 \%, 0 \%$ and $0 \%$, respectively. From 2015 to 2017, obviously, Grade I comprised the 
Table 3(a). Cumulative number of days of major pollutants for Puzih City from 2015-2017.

\begin{tabular}{|c|c|c|c|c|c|c|c|c|c|c|c|c|c|c|c|c|c|}
\hline \multirow{2}{*}{ Year } & \multirow{2}{*}{$\begin{array}{l}\text { AQI } \\
\text { Class }\end{array}$} & \multicolumn{4}{|c|}{ Spring } & \multicolumn{4}{|c|}{ Summer } & \multicolumn{4}{|c|}{ Fall } & \multicolumn{4}{|c|}{ Winter } \\
\hline & & $\mathrm{PM}_{2.5}$ & $\mathrm{PM}_{10}$ & $\mathrm{SO}_{2}$ & $\mathrm{O}_{3}$ & $\mathrm{PM}_{2.5}$ & $\mathrm{PM}_{10}$ & $\mathrm{SO}_{2}$ & $\mathrm{O}_{3}$ & $\mathrm{PM}_{2.5}$ & $\mathrm{PM}_{10}$ & $\mathrm{SO}_{2}$ & $\mathrm{O}_{3}$ & $\mathrm{PM}_{2.5}$ & $\mathrm{PM}_{10}$ & $\mathrm{SO}_{2}$ & $\mathrm{O}_{3}$ \\
\hline \multirow[t]{5}{*}{2015} & $51-100$ & 41 & 8 & 0 & 1 & 13 & 6 & 0 & 4 & 23 & 5 & 0 & 13 & 36 & 10 & 0 & 1 \\
\hline & $101-150$ & 15 & 0 & 0 & 1 & 0 & 0 & 0 & 0 & 15 & 1 & 0 & 16 & 28 & 0 & 0 & 1 \\
\hline & $151-200$ & 1 & 0 & 0 & 0 & 0 & 0 & 0 & 0 & 3 & 0 & 0 & 5 & 12 & 0 & 0 & 0 \\
\hline & 201-300 & 0 & 0 & 0 & 0 & 0 & 0 & 0 & 0 & 0 & 0 & 0 & 0 & 0 & 0 & 0 & 0 \\
\hline & $>300$ & 0 & 0 & 0 & 0 & 0 & 0 & 0 & 0 & 0 & 0 & 0 & 0 & 0 & 0 & 0 & 0 \\
\hline \multirow[t]{5}{*}{2016} & $51-100$ & 35 & 0 & 0 & 4 & 26 & 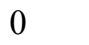 & 0 & 5 & 35 & 4 & 0 & 9 & 49 & 4 & 0 & 0 \\
\hline & 101-150 & 25 & 0 & 0 & 5 & 1 & 0 & 0 & 4 & 6 & 0 & 0 & 8 & 20 & 1 & 0 & 1 \\
\hline & 151-200 & 9 & 0 & 0 & 0 & 0 & 0 & 0 & 1 & 5 & 0 & 0 & 4 & 7 & 0 & 0 & 0 \\
\hline & 201-300 & 0 & 0 & 0 & 1 & 0 & 0 & 0 & 0 & 0 & 0 & 0 & 0 & 0 & 0 & 0 & 0 \\
\hline & $>300$ & 0 & 0 & 0 & 0 & 0 & 0 & 0 & 0 & 0 & 0 & 0 & 0 & 0 & 0 & 0 & 0 \\
\hline \multirow{5}{*}{2017} & $51-100$ & 27 & 3 & 0 & 17 & 16 & 1 & 0 & 6 & 12 & 15 & 0 & 18 & 35 & 24 & 0 & 1 \\
\hline & $101-150$ & 13 & 0 & 0 & 19 & 0 & O & 0 & 1 & 6 & 2 & 0 & 6 & 21 & 3 & 0 & 0 \\
\hline & $151-200$ & 1 & 0 & 0 & 7 & 0 & 0 & 0 & 0 & 0 & 0 & 0 & 1 & 1 & 0 & 0 & 0 \\
\hline & 201-300 & 0 & 0 & 0 & 0 & 0 & 0 & 0 & 0 & 0 & 0 & 0 & 0 & 0 & 0 & 0 & 0 \\
\hline & $>300$ & 0 & 0 & 0 & 0 & 0 & 0 & 0 & 0 & 0 & 0 & 0 & 0 & 0 & 0 & 0 & 0 \\
\hline
\end{tabular}

Table 3(b). Cumulative number of days of major pollutants for Singang Township from 2015-2017.

\begin{tabular}{|c|c|c|c|c|c|c|c|c|c|c|c|c|c|c|c|c|c|}
\hline \multirow{2}{*}{ Year } & \multirow{2}{*}{$\begin{array}{l}\text { AQI } \\
\text { Class }\end{array}$} & \multicolumn{4}{|c|}{ Spring } & \multicolumn{4}{|c|}{ Summer } & \multicolumn{4}{|c|}{ Fall } & \multicolumn{4}{|c|}{ Winter } \\
\hline & & $\mathrm{PM}_{2.5}$ & $\mathrm{PM}_{10}$ & $\mathrm{SO}_{2}$ & $\overline{\mathrm{O}_{3}}$ & $\mathrm{PM}_{2.5}$ & $\mathrm{PM}_{10}$ & $\mathrm{SO}_{2}$ & $\overline{\mathrm{O}_{3}}$ & $\mathrm{PM}_{2.5}$ & $\mathrm{PM}_{10}$ & $\mathrm{SO}_{2}$ & $\overline{\mathrm{O}_{3}}$ & $\mathrm{PM}_{2.5}$ & $\mathrm{PM}_{10}$ & $\mathrm{SO}_{2}$ & $\overline{\mathrm{O}_{3}}$ \\
\hline \multirow[t]{5}{*}{2015} & 51-100 & 43 & 1 & 0 & 8 & 17 & 1 & 0 & 5 & 30 & 2 & 0 & 14 & 45 & 0 & 0 & 1 \\
\hline & $101-150$ & 10 & 0 & 0 & 6 & 0 & 0 & 0 & 1 & 12 & 0 & 0 & 13 & 29 & 0 & 0 & 0 \\
\hline & $151-200$ & 0 & 0 & 0 & 0 & 0 & 0 & 0 & 0 & 2 & 0 & 0 & 5 & 12 & 0 & 0 & 0 \\
\hline & $201-300$ & 0 & 0 & 0 & 0 & 0 & 0 & 0 & 0 & 0 & 0 & 0 & 0 & 0 & 0 & 0 & 0 \\
\hline & $>300$ & 0 & 0 & 0 & 0 & 0 & 0 & 0 & 0 & 0 & 0 & 0 & 0 & 0 & 0 & 0 & 0 \\
\hline \multirow[t]{5}{*}{2016} & $51-100$ & 40 & 0 & 0 & 5 & 18 & 0 & 0 & 7 & 27 & 1 & 0 & 8 & 49 & 1 & 0 & 0 \\
\hline & $101-150$ & 24 & 0 & 0 & 5 & 2 & 0 & 0 & 1 & 13 & 0 & 0 & 7 & 25 & 0 & 0 & 1 \\
\hline & $151-200$ & 6 & 0 & 0 & 1 & 0 & 0 & 0 & 2 & 6 & 0 & 0 & 2 & 5 & 0 & 0 & 0 \\
\hline & 201-300 & 0 & 0 & 0 & 0 & 0 & 0 & 0 & 0 & 0 & 0 & 0 & 0 & 0 & 0 & 0 & 0 \\
\hline & $>300$ & 0 & 0 & 0 & 0 & 0 & 0 & 0 & 0 & 0 & 0 & 0 & 0 & 0 & 0 & 0 & 0 \\
\hline \multirow[t]{5}{*}{2017} & $51-100$ & 27 & 1 & 0 & 6 & 21 & 1 & 0 & 6 & 34 & 5 & 0 & 12 & 42 & 5 & 0 & 0 \\
\hline & 101-150 & 24 & 0 & 0 & 12 & 0 & 0 & 0 & 1 & 3 & 0 & 0 & 15 & 32 & 1 & 0 & 0 \\
\hline & $151-200$ & 3 & 0 & 0 & 5 & 0 & 0 & 0 & 0 & 1 & 0 & 0 & 1 & 3 & 0 & 0 & 0 \\
\hline & $201-300$ & 0 & 0 & 0 & 0 & 0 & 0 & 0 & 0 & 0 & 0 & 0 & 0 & 0 & 0 & 0 & 0 \\
\hline & $>300$ & 0 & 0 & 0 & 0 & 0 & 0 & 0 & 0 & 0 & 0 & 0 & 0 & 0 & 0 & 0 & 0 \\
\hline
\end{tabular}

Table 3(c). Cumulative number of days of major pollutants for Chiayi County from 2015-2017.

\begin{tabular}{|c|c|c|c|c|c|c|c|c|c|c|c|c|c|c|c|c|c|}
\hline \multirow{2}{*}{ Year } & \multirow{2}{*}{$\begin{array}{l}\text { AQI } \\
\text { Class } \\
\end{array}$} & \multicolumn{4}{|c|}{ Spring } & \multicolumn{4}{|c|}{ Summer } & \multicolumn{4}{|c|}{ Fall } & \multicolumn{4}{|c|}{ Winter } \\
\hline & & $\mathrm{PM}_{2.5}$ & $\mathrm{PM}_{10}$ & $\mathrm{SO}_{2}$ & $\mathrm{O}_{3}$ & $\mathrm{PM}_{2.5}$ & $\mathrm{PM}_{10}$ & $\mathrm{SO}_{2}$ & $\mathrm{O}_{3}$ & $\mathrm{PM}_{2.5}$ & $\mathrm{PM}_{10}$ & $\mathrm{SO}_{2}$ & $\mathrm{O}_{3}$ & $\mathrm{PM}_{2.5}$ & $\mathrm{PM}_{10}$ & $\mathrm{SO}_{2}$ & $\mathrm{O}_{3}$ \\
\hline \multirow[t]{5}{*}{2015} & 51-100 & 38 & 0 & 0 & 3 & 18 & 1 & 0 & 8 & 26 & 1 & 0 & 9 & 30 & 4 & 0 & 0 \\
\hline & $101-150$ & 16 & 0 & 0 & 5 & 1 & 0 & 0 & 1 & 8 & 0 & 0 & 22 & 36 & 0 & 0 & 0 \\
\hline & $151-200$ & 3 & 0 & 0 & 0 & 0 & 0 & 0 & 0 & 4 & 0 & 0 & 7 & 17 & 0 & 0 & 0 \\
\hline & $201-300$ & 0 & 0 & 0 & 0 & 0 & 0 & 0 & 0 & 0 & 0 & 0 & 0 & 0 & 0 & 0 & 0 \\
\hline & $>300$ & 0 & 0 & 0 & 0 & 0 & 0 & 0 & 0 & 0 & 0 & 0 & 0 & 0 & 0 & 0 & 0 \\
\hline \multirow[t]{5}{*}{2016} & $51-100$ & 24 & 0 & 0 & 4 & 14 & 0 & 0 & 9 & 30 & 0 & 0 & 5 & 43 & 2 & 0 & 2 \\
\hline & $101-150$ & 26 & 0 & 0 & 6 & 3 & 0 & 0 & 5 & 11 & 0 & 0 & 10 & 18 & 0 & 0 & 0 \\
\hline & $151-200$ & 7 & 0 & 0 & 1 & 0 & 0 & 0 & 1 & 9 & 0 & 0 & 2 & 9 & 0 & 0 & 0 \\
\hline & $201-300$ & 0 & 0 & 0 & 0 & 0 & 0 & 0 & 0 & 0 & 0 & 0 & 0 & 0 & 0 & 0 & 0 \\
\hline & $>300$ & 0 & 0 & 0 & 0 & 0 & 0 & 0 & 0 & 0 & 0 & 0 & 0 & 0 & 0 & 0 & 0 \\
\hline \multirow[t]{5}{*}{2017} & $51-100$ & 32 & 0 & 0 & 4 & 16 & 0 & 0 & 12 & 36 & 1 & 0 & 11 & 39 & 1 & 0 & 0 \\
\hline & $101-150$ & 32 & 0 & 0 & 10 & 0 & 0 & 0 & 0 & 15 & 0 & 0 & 16 & 37 & 0 & 0 & 0 \\
\hline & $151-200$ & 3 & 0 & 0 & 2 & 0 & 0 & 0 & 0 & 0 & 0 & 0 & 1 & 23 & 0 & 0 & 0 \\
\hline & $201-300$ & 0 & 0 & 0 & 0 & 0 & 0 & 0 & 0 & 0 & 0 & 0 & 0 & 0 & 0 & 0 & 0 \\
\hline & $>300$ & 0 & 0 & 0 & 0 & 0 & 0 & 0 & 0 & 0 & 0 & 0 & 0 & 0 & 0 & 0 & 0 \\
\hline
\end{tabular}


Table 3(d). Cumulative number of days of major pollutants for Douliou City from 2015-2017.

\begin{tabular}{|c|c|c|c|c|c|c|c|c|c|c|c|c|c|c|c|c|c|}
\hline \multirow{2}{*}{ Year } & \multirow{2}{*}{$\begin{array}{l}\text { AQI } \\
\text { Class } \\
\end{array}$} & \multicolumn{4}{|c|}{ Spring } & \multicolumn{4}{|c|}{ Summer } & \multicolumn{4}{|c|}{ Fall } & \multicolumn{4}{|c|}{ Winter } \\
\hline & & $\mathrm{PM}_{2.5}$ & $\mathrm{PM}_{10}$ & $\mathrm{SO}_{2}$ & $\overline{\mathrm{O}_{3}}$ & $\mathrm{PM}_{2.5}$ & $\mathrm{PM}_{10}$ & $\mathrm{SO}_{2}$ & $\overline{\mathrm{O}_{3}}$ & $\mathrm{PM}_{2.5}$ & $\mathrm{PM}_{10}$ & $\mathrm{SO}_{2}$ & $\mathrm{O}_{3}$ & $\mathrm{PM}_{2.5}$ & $\mathrm{PM}_{10}$ & $\mathrm{SO}_{2}$ & $\mathrm{O}_{3}$ \\
\hline \multirow[t]{5}{*}{2015} & $51-100$ & 35 & 0 & 0 & 7 & 13 & 0 & 0 & 9 & 24 & 3 & 0 & 8 & 20 & 6 & 0 & 0 \\
\hline & $101-150$ & 14 & 0 & 0 & 7 & 4 & 0 & 0 & 2 & 18 & 0 & 0 & 15 & 33 & 0 & 0 & 0 \\
\hline & $151-200$ & 9 & 0 & 0 & 0 & 0 & 0 & 0 & 0 & 11 & 0 & 0 & 6 & 20 & 0 & 0 & 0 \\
\hline & $201-300$ & 0 & 0 & 0 & 0 & 0 & 0 & 0 & 0 & 0 & 0 & 0 & 0 & 0 & 0 & 0 & 0 \\
\hline & $>300$ & 0 & 0 & 0 & 0 & 0 & 0 & 0 & 0 & 0 & 0 & 0 & 0 & 0 & 0 & 0 & 0 \\
\hline \multirow[t]{5}{*}{2016} & $51-100$ & 32 & 0 & 0 & 3 & 16 & 0 & 0 & 12 & 18 & 1 & 0 & 12 & 40 & 0 & 0 & 4 \\
\hline & $101-150$ & 18 & 0 & 0 & 13 & 2 & 0 & 0 & 7 & 15 & 0 & 0 & 10 & 27 & 0 & 0 & 1 \\
\hline & $151-200$ & 10 & 0 & 0 & 1 & 0 & 0 & 0 & 2 & 8 & 0 & 0 & 5 & 10 & 0 & 0 & 0 \\
\hline & $201-300$ & 0 & 0 & 0 & 1 & 0 & 0 & 0 & 0 & 0 & 0 & 0 & 0 & 0 & 0 & 0 & 0 \\
\hline & $>300$ & 0 & 0 & 0 & 0 & 0 & 0 & 0 & 0 & 0 & 0 & 0 & 0 & 0 & 0 & 0 & 0 \\
\hline \multirow[t]{5}{*}{2017} & $51-100$ & 27 & 0 & 0 & 8 & 20 & 0 & 0 & 11 & 30 & 0 & 0 & 22 & 45 & 1 & 0 & 1 \\
\hline & $101-150$ & 24 & 0 & 0 & 19 & 0 & 0 & 0 & 6 & 6 & 0 & 0 & 19 & 31 & 0 & 0 & 0 \\
\hline & $151-200$ & 3 & 0 & 0 & 5 & 0 & 0 & 0 & 0 & 1 & 0 & 0 & 4 & 9 & 0 & 0 & 0 \\
\hline & $201-300$ & 0 & 0 & 0 & 0 & 0 & 0 & 0 & 0 & 0 & 0 & 0 & 0 & 0 & 0 & 0 & 0 \\
\hline & $>300$ & 0 & 0 & 0 & 0 & 0 & 0 & 0 & 0 & 0 & 0 & 0 & 0 & 0 & 0 & 0 & 0 \\
\hline
\end{tabular}

Table 3(e). Cumulative number of days of major pollutants for Taisi Township from 2015-2017.

\begin{tabular}{|c|c|c|c|c|c|c|c|c|c|c|c|c|c|c|c|c|c|}
\hline \multirow{2}{*}{ Year } & \multirow{2}{*}{$\begin{array}{l}\text { AQI } \\
\text { Class }\end{array}$} & \multicolumn{4}{|c|}{ Spring } & \multicolumn{4}{|c|}{ Summer } & \multicolumn{4}{|c|}{ Fall } & \multicolumn{4}{|c|}{ Winter } \\
\hline & & $\mathrm{PM}_{2.5}$ & $\mathrm{PM}_{10}$ & $\mathrm{SO}_{2}$ & $\overline{\mathrm{O}_{3}}$ & $\mathrm{PM}_{2.5}$ & $\mathrm{PM}_{10}$ & $\mathrm{SO}_{2}$ & $\overline{\mathrm{O}_{3}}$ & $\mathrm{PM}_{2.5}$ & $\mathrm{PM}_{10}$ & $\mathrm{SO}_{2}$ & $\overline{\mathrm{O}_{3}}$ & $\mathrm{PM}_{2.5}$ & $\mathrm{PM}_{10}$ & $\mathrm{SO}_{2}$ & $\overline{\mathrm{O}_{3}}$ \\
\hline \multirow[t]{5}{*}{2015} & $51-100$ & 23 & 1 & 0 & 10 & 15 & 1 & 1 & 2 & 28 & 0 & 1 & 14 & 39 & 1 & 0 & 2 \\
\hline & $101-150$ & 15 & 0 & 0 & 8 & 1 & 0 & 0 & 2 & 14 & 1 & 0 & 15 & 25 & 1 & 0 & 1 \\
\hline & $151-200$ & 3 & 0 & 0 & 3 & 0 & 0 & 0 & 0 & 5 & 0 & 0 & 5 & 10 & 0 & 0 & 0 \\
\hline & $201-300$ & 0 & 0 & 0 & 0 & 0 & 0 & 0 & 0 & 0 & 0 & 0 & 0 & 0 & 0 & 0 & 0 \\
\hline & $>300$ & 0 & 0 & 0 & 0 & 0 & 0 & 0 & 0 & 0 & 0 & 0 & 0 & 0 & 0 & 0 & 0 \\
\hline \multirow[t]{5}{*}{2016} & $51-100$ & 38 & 0 & 0 & 5 & 25 & 0 & 0 & 4 & 46 & 3 & 0 & 3 & 54 & 0 & 0 & 2 \\
\hline & $101-150$ & 22 & 0 & 0 & 7 & 2 & 0 & 0 & 2 & 7 & 0 & 0 & 5 & 25 & 0 & 0 & 0 \\
\hline & $151-200$ & 4 & 0 & 0 & 3 & 0 & 0 & 0 & 1 & 4 & 0 & 0 & 0 & 2 & 0 & 0 & 0 \\
\hline & $201-300$ & 0 & 0 & 0 & 1 & 0 & 0 & 0 & 0 & 0 & 0 & 0 & 0 & 0 & 0 & 0 & 0 \\
\hline & $>300$ & 0 & 0 & 0 & 0 & 0 & 0 & 0 & 0 & 0 & 0 & 0 & 0 & 0 & 0 & 0 & 0 \\
\hline \multirow[t]{5}{*}{2017} & $51-100$ & 32 & 0 & 0 & 12 & 43 & 0 & 0 & 2 & 49 & 4 & 0 & 9 & 55 & 3 & 0 & 1 \\
\hline & $101-150$ & 22 & 0 & 0 & 10 & 0 & 0 & 0 & 0 & 9 & 2 & 0 & 3 & 23 & 0 & 0 & 1 \\
\hline & $151-200$ & 6 & 0 & 0 & 5 & 0 & 0 & 0 & 0 & 0 & 0 & 0 & 1 & 4 & 0 & 0 & 0 \\
\hline & $201-300$ & 0 & 0 & 0 & 0 & 0 & 0 & 0 & 0 & 0 & 0 & 0 & 0 & 0 & 0 & 0 & 0 \\
\hline & $>300$ & 0 & 0 & 0 & 0 & 0 & 0 & 0 & 0 & 0 & 0 & 0 & 0 & 0 & 0 & 0 & 0 \\
\hline
\end{tabular}

Table 3(f). Cumulative number of days of major pollutants for Lunbei Township from 2015-2017.

\begin{tabular}{|c|c|c|c|c|c|c|c|c|c|c|c|c|c|c|c|c|c|}
\hline \multirow{2}{*}{ Year } & \multirow{2}{*}{$\begin{array}{l}\text { AQI } \\
\text { Class }\end{array}$} & \multicolumn{4}{|c|}{ Spring } & \multicolumn{4}{|c|}{ Summer } & \multicolumn{4}{|c|}{ Fall } & \multicolumn{4}{|c|}{ Winter } \\
\hline & & $\mathrm{PM}_{2.5}$ & $\mathrm{PM}_{10}$ & $\mathrm{SO}_{2}$ & $\overline{\mathrm{O}_{3}}$ & $\mathrm{PM}_{2.5}$ & $\mathrm{PM}_{10}$ & $\mathrm{SO}_{2}$ & $\overline{\mathrm{O}_{3}}$ & $\mathrm{PM}_{2.5}$ & $\mathrm{PM}_{10}$ & $\mathrm{SO}_{2}$ & $\overline{\mathrm{O}_{3}}$ & $\mathrm{PM}_{2.5}$ & $\mathrm{PM}_{10}$ & $\mathrm{SO}_{2}$ & $\overline{\mathrm{O}_{3}}$ \\
\hline \multirow[t]{5}{*}{2015} & $51-100$ & 45 & 1 & 0 & 2 & 37 & 1 & 0 & 0 & 40 & 1 & 0 & 3 & 37 & 1 & 0 & 0 \\
\hline & $101-150$ & 22 & 0 & 0 & 2 & 4 & 0 & 0 & 1 & 25 & 1 & 0 & 4 & 30 & 0 & 0 & 0 \\
\hline & $151-200$ & 5 & 0 & 0 & 0 & 0 & 0 & 0 & 0 & 11 & 0 & 0 & 2 & 20 & 0 & 0 & 0 \\
\hline & $201-300$ & 0 & 0 & 0 & 0 & 0 & 0 & 0 & 0 & 0 & 0 & 0 & 0 & 0 & 0 & 0 & 0 \\
\hline & $>300$ & 0 & 0 & 0 & 0 & 0 & 0 & 0 & 0 & 0 & 0 & 0 & 0 & 0 & 0 & 0 & 0 \\
\hline \multirow[t]{5}{*}{2016} & $51-100$ & 41 & 0 & 0 & 4 & 46 & 0 & 0 & 4 & 41 & 1 & 0 & 3 & 52 & 0 & 0 & 0 \\
\hline & $101-150$ & 23 & 0 & 0 & 4 & 3 & 0 & 0 & 2 & 16 & 0 & 0 & 5 & 27 & 1 & 0 & 0 \\
\hline & $151-200$ & 10 & 0 & 0 & 1 & 0 & 0 & 0 & 2 & 7 & 0 & 0 & 1 & 8 & 0 & 0 & 0 \\
\hline & $201-300$ & 0 & 0 & 0 & 1 & 0 & 0 & 0 & 0 & 0 & 0 & 0 & 0 & 0 & 0 & 0 & 0 \\
\hline & $>300$ & 0 & 0 & 0 & 0 & 0 & 0 & 0 & 0 & 0 & 0 & 0 & 0 & 0 & 0 & 0 & 0 \\
\hline \multirow[t]{5}{*}{2017} & $51-100$ & 29 & 0 & 0 & 8 & 32 & 0 & 0 & 2 & 39 & 6 & 0 & 7 & 45 & 2 & 0 & 0 \\
\hline & $101-150$ & 33 & 0 & 0 & 7 & 1 & 0 & 0 & 0 & 11 & 8 & 0 & 6 & 30 & 5 & 0 & 0 \\
\hline & $151-200$ & 6 & 0 & 0 & 3 & 0 & 0 & 0 & 0 & 0 & 0 & 0 & 2 & 6 & 0 & 0 & 0 \\
\hline & $201-300$ & 0 & 0 & 0 & 0 & 0 & 0 & 0 & 0 & 0 & 0 & 0 & 0 & 0 & 0 & 0 & 0 \\
\hline & $>300$ & 0 & 0 & 0 & 0 & 0 & 0 & 0 & 0 & 0 & 0 & 0 & 0 & 0 & 0 & 0 & 0 \\
\hline
\end{tabular}


Table 3(g). Cumulative number of days of major pollutants for Mailiao Township from 2015-2017.

\begin{tabular}{|c|c|c|c|c|c|c|c|c|c|c|c|c|c|c|c|c|c|}
\hline \multirow{2}{*}{ Year } & \multirow{2}{*}{$\begin{array}{l}\text { AQI } \\
\text { Class }\end{array}$} & \multicolumn{4}{|c|}{ Spring } & \multicolumn{4}{|c|}{ Summer } & \multicolumn{4}{|c|}{ Fall } & \multicolumn{4}{|c|}{ Winter } \\
\hline & & $\mathrm{PM}_{2.5}$ & $\mathrm{PM}_{10}$ & $\mathrm{SO}_{2}$ & $\overline{\mathrm{O}_{3}}$ & $\mathrm{PM}_{2 .}$ & $\mathrm{PM}_{10}$ & $\mathrm{SO}_{2}$ & $\mathrm{O}_{3}$ & $\mathrm{PM}_{2.5}$ & $\mathrm{PM}_{10}$ & $\mathrm{SO}_{2}$ & $\overline{\mathrm{O}_{3}}$ & $\mathrm{PM}_{2.5}$ & $\mathrm{PM}_{10}$ & $\mathrm{SO}_{2}$ & $\mathrm{O}_{3}$ \\
\hline \multirow[t]{5}{*}{2015} & $51-100$ & 38 & 4 & 0 & 6 & 9 & 9 & 0 & 3 & 20 & 21 & 0 & 11 & 30 & 16 & 0 & 0 \\
\hline & $101-150$ & 19 & 1 & 0 & 2 & 1 & 0 & 0 & 1 & 13 & 1 & 0 & 10 & 27 & 3 & 0 & 0 \\
\hline & $151-200$ & 4 & 0 & 0 & 2 & 0 & 0 & 0 & 0 & 2 & 0 & 0 & 4 & 12 & 0 & 0 & 0 \\
\hline & $201-300$ & 0 & 0 & 0 & 0 & 0 & 0 & 0 & 0 & 0 & 0 & 0 & 0 & 0 & 0 & 0 & 0 \\
\hline & $>300$ & 0 & 0 & 0 & 0 & 0 & 0 & 0 & 0 & 0 & 0 & 0 & 0 & 0 & 0 & 0 & 0 \\
\hline \multirow[t]{5}{*}{2016} & $51-100$ & 40 & 0 & 0 & 6 & 16 & 2 & 0 & 6 & 35 & 10 & 0 & 0 & 50 & 3 & 0 & 1 \\
\hline & $101-150$ & 23 & 0 & 0 & 6 & 2 & 0 & 0 & 1 & 11 & 3 & 0 & 4 & 26 & 4 & 0 & 0 \\
\hline & $151-200$ & 5 & 0 & 0 & 0 & 0 & 0 & 0 & 1 & 4 & 0 & 0 & 0 & 1 & 0 & 0 & 0 \\
\hline & 201-300 & 0 & 0 & 0 & 1 & 0 & 0 & 0 & 0 & 0 & 0 & 0 & 0 & 0 & 0 & 0 & 0 \\
\hline & $>300$ & 0 & 0 & 0 & 0 & 0 & 0 & 0 & 0 & 0 & 0 & 0 & 0 & 0 & 0 & 0 & 0 \\
\hline \multirow[t]{5}{*}{2017} & $51-100$ & 39 & 0 & 0 & 4 & 51 & 0 & 0 & 1 & 51 & 16 & 0 & 3 & 35 & 17 & 0 & 0 \\
\hline & $101-150$ & 27 & 0 & 0 & 11 & 1 & 0 & 0 & 1 & 12 & 5 & 0 & 2 & 25 & 7 & 0 & 0 \\
\hline & $151-200$ & 7 & 0 & 0 & 1 & 0 & 0 & 0 & 0 & 0 & 0 & 0 & 0 & 6 & 0 & 0 & 0 \\
\hline & $201-300$ & 0 & 0 & 0 & 0 & 0 & 0 & 0 & 0 & 0 & 0 & 0 & 0 & 0 & 0 & 0 & 0 \\
\hline & $>300$ & 0 & 0 & 0 & 0 & 0 & 0 & 0 & 0 & 0 & 0 & 0 & 0 & 0 & 0 & 0 & 0 \\
\hline
\end{tabular}

largest fraction among the six AQI classes but had the lowest proportion in 2016, when the fraction of Grade II increased obviously. Grade III had the highest proportion in 2016, but the total fractions were relatively low in the different AQI classes. The levels of Grade IV, V, and VI, with the exception of Grade IV, had fractions from 1\%-2\% in 2016, and the other classes remained constant at $0 \%$ over the study period. Therefore, the air quality exhibited a marked Good (Grade I) condition, and the lowest Good level and highest Unhealthy for Sensitive Groups levels reflected the worst air quality in 2016 during the study period in the summer among all seven districts.

The total polluted days in summer were much lower than other seasons, $\mathrm{PM}_{2.5}$ was the most frequent primary air pollutant at the Grade II level, while the fraction of $\mathrm{O}_{3}$ as the primary air pollutant rise significantly compared with that in spring. The number of days of $\mathrm{PM}_{2.5}$ and $\mathrm{O}_{3}$ as primary air pollutant were equivalent, and both occurred at extremely low levels as Grade III pollutants. As in spring, Grade IV pollution occurred in 2016, where the primary air pollutant was all $\mathrm{O}_{3}$ at the monitored stations, indicating that $\mathrm{O}_{3}$ has a greater impact on the unhealthy situation occurring during the summer. It was also found that $\mathrm{PM}_{10}$ and $\mathrm{NO}_{2}$ occasionally acted as the primary pollutants.

In the of 2015, the percentages with Grade I, II, III, IV, $\mathrm{V}$, and VI ranged from 5\% (Lunbei Township)-15\% (Chiayi County), 39\% (Douliou City)-57\% (Mailiao Township), 26\% (Mailiao Township)-36\% (Douliou City), 7\% (Mailiao Township)-18\% (Douliou City), and $0 \%$ and $0 \%$, respectively. In 2016, the percentages with Grade I, II, III, IV, V, and VI were 19\% (Lunbei Township)-45\% (Mailiao Township), 34\% (Douliou City)-57\% (Taisi Township), 13\% (Taisi Township)-28\% (Douliou City), 4\% (Mailiao Township)-14\% (Douliou City), and $0 \%$ and $0 \%$, respectively. And in 2017, the percentages with Grade I, II, III, IV, V, and VI were 2\% (Mailiao Township)-31\% (Puzih City), 52\% (Puzih City)-77\% (Mailiao Township), 15\% (Taisi Township)-34\% (Chiayi County), 0\% (Mailiao Township) $-6 \%$ (Douliou City), and $0 \%$ and $0 \%$, respectively.
Contrary to summer, the fraction of Grade I with the highest values and Grade III with the lowest values occurred in 2016, and Grade II had a larger fraction than other classes, and the values significantly increased in 2017. The fraction of Grade IV declined from 2015-2017, with the highest values always occurring in Douliou City, and the lowest values always occurring in Mailiao Township. Compared with the other seasons, the lowest Good level and the highest Unhealthy for Sensitive Groups level indicated that the air quality in the fall of 2016 was not the worst in these study areas. It also could be observed that the air quality remained for the most part at Moderate (Grade II) levels in the fall in the seven districts. Furthermore, among the seven areas, Unhealthy (Grade IV) condition was the most serious in Duliou City and the least serious in Mailiao Township.

$\mathrm{PM}_{2.5}$ was still the most important primary air pollutant in fall, followed by $\mathrm{O}_{3}$, and the number days it was the primary pollutant was significantly higher in fall than in spring and summer. It is worth noting that the number of days in which $\mathrm{PM}_{10}$ was the primary air pollutant at of Grade II and III was also significantly higher than in spring and summer. This means $\mathrm{PM}_{10}$ had a more significant influence on autumn pollution.

In winter, during 2015, the percentages of Grade I, II, III, IV, V, and VI ranged from 2\% (Puzih City, Douliou City and Mailiao Township)-12\% (Taisi Township), 38\% (Chiayi County)-52\% (Puzih City),30\% (Taisi Township)40\% (Chiayi County), 11\% (Taisi Township)-22\% (Douliou City), $0 \%$ and $0 \%$, respectively. In 2016, the percentages with Grade I, II, III, IV, V, and VI ranged from 3\% (Lunbei Township)-11\% (Singang Township), 41\% (Chiayi County)62\% (Taisi Township), 24\% (Puzih City)-34\% (Chiayi County), 1\% (Mailiao Township)-15\% (Chiayi County), $0 \%$ and $0 \%$, respectively. In 2017, the percentages with Grade I, II, III, IV, V, and VI ranged from $0 \%$ (Mailiao Township and Chiayi County)-5\% (Puzih City), 44\% (Chiayi County)-67\% (Puzih City), 27\% (a Puzih City and Taisi Township)-41\% (Chiayi County), 1\% (Puzih City)$15 \%$ (Chiayi County), $0 \%$ and $0 \%$, respectively. Compared 
with spring, summer, and fall, winter was accompanied with the lowest percentages of Grade I, and the lowest values occurred in 2017 during the study period. While Grade II and Grade III occupied the majority, and the former is slighter higher than the latter. The levels of Grade IV in 2015 were significantly higher than those in 2016 and 2017 , but the $\mathrm{V}$ and VI classes remained constant at $0 \%$. The winter in the studied districts had few with Good (Grade I) conditions, but Moderate (Grade II) and Unhealthy for Sensitive Groups (Grade III) conditions occurred frequently. In addition, Unhealthy (Grade IV) conditions in winter was the most serious in 2015.

Generally, $\mathrm{PM}_{2.5}$ was the most important primary air pollutant, followed by $\mathrm{PM}_{10}$ and $\mathrm{O}_{3}$ occasionally being the primary air pollutants in winter. This indicates that particulate matter played a decisive role in the winter AQI in these seven districts. Moreover, the most frequent primary pollutant lead to a Grade IV was $\mathrm{PM}_{2.5}$ in all the study areas, which means $\mathrm{PM}_{2.5}$ has a huge impact on unhealthy winter air quality.

Similar to the results of previous studies (Shen et al., 2017; Wang et al., 2018b), when observing the seasonal variations in air quality in these areas, summer had the best air quality, with a marked Good (Grade I) condition, and winter had the worst, with typically Moderate (Grade II) and Unhealthy for Sensitive Groups (Grade III) rankings, while the spring was similar to fall at the Moderate (Grade II) level. As for the primary air pollutants, $\mathrm{PM}_{2.5}$ was the typical primary air pollutant in all four seasons, while the frequency of $\mathrm{O}_{3}$ as the primary air pollutant rose annually in spring, and the fraction of $\mathrm{O}_{3}$ as the primary air pollutant in summer was higher than that in spring. It should be noted that $\mathrm{O}_{3}$ had a significant impact on the occurrence of pollution, which were Unhealthy (Grade V) in spring and Unhealthy for Sensitive Groups in summer (Grade IV). The number of days of both $\mathrm{O}_{3}$ and $\mathrm{PM}_{10}$ as the primary pollutant in autumn was significantly higher than that in spring and summer. Finally, in winter, $\mathrm{PM}_{2.5}$ was the most important primary air pollutant, followed by $\mathrm{PM}_{10}$, and the frequency of $\mathrm{O}_{3}$ as the primary air pollutant was extremely low.

\section{CONCLUSION}

The results of this study on air quality index in southwestern Taiwan can be summarized as follows:

1.The $\mathrm{PM}_{2.5}$ concentrations fluctuate significantly in the study areas, where the focal three-year mean $\mathrm{PM}_{2.5}$ concentrations in Puzih City, Singang Township, Chiayi County, Douliou City, Taisi Township, Lunbei Township and Mailiao Township were 24.1, 24.9, 27.2, 27.5, 25.0, 29.2 and $25.7 \mu \mathrm{g} \mathrm{m}^{-3}$, respectively. It can be seen that Lunbei Township had the $\mathrm{PM}_{2.5}$ highest values, and Puzih City had the lowest. The seasonal characteristic of $\mathrm{PM}_{2.5}$ generally are in the following order: winter > spring $>$ fall $>$ summer.

2. The three-year mean $\mathrm{PM}_{10}$ concentrations in Puzih City, Singang Township, Chiayi County, Douliou City, Taisi Township, Lunbei Township, and Mailiao Township were $65,58,57,52,47,54$ and $70 \mu \mathrm{g} \mathrm{m}^{-3}$, respectively, which were lower than those in Wuhu $\left(82 \mu \mathrm{g} \mathrm{m}^{-3}\right)$ and Bengbu $\left(95 \mu \mathrm{g} \mathrm{m}^{-3}\right)$. As a whole, of these seven observed districts, the average $\mathrm{PM}_{10}$ values in summer $\left(36 \mu \mathrm{g} \mathrm{m}^{-3}\right)$ were $52.0 \%$ lower than those in winter $\left(75 \mu \mathrm{g} \mathrm{m}^{-3}\right)$, and spring $\left(60 \mu \mathrm{g} \mathrm{m}^{-3}\right)$ had the similar levels to those observed in fall $\left(61 \mu \mathrm{g} \mathrm{m}^{-3}\right)$.

3. From 2015-2017, Taisi Township always had the highest concentration of $\mathrm{SO}_{2}$, and Douliou City had the lowest values, and the three-year average $\mathrm{SO}_{2}$ concentrations in Puzih City, Singang Township, Chiayi County, Douliou City, Taisi Township, Lunbei Township, and Mailiao Township were 5.51, 5.66, 6.20, 5.24, 8.55, 5.85 and $6.69 \mathrm{ppb}$, respectively. In summer (4.86 ppb) the minimum $\mathrm{SO}_{2}$ levels were observed, which were $26.1 \%$ lower than that found for the other seasons $(6.40,6.58$ and $6.75 \mathrm{ppb}$ in spring, fall and winter, respectively).

4. The average $\mathrm{NO}_{2}$ concentration in Puzih City, Singang Township, Chiayi County, Douliou City, Taisi Township, Lunbei Township, and Mailiao Township were 18.0, $18.4,22.9,23.9,18.3,18.2$ and $18.2 \mathrm{ppb}$, respectively, during the three-year study period. These values were comparable to those of Wuhu (21.4 ppb) and Bengbu $(18.0 \mathrm{ppb})$. In terms of seasonal variations, Douliou City usually had the maximum $\mathrm{NO}_{2}$ levels in terms of spatial distribution, while summer always had the minimum values. Winter had the maximum values in terms of temporal distribution, for which the three-year average values in summer (13.7 ppb) were $43.2 \%$ lower than those in winter (24.1 ppb).

5. The mean $\mathrm{CO}$ concentrations in the three year study period in Puzih City, Singang Township, Chiayi County, Douliou City, Taisi Township, Lunbei Township, and Mailiao Township were $0.384,0.413,0.499,0.437$, $0.317,0.377$ and $0.374 \mathrm{ppm}$, respectively, which were significantly lower than the WHO standard (8.00 ppm), while the seasonal $\mathrm{CO}$ characteristics generally occurred in the following order: winter $>$ spring $>$ fall $>$ summer.

6 . The $\mathrm{O}_{3}$ concentration in all observed cities rose by $0.43-$ $7.93 \%$. This increasing tendency poses a serious challenge in terms of air quality. The three-year average $\mathrm{O}_{3}$ concentrations in Puzih City, Singang Township, Chiayi County, Douliou City, Taisi Township, Lunbei Township, and Mailiao Township were 47.7, 47.5, 48.0, 50.0, 48.7, 45.0 and $46.1 \mathrm{ppb}$, respectively. The $\mathrm{O}_{3}$ concentrations in most of these places were slightly higher than the WHO standard (46.6 ppb).

7. Due to meteorological conditions, there were three $\mathrm{O}_{3}$ seasonal distribution patterns in the study period. Firstly, all the observed cities had their maximum levels in fall and their minimum levels in summer, while spring and winter were at intermediate levels in 2015. Secondly, the maximum $\mathrm{O}_{3}$ level normally occurred in spring or fall, and the minimum $\mathrm{O}_{3}$ level normally occurred in summer or winter in 2016. Thirdly, the $\mathrm{O}_{3}$ concentrations in spring and fall were both at high levels and those in spring were higher than those in fall, followed by winter, with the lowest in summer in 2017.

8. The percentages of air quality at the Moderate level were greatest in spring in the study areas, after which 
they gradually deteriorated. $\mathrm{PM}_{2.5}$ was the most frequent primary pollutant, followed by $\mathrm{O}_{3}$, which increased in different AQI classes. $\mathrm{PM}_{10}$ was an occasional primary pollutant.

9. The air quality exhibited a marked Good (Grade I) condition in the summer in the study areas. $\mathrm{PM}_{2.5}$ was the most frequent primary air pollutant, and the fraction of $\mathrm{O}_{3}$ as the primary air pollutant was significantly higher in summer than in spring. Furthermore, $\mathrm{O}_{3}$ had a greater impact on unhealthy summer conditions.

10. The air quality mostly remained at Moderate levels in the fall in the study areas, and Unhealthy conditions were the most serious in Duliou City and the least serious in Mailiao Township. $\mathrm{PM}_{2.5}$ was still the most important primary air pollutant in fall, followed by $\mathrm{O}_{3}$, and the number of days of $\mathrm{PM}_{10}$ as the primary air pollutant significantly increased in the fall as compared with spring and summer.

11. Some of the studied districts had Good conditions in winter, but Moderate and Unhealthy for Sensitive Groups occurred frequently. $\mathrm{PM}_{2.5}$ was the most important primary air pollutant, followed by $\mathrm{PM}_{10}$ and occasionally $\mathrm{O}_{3}$ as the primary air pollutants, and particulate matter played a decisive role in the winter AQI in these seven districts.

12. The results of this study provide useful information for the establishment of air pollution control strategies and for future studies conducted by the scientific community.

\section{REFERENCES}

Akinlade, G.O., Olaniyi, H.B., Olise, F.S., Owoade, O.K., Almeida, S.M., Almeida-Silva, M. and Hopke, P.K. (2015). Spatial and temporal variations of the particulate size distribution and chemical composition over Ibadan, Nigeria. Environ. Monit. Assess. 187: 544.

An, J.L. (2006). Ozone production efficiency in Beijing area with high $\mathrm{NO}_{\mathrm{x}}$ emissions. Acta Sci. Circumst. 26: 652-657.

Anderson, K.R., Avol, E.L., Edwards, S.A., Shamoo, D.A., Peng, R.C., Linn, W.S. and Hacknery, J.D. (1992). Controlled exposures of volunteers to respirable carbon and sulfuric acid aerosols. J. Air Waste Manage. Assoc. 42: 771-782.

Andres, R.J. and Kasgnoc, A.D. (1998). A time-averaged inventory of subaerial volcanic sulfur emissions. $J$. Geophys. Res. 103: 25251-25261.

Aneja, V.P., Agarwal, A., Roelle, P.A., Phillips, S.B., Tong, Q.S., Watkins, N. and Yablonsky, R. (2001). Measurements and analysis of criteria pollutants in New Delhi, India. Environ. Int. 27: 35-42.

Anttila, P., Tuovinen, J.P. and Niemi, J.V. (2011). Primary $\mathrm{NO}_{2}$ emissions and their role in the development of $\mathrm{NO}_{2}$ concentrations in a traffic environment. Atmos. Environ. 45: 986-992.

Blanco-Becerra, L.C., Gáfaro-Rojas, A.I. and Rojas-Roa, N.Y. (2015). Influence of precipitation scavenging on the $\mathrm{PM}_{2.5} / \mathrm{PM}_{10}$ ratio at the Kennedy locality of Bogotá, Colombia. Rev. Fac. Ing. Univ. Antioquia 76: 58-65.

Bowman, F.M. and Seinfeld, J.H. (1994). Ozone productivity of atmospheric organics. J. Geophys. Res. 99: 5309-5324. Bureau of Air Quality Protection and Noise Control (1991). Air pollution control review report of Taiwan R.O.C., EPA.

Cao, J.J., Xu, H.M., Xu, Q., Chen, B.H. and Kan, H.D. (2012). Fine particulate matter constituents and cardiopulmonary mortality in a heavily polluted Chinese city. Environ. Health Perspect. 120: 373-378.

Chen, B.H., Kan, H.D., Chen, R.J., Jiang, S.H. and Hong, C.J. (2011). Air pollution and health studies in ChinaPolicy implications. J. Air Waste Manage. Assoc. 61: 1292-1299.

Chen, W.H. (2001). Unsteady absorption of sulfur dioxide by an atmospheric water droplet with internal circulation. Atmos. Environ. 35: 2375-2393.

Cheng, F.Y., Jian, S.P., Yang, Z.M., Yen, M.C. and Tsuang, B.J. (2015). Influence of regional climate change on meteorological characteristics and their subsequent effect on ozone dispersion in Taiwan. Atmos. Environ. 103: 66-81.

Cheng, N.L., Li, Y.T., Sun, F., Chen, C., Wang, B.Y., Li, Q., Wei, P. and Cheng, B.F. (2018). Ground-level $\mathrm{NO}_{2}$ in urban Beijing: Trends, distribution, and effects of emission reduction measures. Aerosol Air Qual. Res. 18: 343-356.

Cox, R.M. (2003). The use of passive sampling to monitor forest exposure to $\mathrm{O}_{3}, \mathrm{NO}_{2}$ and $\mathrm{SO}_{2}$ : A review and Some Cease studis. Environ. Pollut. 126: 301-311.

Dentener, F., Kinne, S., Bond, T., Boucher, O., Cofala, J., Generoso, S., Ginoux, P., Gong, S., Hoelzemann, J.J., Ito, A., Marelli, L., Penner, J.E., Putaud, J.P., Textor, C., Schulz, M., Van der Werf, G.R. and Wilson, J. (2006). Emissions of primary aerosol and precursor gases in the years 2000 and 1750 prescribed data-sets for AeroCom. Atmos. Chem. Phys. 6: 4321-4344.

Dong, C, Huang, K.L., Chen, C.W., Lee, C.W., Lin, H.Y. and Chen, C.F. (2002) Estimation of air pollutant emission from ship in Kaohsiung Harbor area. Aerosol Air Qual. Res. 2: 31-40.

Evagelopoulos, V., Zoras, S., Triantafyllou, A.G. and Albanis, T.A. (2006). $\mathrm{PM}_{10}-\mathrm{PM}_{2.5}$ time series and fractal analysis. Global NEST J. 8: 234-240.

Fang, S.H. and Chen, H.W. (1996). Air quality and pollution control in Taiwan. Atmos. Environ. 30: 735-741.

Ferrari, L. and Salisbury, J. (1999). Sulfur dioxide, National Environmental Health Forum Monographs, Air Series No. 4, National Environmental Health Forum, Australia.

Fu, L.X., Hao, J.M., He, D.Q. and He, K.B. (2000). The emission characteristics of pollutants from motor vehicles in Beijing. Environ. Sci. 21: 68-74. (in Chinese)

Goncalves, F.L.T., Ramos, A.M., Freitas, S., Silva Dias, M.A. and Massambani, O. (2002). In-cloud and Belowcloud Numerical Simulation of Scavenging Processes at Serra Do Mar Region, SE Brazil. Atmos. Environ. 36: 5245-5255.

Gong, X., Hong, S. and Jaffe, D.A. (2018). Ozone in China: Spatial distribution and leading meteorological factors controlling $\mathrm{O}_{3}$ in 16 Chinese cities. Aerosol Air Qual. Res. 18: 2287-2300. 
Halmer, M.M., Schmincke, H.U. and Graf, H.F. (2002). The annual volcanic gas input into the atmosphere, in particular into the stratosphere: A global data set for the past 100 years. J. Volcanol. Geotherm. Res. 115: 511528.

He, J., Xu, H.H., Balasubramanian, R., Chan, C.Y. and Wang, C.J. (2014). Comparison of $\mathrm{NO}_{2}$ and $\mathrm{SO}_{2}$ measurements using different passive samplers in tropical environment. Aerosol Air Qual. Res. 14: 355363.

Heal, M.R., Kumar, P. and Harrison, R.M. (2012). Particles, air quality, policy and health. Chem. Soc. Rev. 41: 6606-6630.

Hu, J.L., Ying, Q., Wang, Y.G. and Zhang, H.L. (2015). Characterizing multi-pollutant air pollution in China: Comparison of three air quality indices. J. Environ. Int. 15: $17-25$.

Jin, L., Loisy, A. and Brown, N.J. (2013). Role of meteorological processes in ozone responses to emission controls in California's San Joaquin Valley. J. Geophys. Res. 118: 8010-8022.

Jin, L., Luo, X.S., Fu, P.Q. and Li, X.D. (2017). Airborne particulate matter pollution in urban China: A chemical mixture perspective from sources to impacts. Nat. Sci. Rev. 4: 593-610.

Kato, S., Shiobara, Y., Uchiyama, K., Miura, K., Okochi, H., Kobayashi, H. and Hatakeyama, S. (2016). Atmospheric $\mathrm{CO}, \mathrm{O}_{3}$, and $\mathrm{SO}_{2}$ Measurements at the Summit of Mt. Fuji during the Summer of 2013. Aerosol Air Qual. Res. 16: 2368-2377.

Kettle, A. and Andreae, M. (2000). Flux of dimethylsulfide from the oceans: A comparison of updated data sets and flux models J. Geophys. Res. 105: 26793-26808.

Khattak, P., Khokhar, M.F. and Khan, S.A. (2013). Transboundary volcanic $\mathrm{SO}_{2}$ detected over Pakistan from satellite observations during the time period 2004-2012. Aerosol Air Qual. Res. 14: 1543-1557.

Khokhar, M.F., Mehdi, H., Abbas, Z. and Javed, Z. (2016). Temporal assessment of $\mathrm{NO}_{2}$ pollution levels in urban centers of Pakistan by employing ground-based and satellite observations. Aerosol Air Qual. Res. 16: 18541867.

Lan, Y.Y., Tsuang, B.J., Lin, N.H., Hsu, H.H., Yu, C.C. and Chen, Y.T. (2015). Distribution of ozone and related compounds in the marine boundary layer of the northern South China Sea in 2010. Aerosol Air Qual. Res. 15: 1990-2008.

Lanzafame, R., Monforte, P., Patane, G. and Strano, S. (2015). Trend analysis of Air Quality Index in Catania from 2010 to 2014. Energy Procedia 82: 708-715.

Lee, C., Richter, A., Weber, M. and Burrows, J.P. (2008). $\mathrm{SO}_{2}$ Retrieval from SCIAMACHY using the Weighting Function DOAS (WFDOAS) technique: Comparison with Standard DOAS retrieval. Atmos. Chem. Phys. 8: 6137-6145.

Lee, Y.Y., Wang, L.C., Zhu, J.N., Wu, J.L. and Lee, K.L. (2018). Atmospheric $\mathrm{PM}_{2.5}$ and polychlorinated dibenzo$p$-dioxins and dibenzofurans in Taiwan. Aerosol Air Qual. Res. 18: 762-779.
Lelieveld, J., Evans, J.S., Fnais, M., Giannadaki, D. and Pozzer, A. (2015). The contribution of outdoor air pollution sources to premature mortality on a global scale. Nature 525: 367-371.

Li, J.Y., Zhang, H.L. and Ying, Q. (2012). Comparison of the SAPRC07 and SAPRC99 photochemical mechanisms during a high ozone episode in Texas: Differences in concentrations, $\mathrm{OH}$ budget and relative response factors. Atmos. Environ. 54: 25-35.

Li, K., Chen, L., Han, K., Lv, B., Bao, K., Wu, X., Guo, X. and Cen, K. (2017a). Smog chamber study on aging of combustion soot in isoprene/ $\mathrm{SO}_{2} / \mathrm{NO}_{\mathrm{x}}$ system: Changes of mass, size, effective density, morphology and mixing state. Atmos. Res. 184: 139-148.

Li, K.W., Chen, L.H., Ying, F., White, S.J., Jang, G., Wu, X.C., Gao, X., Hong, S.M., Shen, J.D., Azzi, M. and Cen, K. (2017b). Meteorological and chemical impacts on ozone formation: A case study in Hangzhou, China. Atmos. Res. 196: 40-52.

Liang, D., Wang, Y.Q., Ma, C. and Wang, Y.J. (2016). Variability in transport pathways and source areas of $\mathrm{PM}_{10}$ in Beijing during 2009-2012. Aerosol Air Qual. Res. 16: 3130-3141.

Lin, W.Y., Wu, Y.L., Yu, L.K., Wang, L.C. and Lu, X. (2010). The emission and distribution of PCDD/Fs in municipal solid waste incinerators and coal-fired power plant. Aerosol Air Qual. Res. 10: 519-532.

Liu, C.M. (2002). Effect of $\mathrm{PM}_{2.5}$ on AQI in Taiwan. Environ. Modell. Software 17: 29-37.

Liu, Y., Zhang, J., Pan, J. and Tang, A. (2012). Investigation on the removal of $\mathrm{NO}$ from $\mathrm{SO}_{2}$-containing simulated flue gas by an ultraviolet/Fenton-like reaction. Energy Fuels 26: 5430-5436.

Liu, Y. and Wang, Q. (2014). Removal of elemental mercury from flue gas by thermally activated ammonium persulfate in a bubble column reactor. Environ. Sci. Technol. 48: 12181-12189.

Lovati, M.R., Manzoni, C., Daldossi, M., Spolti, S. and Sirtori, C.R. (1996). Effects of sub-chronic exposure to $\mathrm{SO}_{2}$ on lipid and carbohydrate metabolism in rats. Arch. Toxicol. 70: 164-173.

Mao, Y.F. (1997). Study of the design of national ambient air quality standard. Environmental Protection Administration, Taiwan. (in Chinese)

Matus, K., Nam, K.M., Selin, N.E., Lamsal, L.N., Reilly, J.M. and Paltsev, S. (2012). Health damages from air pollution in China. Global Environ. Change 22: 55-66.

Plaisance, H., Sagnier, I., Saison, J.Y., Galloo, J.C. and Guillermo, R. (2002). Performances and application of a passive sampling method for the simultaneous determination of nitrogen dioxide and sulfur dioxide in ambient air. Environ. Monit. Assess. 79: 301-315.

Pope, C.A., Dockery, D.W. (2006). Health effects of fine particulate air pollution: Lines that connect. J. Air Waste Manage. Assoc. 56: 709-742.

Pope, C.A. and Dockery, D.W. (2013). Air pollution and life expectancy in China and beyond. Proc. Natl. Acad. Sci. U.S.A. 110: 12861-12862.

Querol, X., Alastuey, A., Rodriguez, S., Plana, F., Ruiz, 
C.R., Cots, N., Massagué, G. and Puig, O. (2001). PM $_{10}$ and $\mathrm{PM}_{2.5}$ source apportionment in the Barcelona metropolitan area, Catalonia, Spain. Atmos. Environ. 35: 6407-6419.

Seinfeld, J.H. and Pandis, S.N. (1998). Atmospheric chemistry and physics. From air pollution to climate changes. Wiley, New York, NY.

Shang, X.N., Lee, M., Han, J.Y., Kang, E., Kim, S.W., Gustafsson, O. and Chang, L. (2015). Distribution of ozone and related compounds in the marine boundary layer of the Northern South China Sea in 2010. Aerosol Air Qual. Res. 15: 1990-2008.

She, Q.N., Peng, X., Xu, Q., Long, L.B., Wei, N., Liu, M., Jia, W.X., Zhou, T.Y., Han, J. and Xiang, W.N. (2017). Air quality and its response to satellite-derived urban form in the Yangtze River Delta, China. Ecol. Indic. 75: 297-306.

Shen, F.Z., Ge, X.L., Hu, J.L., Nie, D.Y., Tian, L. and Chen, M.D. (2017). Air pollution characteristics and health risks in Henan Province, China. Environ. Res. Sci. 156: 625-634.

Silva, R.A., West, J.J., Zhang, Y., Anenberg, S.C., Lamarque, J.F., Shindell, D.T., Collins, W.J., Dalsoren, S., Faluvegi, G., Folberth, G., Horowitz, L.W., Nagashima, T., Naik, V., Rumbold, S., Skeie, R., Sudo, K., Takemura, T., Bergmann, D., Cameron-Smith, P., Cionni, I., Doherty, R.M., Eyring, V., Josse, B., MacKenzie, I.A., Plummer, D., Righi, M., Stevenson, D.S., Strode, S., Szopa, S. and Zeng, G. (2013). Global premature mortality due to anthropogenic outdoor air pollution and the contribution of past climate change. Environ. Res. Lett. 8: 034005.

Solomon, P., Cowling, E., Hidy, G. and Furiness, C. (2000). Comparison of scientific findings from major ozone field studies in North America and Europe. Atmos. Environ. 34: 1885-1920.

Song, Y., Miao, W., Liu, B., Dai, W. and Cai, X. (2008). Identifying anthropogenic and natural influences on extreme pollution of respirable suspended particulates in Beijing using backward trajectory analysis. J. Hazard. Mater. 154: 459-468.

Speranza, A., Caggiano, R., Margiotta, S. and Trippetta, S. (2014). A novel approach to comparing simultaneous size-segregated particulate matter (PM) concentration ratios by means of a dedicated triangular diagram using the Agri Valley PM measurements as an example. Nat. Hazards Earth Syst. Sci. 14: 2727-2733.

Sun, Y., Jiang, Q., Wang, Z., Fu, P., Li, J., Yang, T. and Yin, Y. (2014). Investigation of the sources and evolution processes of severe haze pollution in Beijing in January 2013. J. Geophys. Res. 119: 4380-4398.

Tang, H.Y., Cui, K.P., Xing, J., Zhu, J.N., Lee, W.J., John, K.M. and Lee, Y.C. (2017). Part I: $\mathrm{PM}_{2.5}$ and polychlorinated dibenzo- $p$-dioxins and dibenzofurans (PCDD/Fs) in the ambient air of southern China. Aerosol Air Qual. Res. 17: 1550-1569.

Tao, J., Ho, K.F., Chen, L., Zhu, L., Han, J. and Xu, Z. (2009). Effect of chemical composition of $\mathrm{PM}_{2.5}$ on visibility in Guangzhou, China, 2007 spring. Particuology 7: 68-75.
Thurston, G.D., Ito, K., Kinney, P.L. and Lippmann, M. (1992). A multiyear study of air pollution and respiratory hospital admissions in three New York State metropolitan areas: results for 1988 and 1989 summers. J. Exposure Anal. Environ. Epidemiol. 2: 429-450.

Tu, J., Xia, Z.G., Wang, H. and Li, W. (2007). Temporal variations in surface ozone and its precursors and meteorological effects at an urban site in China. Atmos. Res. 85: 310-337.

Vijay, S., Molina, L.T. and Molina, M.J. (2004). Estimating air pollution emissions from fossil fuel use in the electricity sector in Mexico. Integrated Program on Urban, Regional and Global Air Pollution, Prepared for North American Commission for Environmental Cooperation. Massachusetts Institute of technology, Cambridge, USA.

Wang, W.W., Cui, K.P., Zhao, R., Zhu, J.N., Huang, Q.L. and Lee, W.J. (2018a). Sensitivity analysis of $\mathrm{PM}_{2.5}$-bound total PCDD/Fs-TEQ content: in the case of Wuhu city, China. Aerosol Air Qual. Res. 18: 407-420.

Wang, W.W., Cui, K.P., Zhao, R., Zhu, J.N., Huang, Q.L. and Lee, W.J. (2018b). Characterization of the air quality index for Wuhu and Bengbu cities, China. Aerosol Air Qual. Res. 18: 1198-1220.

Wu, X.H., Huang, W.W., Zhang, Y.X., Zheng, C.H., Jiang, X., Gao, X. and Cen, K.F. (2015). Characteristics and uncertainty of industrial VOCs emissions in China. Aerosol Air Qual. Res. 15: 1045-1058.

Xing, J., Cui, K.P., Tang, H.Y., Lee, W.J., Wang, L.C., Zhu, J.N. and Huang, Q.L. (2017). Part II: $\mathrm{PM}_{2.5}$ and polychlorinated dibenzo- $p$-dioxins and dibenzofurans (PCDD/Fs) in the ambient air of northern China. Aerosol Air Qual. Res. 17: 2010-2016.

Xu, G., Jiao, L.M., Zhang, B.E., Zhao, S.L., Yuan, M., Gu, Y.Y., Liu, J.F. and Tang, X. (2017). Spatial and temporal variability of the $\mathrm{PM}_{2.5} / \mathrm{PM}_{10}$ ratio in Wuhan, Central China. Aerosol Air Qual. Res. 17: 741-751.

Yang, C.S. (1997). Study of the characteristics and sources of the urban aerosols in metropolitan Taipei. M.S. Thesis, Graduate Institute of Environmental Engineering, National Taiwan University, Taiwan. (in Chinese)

Zhang, H., Hoff, R.M. and Engel-Cox, J.A. (2009). The relation between Moderate Resolution Imaging Spectroradiometer (MODIS) aerosol optical depth and $\mathrm{PM}_{2.5}$ over the United States: A geographical comparison by U.S. Environmental Protection Agency regions. $J$. Air Waste Manage. Assoc. 59: 1358-1369.

Zhang, Y. and Cao, F. (2015). Fine particulate matter $\left(\mathrm{PM}_{2.5}\right)$ in China at a city level. Sci. Rep. 5: 14884.

Zhao, R., Cui, K.P., Wang, W.W., Wang, L.C. and Yan, P. (2018). Atmospheric $\mathrm{PM}_{2.5}$ and total PCDD/Fs-WHO $\mathrm{WH}_{205}$ TEQ level: A case of Handan and Kaifeng cities, China. Aerosol Air Qual. Res. 18: 994-1007.

Received for review, February 16, 2019 Revised, March 17, 2019 Accepted, March 17, 2019 